\title{
Design analysis of single-span advanced composite deck-and- stringer bridge systems
}

\author{
Brian James Brown \\ West Virginia University
}

Follow this and additional works at: https://researchrepository.wvu.edu/etd

\section{Recommended Citation}

Brown, Brian James, "Design analysis of single-span advanced composite deck-and-stringer bridge systems" (1998). Graduate Theses, Dissertations, and Problem Reports. 908.

https://researchrepository.wvu.edu/etd/908

This Thesis is protected by copyright and/or related rights. It has been brought to you by the The Research Repository @ WVU with permission from the rights-holder(s). You are free to use this Thesis in any way that is permitted by the copyright and related rights legislation that applies to your use. For other uses you must obtain permission from the rights-holder(s) directly, unless additional rights are indicated by a Creative Commons license in the record and/ or on the work itself. This Thesis has been accepted for inclusion in WVU Graduate Theses, Dissertations, and Problem Reports collection by an authorized administrator of The Research Repository @ WVU. For more information, please contact researchrepository@mail.wvu.edu. 


\title{
DESIGN ANALYSIS OF SINGLE-SPAN ADVANCED COMPOSITE DECK-AND-STRINGER BRIDGE SYSTEMS
}

\author{
THESIS \\ Submitted to the \\ College of Engineering and Mineral Resources \\ of \\ West Virginia University \\ In Partial Fulfillment of the Requirements for the \\ Degree of Master of Science in \\ Civil and Environmental Engineering \\ by \\ Brian J. Brown \\ West Virginia University \\ Morgantown, West Virginia \\ December 1998
}




\title{
Design Analysis of Single-Span Advanced Composite Material (ACM) \\ Deck-and-Stringer Bridge Systems
}

\author{
by: Brian James Brown \\ Advisor: Julio F. Davalos and Co-Advisor: Pizhong Qiao \\ Civil and Environmental Engineering, West Virginia University
}

There is a concern with worldwide deterioration of highway bridges, particularly reinforced concrete. Due to the corrosive nature of steel re-bars used in concrete bridge decks, the servicelife of these bridges is reduced. The advantages of advanced composite materials (ACM) over conventional materials motivate their use in highway bridges for rehabilitation and replacement of structures. However, the complexity of the composites has prevented widespread implementation of ACM members in highway bridge design. There is a need for simplified design analysis procedures that account for both the geometry and material properties of ACM members and system.

In this study, a combined analytical and experimental study of fiber-reinforced plastic (FRP) composite bridges consisting of cellular box decks and wide-flange I-beam as stringer is presented. The study includes design, modeling and experimental/numerical verification of FRP composite decks and deck-and-stringer bridge systems. The design analysis covers: (1) ply stiffnesses and strengths; (2) laminate engineering stiffnesses; (3) apparent stiffness 
properties for composite decks; and (4) stringer stiffness properties. A finite element modeling (NISA) is used to verify the accuracy of the design analysis.

For design analysis of FRP deck-and-stringer bridge system, an approximate series solution for orthotropic plate including first-order shear deformation is developed. The results of the explicit solution are correlated with finite element analyses. Based on the analytical/experimental study, simplified design equations are developed for bridge applications, which include global design of deck-and-stringer system accounting for load distribution factors.

Under this research effort, two FRP decks are fabricated. The first deck is 5' 5 ' $\times 5$ ' and consists of bonded box beams that are $5^{\prime} \times 5^{\prime} \times 3 / 8^{\prime \prime}$. The second deck is $10^{\prime} \times 10^{\prime} \times 8^{\prime \prime}$ and consists of bonded box beams that are 4" x 8" x 1/4"; the deck is further placed over FRP wideflange I-beams (12" x 12" x 1/2") and tested as a deck-and-stringer bridge system. The box beams for decks and I-beams for stringers were both produced by pultrusion. The decks and bridge systems are tested under static loads for various boundary conditions. The experimental results are used to compare with the approximate series solution and finite element model. The comprehensive experimental/analytical results of this study are used to propose efficient FRP sections and simplified design equations for new and replacement ACM highway bridge decks and deck-and-stringer system. 


\section{ACKNOWLEDGMENTS}

First I wish to thank God for allowing me the opportunity to study at WVU. Without Him, I would not have had the strength to make it through these past two years. Of course my exceeding appreciation is extended to my family for their love, encouragement, and faithful support.

I would also like to express my sincere appreciation to Dr. Pizhong Qiao for his participation in the implementation of this study. His enthusiastic support and constant review of the manuscript have been invaluable to the progress and completion of this work. Special thanks are also due to Dr. Hani A. Salim for providing the groundwork for this project and for his assistance in the experimental testing. The assistance provided by Dana Humberson with the experimental work is likewise greatly appreciated.

Thanks are also due to my advisor, Dr. Julio Davalos, for his guidance in both my course work and the research effort. I am also very grateful to Dr. Ever Barbero for his help with the finite element modeling and his participation in the advisory committee.

This work was partially sponsored by the National Science Foundation (under Award \# 9700772) and West Virginia Department of Transportation, Division of Highways (WVDOT-DOH RP \# 147). Their financial support is gratefully acknowledged. Creative Pultrusion, Inc. provided the materials used in this study and their consistent support of our research is always appreciated. 


\section{TABLE OF CONTENTS}

TITLE PAGE

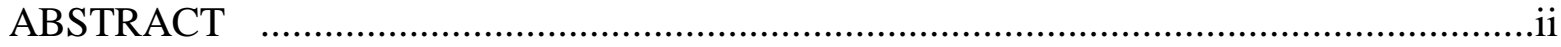

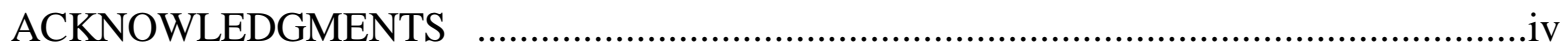

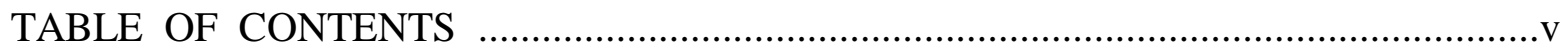

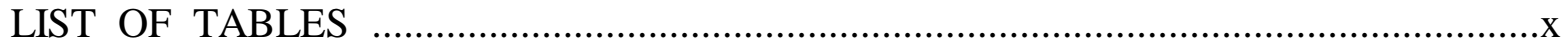

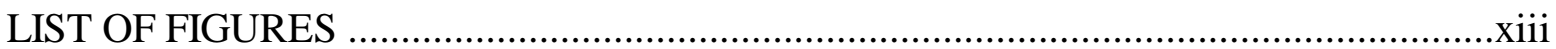

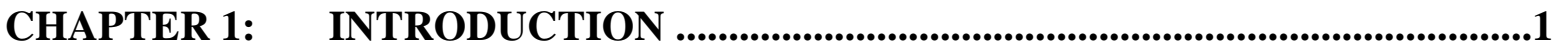

1.1 FRP Composite Bridges: Overview and Challenges .................................. 1

1.2 Problem Statement and Objectives ....................................................2

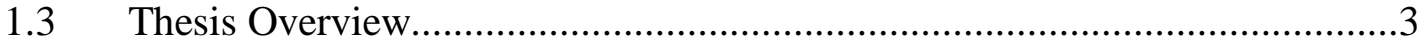

1.4 Previous Works on FRP Bridge Decks...................................................5

North Carolina State and California State Universities.........................6

Massachusetts Institute of Technology..............................................8

University of Virginia.............................................................

West Virginia University.......................................................

Recent Developments .............................................................11

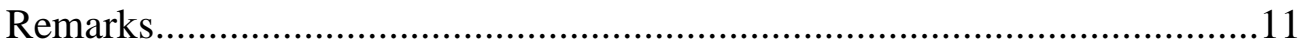


CHAPTER 2: $\quad$ FRP STRUCTURAL SHAPES: MECHANICS AND DESIGN .......12

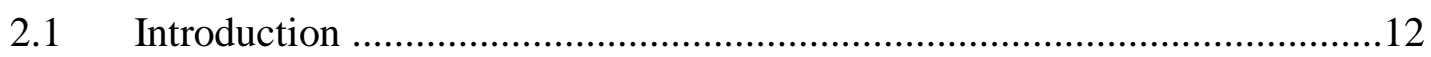

2.2 Basics for Modeling of FRP Shapes................................................. 12

2.2.1 Microstructure and Fiber Volume Fraction of FRP Shapes..............13

2.2.2 Micromechanics of Composites ..............................................17

Unidirectional Composites with Periodic Microstructure ..............18

Transversely Isotropic Material and Prediction of Ply Stiffnesses ..20

2.2.3 Macromechanics of Laminate and Prediction of Panel Stiffnesses ..24

2.2.4 Beam Deflection and Strain Predictions.....................................25

2.2.5 Beam Stiffnesses...................................................................28

2.2.6 Application to Design of FRP Beams.........................................32

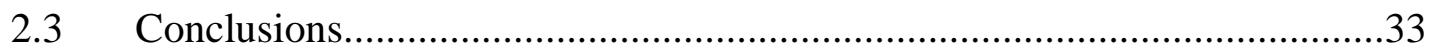

\section{CHAPTER 3: FRP COMPOSITE DECKS: ELASTIC EQUIVALENCE...............34}

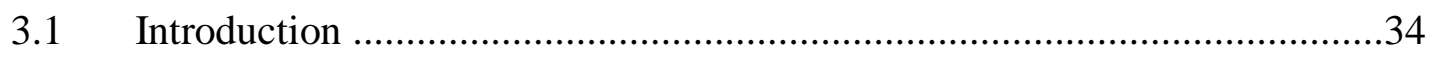

3.2 Design Equations for Stiffness Properties of Cellular FRP Decks................35

3.2.1 Longitudinal Stiffnesses of Cellular FRP Decks...........................36

3.2.2 Transverse Stiffnesses of Cellular FRP Decks................................38

3.2.3 Torsional Stiffness of Cellular FRP Decks...................................40

3.3 Verification of Deck Stiffness Equations by Finite Element Analysis..........42

3.3.1 Verification of Bending and Shear Stiffnesses.............................42

3.3.2 Verification of Torsional Stiffness of the Deck.............................49 
Remarks

3.4 Equivalent Orthotropic Material Properties

3.5 Numerical Verification of Equivalent Orthotropic Material Properties........56

3.6 Conclusions

\section{CHAPTER 4: FRP COMPOSITE DECK-AND-STRINGER BRIDGE SYSTEMS: ANALYSIS AND DESIGN.} .62

4.1 Introduction .62

4.2 First-order Shear Deformation Theory for FRP Composite Plate. .63

4.3 Approximate Series Solution .68

4.3.1 Deck-and-Stringer Bridge under Symmetric Loading. 69

Solution for Orthotropic Deck with Exterior Edge Stiffeners. . .69

Solution for an Interior Stringer under Symmetric Loading...........73

Remarks. .76

4.3.2 Deck-and-Stringer Bridge under Anti-symmetric Loading .77

Solution for Othotropic Deck with Exterior Edge Stiffeners. .77

Solution for an Interior Stringer under Anti-symmetric Loading.....79

Remarks.

4.3.3 Deck-and Stringer Bridge under Asymmetric Loading. .81

Remarks.

4.3.4 Comparison with Finite Element Modeling. .83

4.4 Wheel-load Distribution Factors. .86 


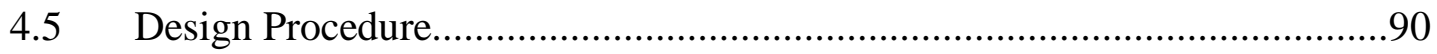

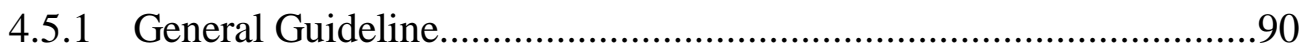

Design criterion based on performance of stringer................91

Design criterion based on performance of deck.....................92

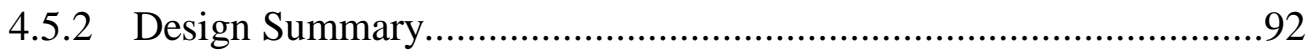

4.5.3 Design Examples......................................................................93

Example 1 1......................................................................

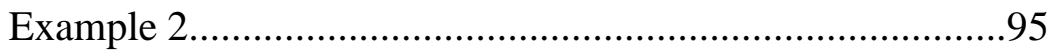

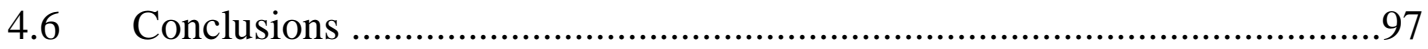

\section{CHAPTER 5: EXPERIMENTAL INVESTIGATIONS OF FRP COMPOSITE} DECKS AND DECK-AND-STRINGER BRIDGES.............................98

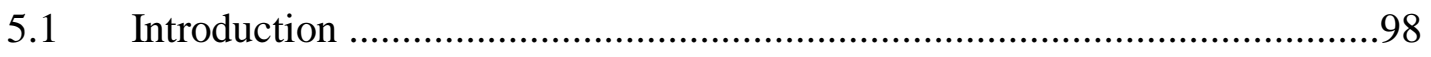

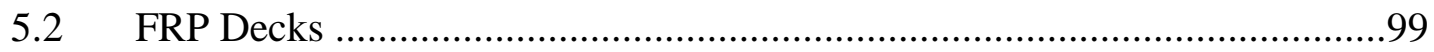

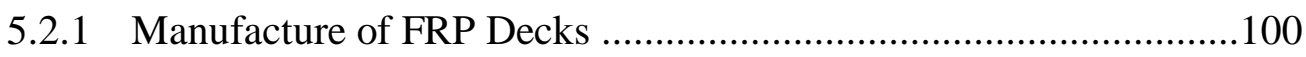

5.2.2 Testing Program ..........................................................................100

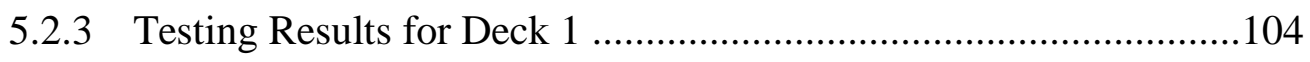

5.2.4 Comparison with Finite Element Modeling ...................................108

5.3 FRP Deck-and Stringer Bridge System …………....................................112

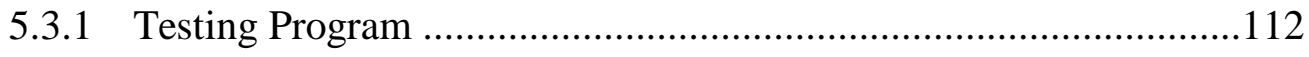

5.3.2 Testing Results .......................................................................118

5.3.3 Comparison with Finite Element Modeling ...................................123 
5.4 Conclusions .............................................................................. 136

CHAPTER 6: CONCLUSIONS AND RECOMMENDATIONS .......................137

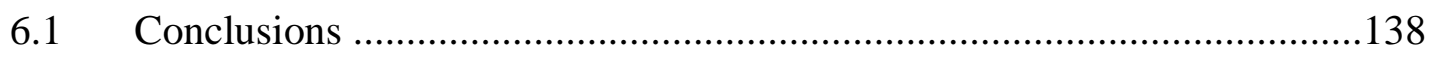

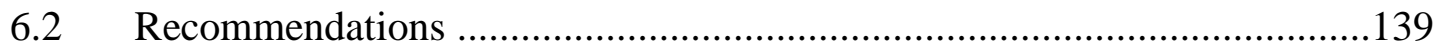

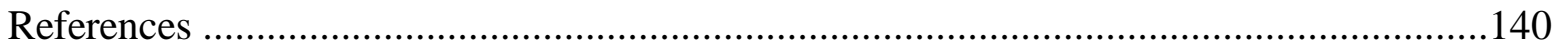




\section{LIST OF TABLES}

Table 2.1 Material properties of the constituents ............................................................16

Table 2.2 Ply material properties of box section computed by micromechanics..........23

Table 2.3 Ply material properties of WF section computed by micromechanics..........23

Table 2.4 Panel properties of box section (4"x8"x1/4") ........................................25

Table 2.5 Panel properties of WF-A section (12"x12"x1/2") …..............................25

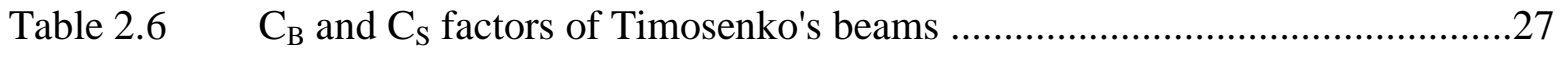

Table 2.7 Strong-axis beam bending and shear stiffness coefficients by MLB............32

Table 2.8 Experimental and analytical predictions of deflections and strains

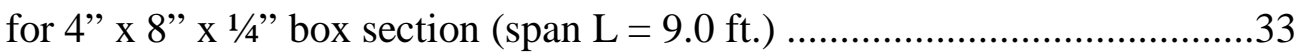

Table 2.9 Experimental and analytical predictions of deflections and strains

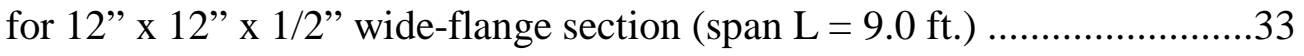

Table 3.1 Center deflections (in.) of longitudinally supported models

for three-point and four-point bending ...........................................45

Table 3.2 Center deflections of multi-cell transversely-supported beam

for three-point and four-point bending ................................................47

Table $3.3 \quad$ Torsional rigidity versus number of cells .............................................51

Table 3.4 Equivalent deck stiffness properties and orthotropic material properties

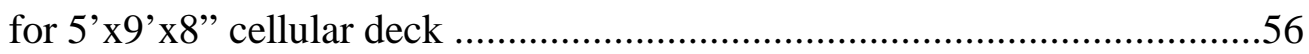

Table 3.5 Deflection of longitudinally-supported plate and deck …........................57

Table 3.6 Deflection of transversely-supported plate and deck .............................58 
Table 4.1 Comparison of series solution and FE model .83

Table 4.2 Center deflections of stringers for 3 -stringer system ...............................85

Table 4.3 Center deflections of stringers for 4-stringer system .............................86

Table 5.1 Displacement measurements $(\delta / \mathrm{P})$ for each load case ................................104

Table $5.2 \quad$ Strain measurements $(\varepsilon / \mathrm{P})$ for each load case .......................................105

Table 5.3 Typical $R^{2}$ values for displacement measurements under each load case ...106

Table 5.4 Typical $R^{2}$ values for strain measurements under each load case ..............106

Table 5.5 Displacement ratio for symmetric load cases ...................................107

Table 5.6 Strain ratio for symmetric load cases ............................................107

Table 5.7 Experimental and finite element comparison for multi-cell box deck

under load case 1 (centric) .........................................................108

Table 5.8 Experimental and finite element comparison for multi-cell box deck under load cases 2 and 3 (asymmetric) ...........................................111

Table 5.9 Displacements $[\delta / P(\mathrm{in} / \mathrm{kip})]$ of stringers for Bridge System $1 \ldots \ldots \ldots \ldots \ldots . . . .118$

Table 5.10 Longitudinal strains of stringers $[\varepsilon / P(\mu \varepsilon /$ kip) for Bridge System 1 .........119

Table 5.11 Displacements $[\delta / P$ (in/kip)] of stringers for Bridge System $2 \ldots \ldots \ldots \ldots \ldots . . .119$

Table 5.12 Longitudinal strains of stringers $[\varepsilon / P(\mu \varepsilon /$ kip $)]$ for Bridge System $2 \ldots . . . .119$

Table 5.13 Effect of end stiffeners on stringer displacements $(\delta / P) \ldots \ldots \ldots \ldots \ldots \ldots \ldots \ldots \ldots \ldots \ldots \ldots \ldots \ldots \ldots . . . . .120$

Table 5.14 Effect of end stiffeners on stringer longitudinal strains $(\varepsilon / P) \ldots \ldots \ldots \ldots \ldots \ldots . . . . .120$

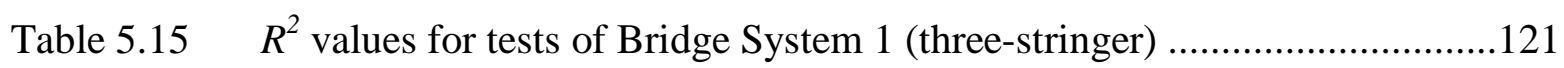

Table 5.16 $\quad R^{2}$ values for tests of Bridge System 2 (four-stringer) ...............................121 
Table 5.17 Deformation ratios for system symmetry (Bridge System 1) ...................122

Table 5.18 Deformation ratios for system symmetry (Bridge System 2) ...................122

Table 5.19 Comparison of experimental, FE, and theoretical values for

Load Case 1 (3-stringer symmetric) ................................................124

Table 5.20 Comparison of experimental, FE, and theoretical values for

Load Case 1 (4-stringer symmetric) ................................................124

Table 5.21 Comparison of experimental, FE, and theoretical values for

Load Cases 2 and 3 (3-stringer asymmetric) .......................................125

Table 5.22 Comparison of experimental, FE, and theoretical values for

Load Cases 2 and 3 (4-stringer asymmetric) .........................................126 


\section{LIST OF FIGURES}

Figure 1.1 Systematic analysis protocol for FRP bridge systems ............................4

Figure 1.2 FRP bridge deck cross-section types considered by Henry [1]

and Ahmad and Plecnik [2] ...............................................................

Figure 1.3 Modified hybrid section from System II: constant composite

thickness - Bakeri and Sunder [4] f................................................ 8

Figure 2.1 Microstructure and dimensions of FRP box beam section ........................14

Figure 2.2 Panel fiber architectures of wide flange beam ....................................15

Figure 2.3 Dimensions of I or wide-flange beam ................................................30

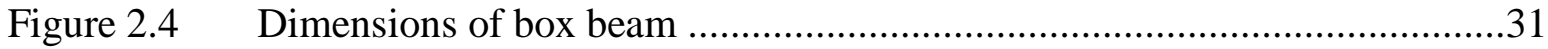

Figure 3.1 Geometric parameters of multi-cell box deck ......................................37

Figure 3.2 Vierendeel distortion in multi-cell box beam [37] .................................39

Figure 3.3 Conceptual model for verification of longitudinal stiffness equations .........44

Figure 3.4 Conceptual model for verification of transverse stiffness equations ...........46

Figure 3.5 Center deflections (in.) of multi-cell longitudinally-supported deck ...........48

Figure 3.6 Center deflections (in.) of multi-cell transversely-supported beam .............48

Figure 3.7 Conceptual model for verification of torsional rigidity equation ................50

Figure 3.8 Torsional rigidity (GJ) vs. number of cells ......................................52

Figure $3.9 \quad$ Multi-cellular deck and equivalent orthotropic plate …..........................54

Figure 3.10 Finite element model of multi-cellular deck for verification of $\mathrm{E}_{\mathrm{x}} \ldots \ldots \ldots \ldots . . .59$ 
Figure 3.11 Finite element model of multi-cellular deck for verification of $E_{y} \ldots \ldots \ldots \ldots . . .60$

Figure 3.12 Location of displacement measurements in Tables 3.5 and 3.6 ................61

Figure 4.1 Sign convention for deformation and plate stress resultants ....................64

Figure 4.2 SDMF flexural analysis model .....................................................67

Figure 4.3 Comparison of series solution and FE model .........................................84

Figure 4.4 Dimensions and panel fiber architecture of optimized Winged-box beam ...94

Figure 4.5 Dimensions and panel fiber architecture of 10"x10"x3/4" box beam .........96

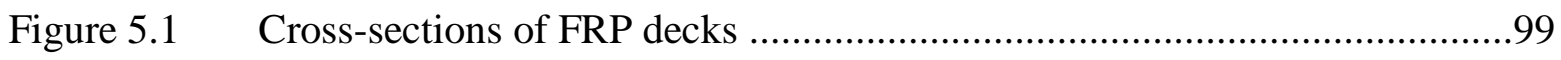

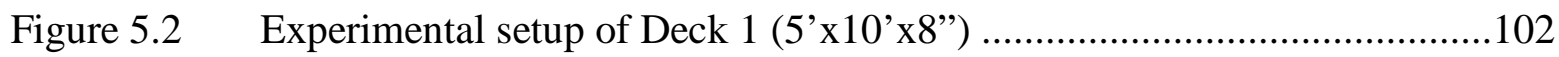

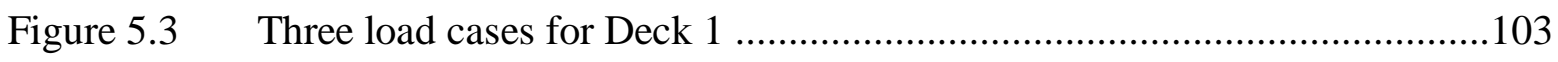

Figure 5.4 Deck 1 deflections under symmetric loading ....................................109

Figure 5.5 Deck 1 deflections under asymmetric loading ....................................110

Figure 5.6 Bridge System 1 with three stringers .................................................114

Figure 5.7 Three load cases for Bridge System 1 ............................................115

Figure $5.8 \quad$ Bridge System 2 with four stringers ...............................................116

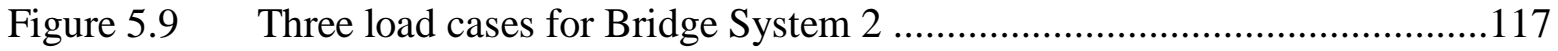

Figure 5.10 Comparison for deck/stringer bridge system ....................................127

Figure 5.11 Deflections of Deck System 1 under symmetric load .............................128

Figure 5.12 Deflections of stringers in Deck System 1 under symmetric load .............129

Figure 5.13 Deflections of Deck System 1 under asymmetric load ...........................130

Figure 5.14 Deflections of stringers in Deck System 1 under asymmetric load ...........131 
Figure 5.15 Deflections of Deck System 2 under symmetric load .............................132

Figure 5.16 Deflections of stringers in Deck System 2 under symmetric load .............133

Figure 5.17 Deflections of Deck System 2 under asymmetric load ...........................134

Figure 5.18 Deflections of stringers in Deck System 2 under asymmetric load ...........135 


\section{Chapter 1}

\section{INTRODUCTION}

\subsection{FRP Composite Bridges: Overview and Challenges}

There is a concern with worldwide deterioration of highway bridges, particularly reinforced concrete. Recently, attention has been focused on fiber reinforced plastic (FRP) shapes as alternative bridge deck materials. Their light weight and high specific stiffness and strength can lead to increased live load capacity and increased durability. Also, the resistance of FRP sections to corrosion allows for their use as replacements to

steel and reinforced concrete in bridges. And their modular fabrication decreases field assembly time, leading to decreased erection and traffic routing costs.

Despite the overall benefits of using FRP sections, they are as yet not widely used. Often, standard materials like steel, concrete, and timber are more economical in terms of material costs. Also, the material properties and the behavior of FRP composites are not as fully developed and understood as conventional materials and therefore there are no standardized codes or specifications to govern their use. However, conventional materials require routine maintenance and eventual replacement while FRP sections, once installed, would have a much longer life span and thus justification for their use. 
The most critical obstacle to widespread FRP applications is the lack of simplified design equations. Unlike standard materials, FRP composites are typically orthotropic or anisotropic and analysis is much more difficult. For example, while changes in the geometry of FRP shapes can be easily related to changes in stiffness, changes in the material constituents do not lead to such obvious results. In addition, shear deformations in pultruded FRP composite materials are usually significant and therefore modeling of FRP structural components should account for shear effects.

Therefore, there is a need to develop simplified design equations and procedures for analysis of bridges composed of FRP materials. This design approach should be easily implemented by practicing engineers and also provide relatively accurate predictions of bridge behavior.

\subsection{Problem Statement and Objectives}

Due to the complexity of FRP materials, current analytical and design tools developed for conventional materials are not suitable for FRP shapes. Also, numerical methods such as finite elements are often difficult to use, require specialized training, and are not always accessible to design engineers. Thus there is a need for a simplified design procedure for FRP composite bridge systems. The primary goal of this study, then, is to present such a design analysis procedure along with numerical and experimental verification of the results.

To fulfill this goal, the objectives of this study are: 
1. To develop simplified equations for predicting a bridge deck's properties by means of an equivalent orthotropic plate approach.

2. To develop a design procedure for analysis and design of FRP composite deck-andstringer systems using a series approximation method.

3. To verify the resulting design equations by both experimental and numerical means.

\subsection{Thesis Overview}

This study employs a systematic approach that presents the analysis of micro/macrostructures of composites, composite beams, and bridge systems. The systematic approach integrates the analyses from the composite ply level to the laminate panel, then to the FRP beam and deck level, and finally to the bridge system level as illustrated in Fig. 1.1.

Composite shapes and sections can be modeled by several micro and macromechanics formulations that have been developed over the years. The determination of fiber volume fractions for various FRP layers is first presented in Chapter 2, followed by a micromechanics model to be used to evaluate ply properties and macromechanics to evaluate the laminate properties. Chapter 2 also presents simplified formulas for beam stiffness properties, which can then be used in the beam equations to predict beam deflections and maximum strains. 


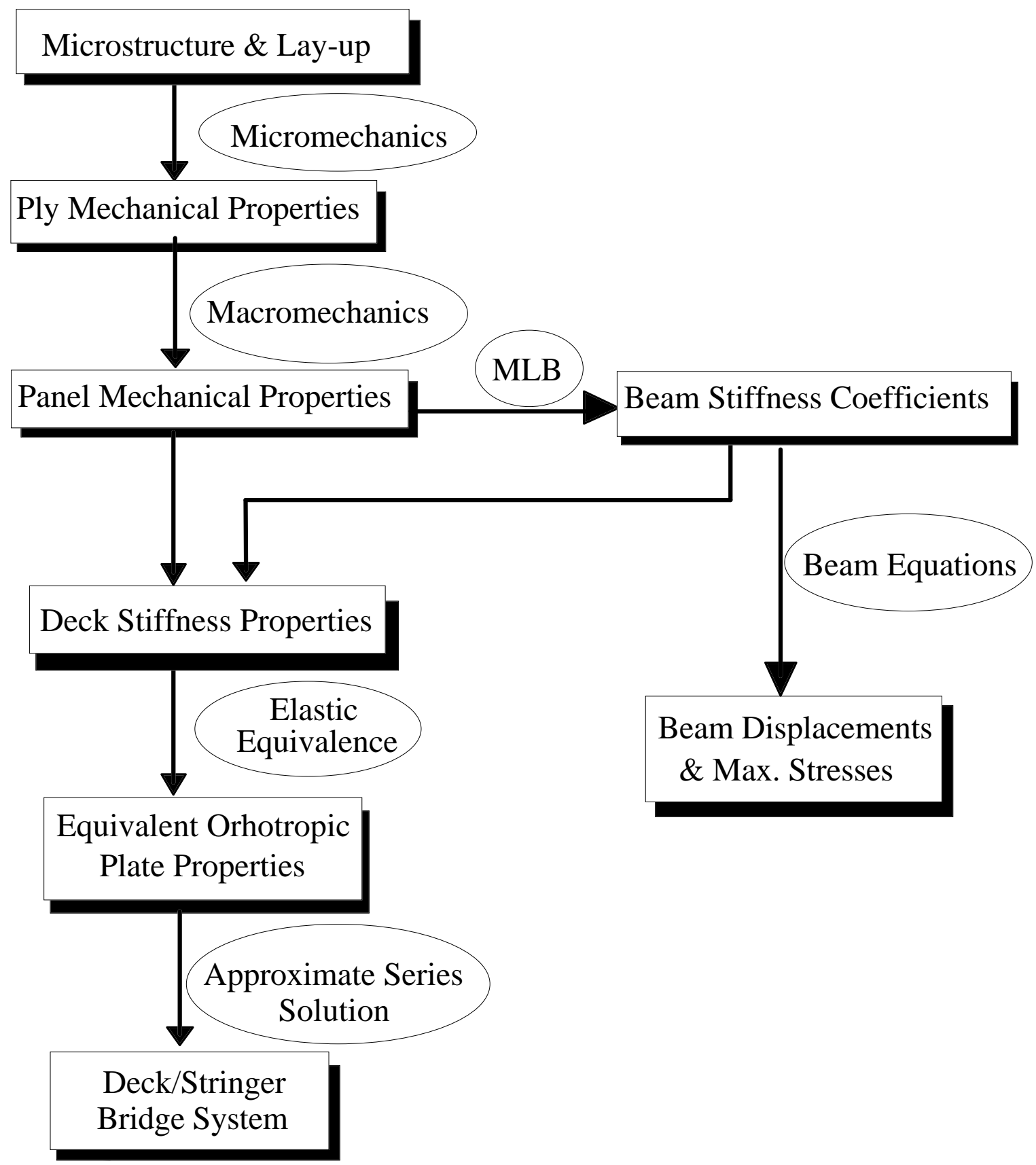

Figure 1.1 Systematic analysis protocol for FRP Bridge Systems 
Based on an elastic equivalence analysis approach the derivation of multicellular deck properties, followed by simplified equivalent orthotropic plate material properties, is presented in Chapter 3. Using these properties, and series approximation techniques, design equations for deck-and-stringer bridges are developed in Chapter 4. Derivations of deflection equations are illustrated for symmetric, antisymmetric, and asymmetric load cases, as well as equations for wheel load distribution factors. Also, to illustrate the design equations, two short-span bridges are analyzed and designed.

Experimental verification of deck and deck-and-stringer systems is provided in Chapter 5. Several specimens and load conditions were tested, and the testing protocol included both symmetric and asymmetric loadings. Comparisons between the analytical solutions, finite element models, and experimental results are given.

Finally, the analytical and experimental studies are used to provide conclusions and recommendations to further investigate and apply this work in highway bridge design, as shown in Chapter 6.

\subsection{Previous Works on FRP Bridge Decks}

In recent years, FRP composites are increasingly becoming part of the civil infrastructure. Due to this use, a number of theoretical and experimental investigations have been conducted to study stiffness, strength, and stability characteristics of FRP composite bridge decks. This section presents summaries of published works pertaining to the analytical and experimental studies performed at several institutions. 
North Carolina State and California State Universities: This was the first research program sponsored by the Federal Highway Administration with the objectives of: developing an FRP deck system; examining both experimentally and analytically the ultimate strength and stiffness of the deck and its components; establishing preliminary fatigue performance criteria; and developing a prototype system for connected deck panels. The preliminary work reported by Henry [1], Ahmad and Plecnik [2], and Plecnik and Azar [3] examined the performance of several glass reinforced polymer bridge deck configurations, shown in Figure 1.2, by means of a general purpose finite element code (SAP IV). The design philosophy was that an FRP deck behaves as a truss member in the direction perpendicular to the traffic flow, and a flexural member in the direction parallel to the traffic flow.

The results indicated that the design was always controlled by the deflection limit state rather than the strength limit states. Also, the X-shaped bridge deck, Type II in Figure 1.2, appeared to have the lowest deflection and satisfied the deflection limit, s/800 ( $s=$ stringer spacing), set by the authors and thus was chosen as the best design in the study.

This deck was later fabricated using a combination of filament winding and hand lay-up processes in order to determine the static and fatigue behavior experimentally. A complete description of the assembly technique is described by Plecnik and Azar [3]. From the extensive testing conducted by Plecnik and his co-workers, it was evident that damage under fatigue loadings consisted primarily of delamination initiation caused by inadequate or defective interface bonding between laminated panels or between adjacent layers of different fiber orientations within a laminate. Local buckling of thin 
delaminated layers under compressive service loads results in a severe opening action along the front of delamination crack and this may cause catastrophic delamination growth. It must be noted that the works conducted at NC State and CA State Universities were limited to the development of conceptual design protocols, with experimental investigations and finite element modeling of truss systems only.

Type I

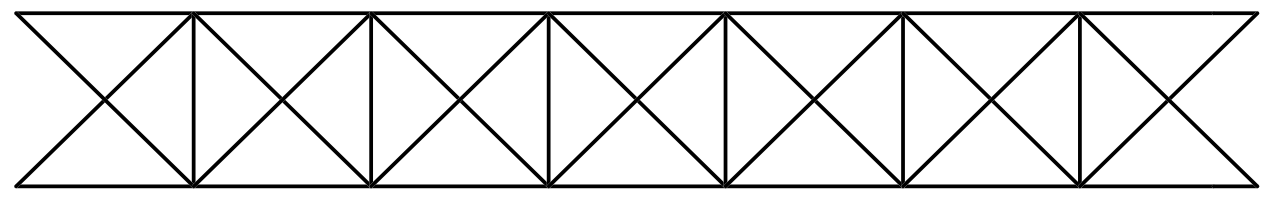

Type II

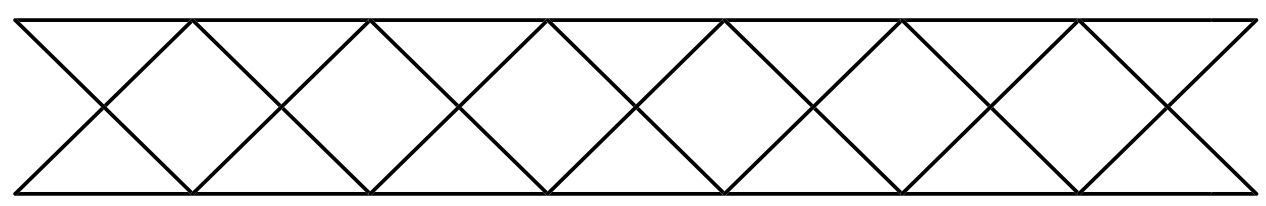

Type III

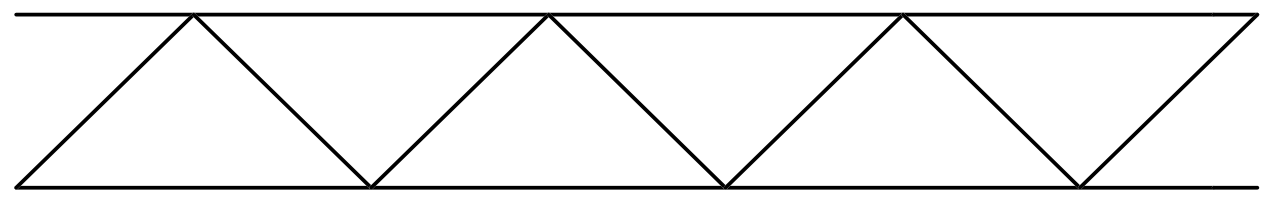

Type IV

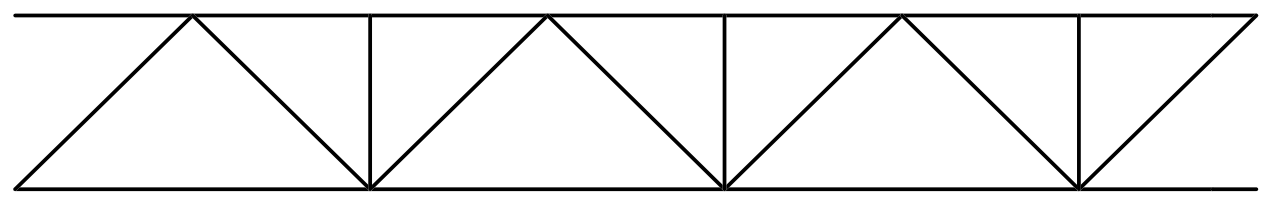

Type V

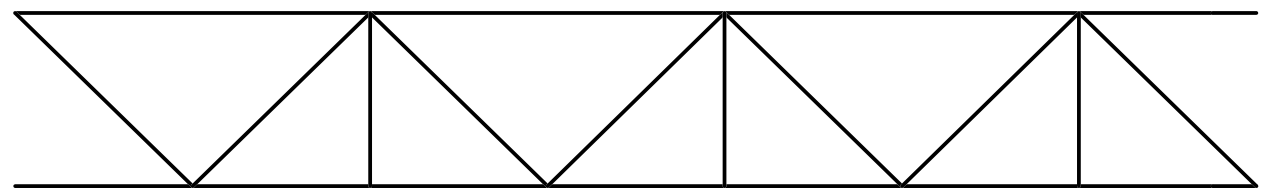

Figure 1.2 FRP bridge deck cross-section types considered by Henry [1] and Ahmad and Plecnik [2] 
Massachusetts Institute of Technology: Bakeri and Sunder [4] used balanced symmetrical lamina to investigate analytically the feasibility of a number of FRP bridge decks, which consisted of different material systems. Two different systems were investigated: 1) the entire deck was assumed to made of glass-reinforced polymer; 2) hybrid materials were used in the deck. They concluded that the hybrid concept, shown in Figure 1.3, composed of glass-reinforced polymer, carbon fiber-reinforced polymer, and light-weight concrete resulted in a bridge deck system having a deflection less than s/800, where s represents the stringer spacing. Their study indicated that a hybrid FRP/concrete system has a promising future in infrastructure applications.

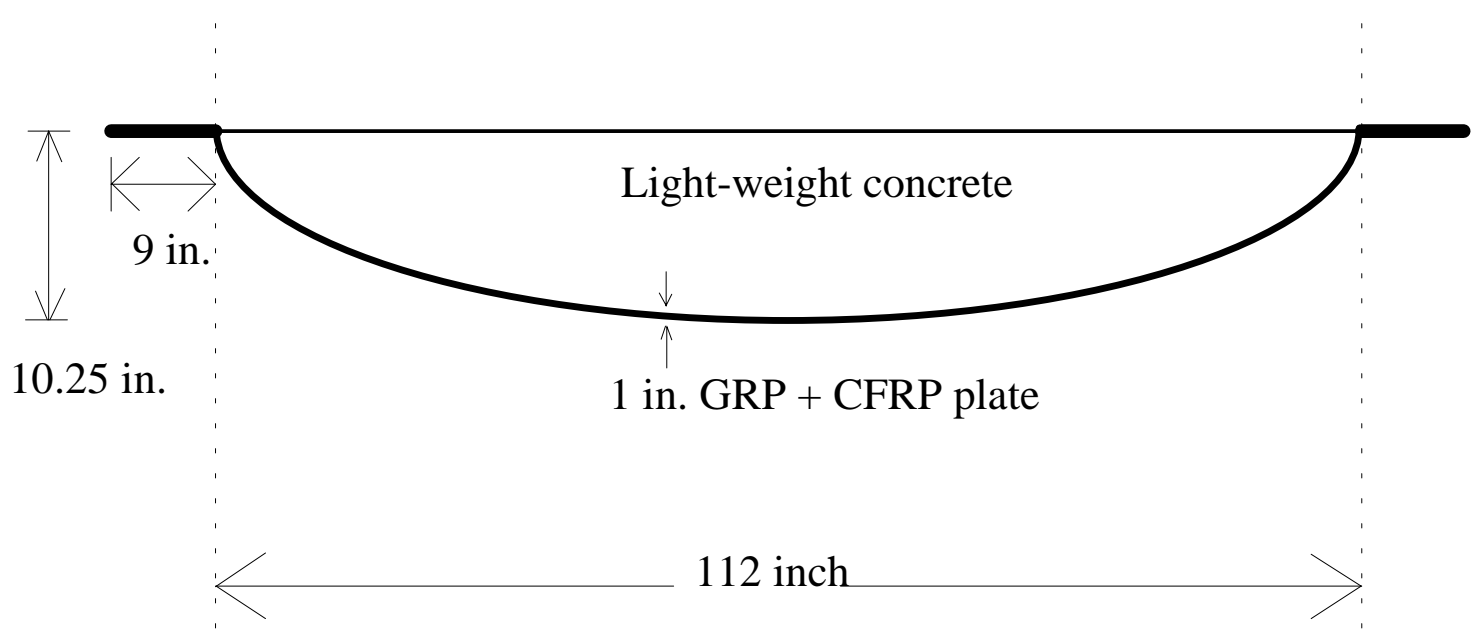

Figure 1.3 Modified hybrid section from System II: constant composite thickness - Bakeri and Sunder [4] 
University of Virginia: Based on the initial study reported by Henry [1] and Ahmad and Plecnik [2], McGhee et al. [5] presented results of the least-weight design of four crosssection types of FRP bridge decks subjected to AASHTO loading [6]. Types I, II, and III (shown in Fig. 1.2), as well as a slightly modified version of type IV, were investigated. The mathematical optimization problem was formulated such that the objective function was represented by the weight of the bridge deck while the behavioral constraints included ultimate strength, local buckling and $s / 800$ deflection limit states. Linear-elastic finite-element analysis, in which orthotropic plane stress elements were combined with space frame members, was used to simulate the cellular deck. The study concluded that the type III cross section is the most efficient design and results in an FRP deck weighing approximately $20 \mathrm{lb} . / \mathrm{ft}^{2}$ of deck surface.

West Virginia University: With the objective of developing an FRP bridge deck system, Mongi [7] tested three full scale floor systems which differ in their size, joint type, and loading conditions. The experimental deflections were compared with theoretical values obtained using Timoshenko's beam theory, finite element method, and the WVU formula. The author concluded that good correlation was found between experimental and theoretical deflections, and floor system 3, consisting of two cellular box sections connected by an I-beam, possessed the best structural efficiency.

In a later study, Gangarao and Sotiropoulos [8] assembled and tested two FRP bridge superstructure systems consisting of bridge decks and stringers. The first system had five parts: two exterior stringers as channels, an interior I-section stringer made from 
two back-to-back connected channels, and two solid composite plates placed on the top and bottom of the box section. The fiber direction of the solid plates was normal to that of the stringers to provide better transverse load distribution. The second system used a cellular section as a substitute for the top plate of the first system in order to improve the bending stiffness.

These two systems were loaded at the midspan of the interior and exterior stringers and at the center of a spread beam placed across the central width of the superstructure. They were subjected to three types of loading: concentric, eccentric, and uniform line loads. For the case of concentric loading, it was noted that deflection values of the outside girders differed from each other by approximately 64 percent. This may be attributed to a number of factors such as inconsistencies in material properties, experimental errors, etc.

To predict the experimental behavior of these two systems, the authors used very simplified finite-element models in which equivalent plates were used as a substitute for the stringers and the cellular deck, and the extension-bending coupling stiffness was ignored. Only the case in which the systems were subjected to concentric loading was analyzed. In order to predict accurately the stiffness and load distribution characteristics of the FRP panel, a coarser model should not be used. Part of this work, along with a summary of tests conducted by Mongi [7] on floor systems of cellular cross section was presented by Sotiropoulos et al. [9].

Burside et al. [10] presented a design optimization of an all-composite bridge deck. Cellular-box and stiffened-box geometries were optimized with consideration of deflection and buckling in their studies. 
Recent Developments: Most recently, two highway bridges were constructed with a modular FRP composite deck in West Virginia [11]: one was built as an all-composite short-span deck/stringer system and another one was constructed with a modular FRP deck supported by steel stingers. Fatigue and failure characteristics of a modular deck were investigated by Lopez-Anido et al. [12] and satisfactory performance was observed. Several projects [13] also demonstrated the potential of FRP composites as highway bridge materials. An overview of current status on research and applications of fiberreinforced polymeric bridge decks was presented by Zureick [14].

Remarks: Although several experimental and numerical efforts have been conducted, there is no simplified design protocol available for FRP composite bridges. The design procedures developed for bridges composed of isotropic materials [15] can not be directly applied; they need to be modified to incorporate the anisotropy of composite materials. Thus a simple but accurate solution for analysis and design of FRP composite bridges is needed. This solution should account for the geometry and material properties of FRP decks and stringers; and it must provide the predictions for performance and load distribution of the system. 


\section{CHAPTER 2}

\section{FRP STRUCTURAL SHAPES: MECHANICS AND DESIGN}

\subsection{Introduction}

In this chapter, an engineering computational approach is presented and developed into simplified design equations for the analysis of pultruded FRP beams under bending. It proceeds from the evaluation of ply and panel stiffnesses using micro/macromechanics to the development of beam simplified equations and their applications to overall beam response [16]. An experimental program then verifies the design approach and equations.

\subsection{Basics for Modeling of FRP Shapes}

Pultruded sections, such as wide-flange, box, and other shapes, consist typically of arrangements of flat walls or panels. Usually, the reinforcement used is E-glass fiber, and the resin or matrix is either vinylester or polyester. Although pultruded FRP shapes are not laminated structures in a rigorous sense, they are pultruded with material architectures that can be simulated as laminated configurations [17]. A typical pultruded section usually includes four types of layers (Figure 2.1): 
(1) Continuous (or Chopped) Strand Mats (CSM) of different weights consisting of continuous (or short) randomly-oriented fibers.

(2) Stitched Fabrics (SF) with different angle orientations and weights.

(3) Roving layers that contain continuous unidirectional fiber bundles (which contribute the most to the stiffness and strength of a section).

(4) A thin layer (veil) of randomly oriented chopped fibers (Nexus) placed on the surface of the composite. This veil is a resin-rich layer primarily used as a protective coating, and its contribution to the laminate response can be neglected.

Each layer is modeled as a homogeneous, linearly elastic, and generally orthotropic material. To evaluate its properties, the information that is provided by the material producer and pultrusion manufacturer is used to compute the fiber volume fraction $\left(V_{f}\right)$ of each equivalent ply, as discussed in the next section.

\subsubsection{Microstructure and Fiber Volume Fraction of FRP Shapes}

For pultruded sections, it is not practical to evaluate the ply stiffnesses through experimental tests, since the material is not produced by lamination lay-up. Therefore, micromechanics formulas are used to compute the ply stiffnesses of the roving, CSM, and SF layers. The ply stiffnesses can then be used in Classical Lamination Theory (CLT) [18] to predict the laminate stiffnesses. 


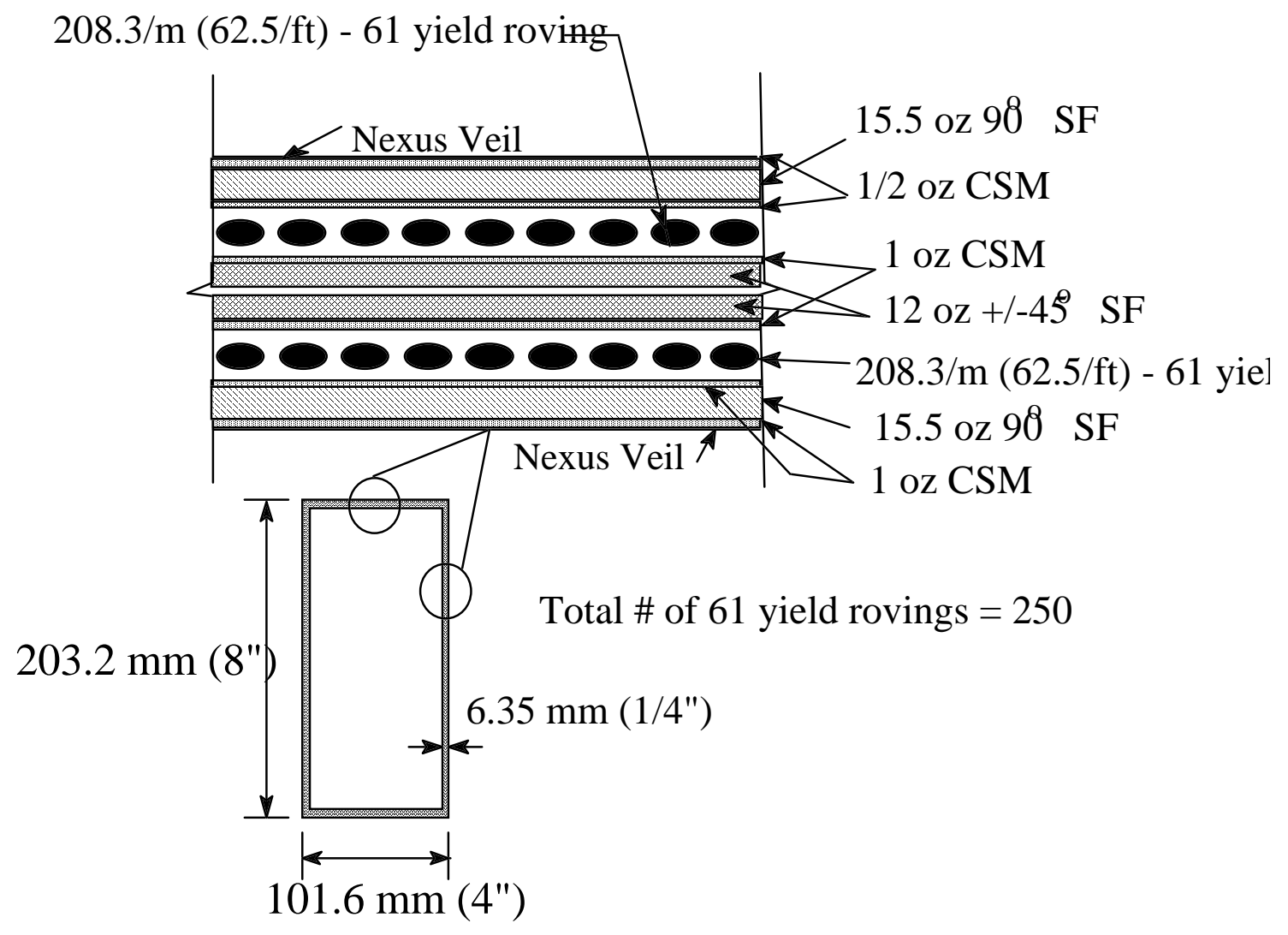

Figure 2.1 Microstructure and dimensions of FRP box beam section 


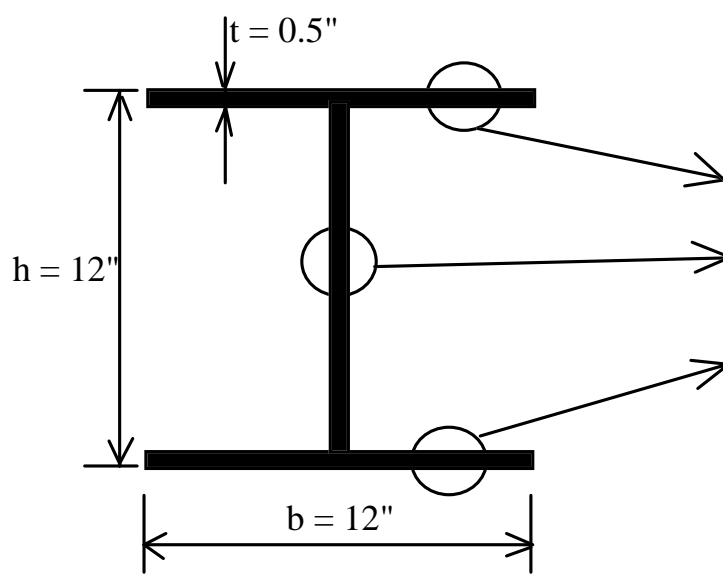

$k \mathrm{~b}=12^{\prime \prime} \rightarrow$

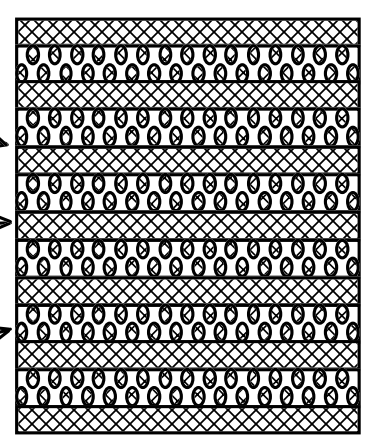

3/4oz. CSM \& 17.7oz. +/-45 SF 54 rovings (62 yield)

3/4oz. CSM \& 17.7oz. +/-45 SF 54 rovings (62 yield)

$3 / 4 \mathrm{oz} . \mathrm{CSM} \& 17.7 \mathrm{oz}$. +/-45 SF 54 rovings (62 yield)

3/4oz. CSM \& 17.7oz. +/-45 SF 54 rovings (62 yield)

3/4oz. CSM \& 17.7oz. +/-45 SF 54 rovings (62 yield)

3/4oz. CSM \& 17.7oz. +/-45 SF 54 rovings (62 yield)

3/4oz. CSM \& 17.7oz. +/-45 SF

21 layers through the thickness of each panel

Fiber volume fraction: $\mathrm{Vf}=44.3 \%$

Figure 2.2 Panel fiber architectures of wide flange beam

For the pultruded FRP sections, the reinforcement usually used is E-glass fiber, and the resin or matrix is either vinylester or polyester, and the properties of fiber and resin (vinylester in this study) are given in Table 2.1. The Lame' constants of fiber and matrix are then given in terms of $E$ and $v$ as

$$
\begin{gathered}
\lambda=\frac{E v}{(1+v)(1-2 v)} \\
\mu=G=\frac{E}{2(1+v)}
\end{gathered}
$$


Table 2.1 Material properties of the constituents

\begin{tabular}{ccccc}
\hline Material & $\mathrm{E}(\mathrm{psi})$ & $\mathrm{G}(\mathrm{psi})$ & $v$ & $\rho\left(\mathrm{lb} / \mathrm{in}^{3}\right)$ \\
\hline E-glass fiber & $10.5 \times 10^{6}$ & $4.1833 \times 10^{6}$ & 0.255 & 0.092 \\
Vinylester resin $^{(\mathrm{a})}$ & $7.336 \times 10^{5}$ & $2.3714 \times 10^{5}$ & 0.30 & 0.041 \\
\hline
\end{tabular}

\footnotetext{
(a) obtained experimentally [19].
}

The fiber volume fraction $\left(V_{f}\right)$ for each ply, whether a roving, CSM or SF layer, is defined as the ratio of the volume of fibers present to the total volume of the layer, and therefore, the relative volumes of fiber and matrix are determined to evaluate the ply stiffnesses. Similarly, the fiber volume fraction $\left(V_{f}\right)$ of the whole section can be defined. For the CSM and SF layers, which are respectively specified in $o z / f t^{2}$ and $o z / y d^{2}$, the $V_{f}$ can be determined as follows:

$$
\left(V_{f}\right)_{C S M / S F}=\frac{w}{\rho t}
$$

where $w$ is the weight per unit area in $l b / i n^{2}, \rho$ is the unconsolidated density of the CSM or SF fibers in $l b / i^{3}$, and $t$ is the "as manufactured" thickness of the material (inches) as provided by the material producer. Thus, as an approximation, it is assumed that the thicknesses of these constituents remain constant during part manufacturing, and that the voids are filled with resin. For the roving layers, the fiber volume fraction $\left(V_{f}\right)_{r}$ is defined as:

$$
\left(V_{f}\right)_{r}=\frac{n_{r} A_{r}}{t_{r}}
$$


where $n_{r}$ is the number of rovings per unit width $\left(\mathrm{in}^{-1}\right)$ provided by the manufacturer, $t_{r}$ is the assumed "in situ" thickness of the roving-matrix layer which is computed by subtracting the thicknesses of the CSM and SF layers from the pultruded laminate thickness. $A_{r}$ is the area of one roving computed from:

$$
A_{r}=\frac{1}{Y \rho_{r}}
$$

where $Y$ is the yield specified in yards/lb and converted to $i n / l b$, and $\rho_{r}$ is the density of the fibers given by the producer. Once the fiber volume fractions $\left(V_{f}\right)$ for all the typical layers are computed, the ply stiffnesses are predicted using selected micromechanics formulas as introduced next.

\subsubsection{Micromechanics of Composites}

Numerous micromechanical models have been developed to predict the effective elastic properties of composite materials (Budiansky [20], Mura [21], Christensen [22], Aboudi [23], Nemat-Nasser and Hori [24]). Luciano and Barbero [25] present a newly developed micromechanical model for composites with periodic microstructure. They extended the model for elastic solids with periodic microstructure (Nemat-Nasser and Taya [26], Iwakuma and Nemat-Nasser [27]) and proposed closed-form expressions for the coefficients of overall stiffness tensors of composite materials with periodically distributed elastic inclusions or voids. Moreover, analytical expressions are given for the elastic moduli of the transversely isotropic material equivalent to the solid reinforced by periodic long fibers. This 
model is further applied in this study to compute the ply stiffnesses for the roving, CSM and SF layers.

In the following sections, the analytical expressions of stiffness tensors for unidirectional composite with periodic microstructure are first introduced. Based on the stiffness tensors of the unidirectional composites, transversely isotropic stiffness tensors are obtained by applying the averaging procedure. Finally, the ply reduced stiffness coefficients are expressed in term of the transversely isotopic stiffness tensors.

\section{Unidirectional Composites with Periodic Microstructure:}

For unidirectional composites which the composite material is reinforced by long circular cylindrical fibers along the $x_{1}$ axis, the linear elastic stiffness tensors $\left(C^{*}\right)$ are expressed as

$$
\begin{gathered}
C_{11}^{*}(s)=\lambda_{0}+2 \mu_{0}-V_{f}\left[\frac{S_{3}^{2}}{\mu_{0}^{2}}-\frac{2 S_{6} S_{3}}{\mu_{0}{ }^{2} g}-\frac{a S_{3}}{\mu_{0} c}+\frac{S_{6}{ }^{2}-S_{7}{ }^{2}}{\mu_{0}{ }^{2} g^{2}}+\frac{a S_{6}+b S_{7}}{\mu_{0} g c}+\frac{a^{2}-b^{2}}{4 c^{2}}\right] / D \\
C_{12}{ }^{*}(s)=\lambda_{0}+V_{f} b\left[\frac{S_{37}}{2 \mu_{0} c}-\frac{S_{6}-S_{7}}{2 \mu_{0} c g}-\frac{a+b}{4 c^{2}}\right] / D \\
C_{23}{ }^{*}(s)=\lambda_{0}+V_{f}\left[\frac{a S_{7}}{2 \mu_{0} g c}-\frac{b a+b^{2}}{4 c^{2}}\right] / D \\
C_{22}{ }^{*}(s)=\lambda_{0}+2 \mu_{0}-V_{f}\left[-\frac{a S_{3}}{2 \mu_{0} c}+\frac{a S_{6}}{2 \mu_{0} g c}+\frac{a^{2}-b^{2}}{4 c^{2}}\right] / D \\
C_{44}{ }^{*}(s)=\mu_{0}-V_{f}\left[-\frac{2 S_{3}}{\mu_{0}}+\left(\mu_{0}-\mu_{1}\right)^{-1}+\frac{4 S_{7}}{\mu_{0}\left(2-2 v_{0}\right)}\right]^{-1}
\end{gathered}
$$




$$
C_{66}{ }^{*}(s)=\mu_{0}-V_{f}\left[-\frac{S_{3}}{\mu_{0}}+\left(\mu_{0}-\mu_{1}\right)^{-1}\right]^{-1}
$$

where $V_{f}$ is the fiber volume fraction and the subscripts 0 and 1 stand for the matrix and fiber respectively. The coefficients of $a, b, c, g$ and $D$ are given by

$$
\begin{gathered}
a=\mu_{1}-\mu_{0}-2 \mu_{1} v_{0}+2 \mu_{0} v_{1} \\
b=\mu_{1} v_{1}-\mu_{0} v_{0}-2 \mu_{1} v_{0} v_{1}+2 \mu_{0} v_{1} v_{0} \\
c=\left(a+b+\mu_{1} v_{1}\right)\left(\mu_{0}-\mu_{1}\right) \\
g=2-2 v_{0}
\end{gathered}
$$

and

$$
\begin{aligned}
D & =\frac{a S_{3}{ }^{2}}{2 \mu_{0}{ }^{2} c}-\frac{a S_{6} S_{3}}{\mu_{0}{ }^{2} g c}+\frac{a\left(S_{6}{ }^{2}-S_{7}{ }^{2}\right)}{2 \mu_{0}{ }^{2} g^{2} c}+\frac{S_{3}\left(b^{2}-a^{2}\right)}{2 \mu_{0} c^{2}}+\frac{S_{6}\left(a^{2}-b^{2}\right)+S_{7}\left(a b+b^{2}\right)}{2 \mu_{0} g c^{2}} \\
& +\frac{a^{3}-2 b^{3}-3 a b^{2}}{8 c^{3}}
\end{aligned}
$$

The series $S_{3}, S_{6}$, and $S_{7}$ are obtained from Nemat-Nasser et al. [28] accounting for the geometries of the fibers and are expressed with the parabolic fittings (Luciano and Barbero [25]) as

$$
\begin{aligned}
& S_{3}=0.49247-0.47603 V_{f}-0.02748 V_{f}^{2} \\
& S_{6}=0.36844-0.14944 V_{f}-0.27152 V_{f}^{2} \\
& S_{7}=0.12346-0.32035 V_{f}+0.23517 V_{f}^{2}
\end{aligned}
$$




\section{Transversely Isotropic Material and Prediction of Ply Stiffnesses:}

Due to the periodicity of the microstructure, the linear elastic stiffness tensors for unidirectional composites represent an orthotropic material with square symmetry. To model the composites with transverse isotropy, the following averaging procedure [23] is adopted to obtain the stiffness tensor $C$ of the transversely isotropic material

$$
C=\frac{1}{\pi} \int_{0}^{\pi}[T(\theta)] C^{*}[T(\theta)]^{T} d \theta
$$

where $\theta$ is the rotation about the $x_{1}$ axis of the $C^{*}$ tensor and $T(\theta)$ is the fourth-order orthogonal rotation tensor. After the integration of Eq. (2.7), the stiffness tensors of transversely isotropic material $(C)$ are expressed explicitly in the terms of the stiffness tensors $\left(C^{*}\right)$ of unidirectional composites as

$$
\begin{aligned}
& C_{11}(s)=C_{11}^{*}(s) \\
& C_{12}(s)=C_{12}^{*}(s) \\
& C_{22}(s)=\frac{3}{4} C_{22}^{*}(s)+\frac{1}{4} C_{23}^{*}(s)+\frac{1}{2} C_{44}^{*}(s) \\
& C_{23}(s)=\frac{1}{4} C_{22}^{*}(s)+\frac{3}{4} C_{23}^{*}(s)-\frac{1}{2} C_{44}^{*}(s) \\
& C_{66}(s)=C_{66}^{*}(s)
\end{aligned}
$$




$$
C_{44}(s)=\frac{1}{4} C_{22}^{*}(s)-\frac{1}{4} C_{23}^{*}(s)+\frac{1}{2} C_{44}^{*}(s)
$$

The constitutive equation (Hooke's law) for a transverse isotropic material, with the axis of symmetry oriented in the $x_{1}$ axis is then expressed [23] as

$$
\left\{\begin{array}{l}
\sigma_{11} \\
\sigma_{22} \\
\sigma_{33} \\
\sigma_{23} \\
\sigma_{13} \\
\sigma_{12}
\end{array}\right\}=\left[\begin{array}{cccccc}
C_{11} & C_{12} & C_{12} & 0 & 0 & 0 \\
C_{12} & C_{22} & C_{23} & 0 & 0 & 0 \\
C_{12} & C_{23} & C_{22} & 0 & 0 & 0 \\
0 & 0 & 0 & C_{44} & 0 & 0 \\
0 & 0 & 0 & 0 & C_{66} & 0 \\
0 & 0 & 0 & 0 & 0 & C_{66}
\end{array}\right]\left\{\begin{array}{l}
\varepsilon_{11} \\
\varepsilon_{22} \\
\varepsilon_{33} \\
\gamma_{23} \\
\gamma_{13} \\
\gamma_{12}
\end{array}\right\}
$$

To model a ply, the assumption of plane stress is used and the constitutive relationship for a unidirectional composite becomes

$$
\left\{\begin{array}{l}
\sigma_{11} \\
\sigma_{22} \\
\sigma_{12}
\end{array}\right\}=\left[\begin{array}{ccc}
Q_{11} & Q_{12} & 0 \\
Q_{12} & Q_{22} & 0 \\
0 & 0 & Q_{66}
\end{array}\right]\left\{\begin{array}{l}
\varepsilon_{11} \\
\varepsilon_{22} \\
\gamma_{12}
\end{array}\right\}
$$

where the reduced stiffness coefficients $Q$ are given by

$$
Q_{11}=C_{11}-\frac{C_{12}^{2}}{C_{22}}
$$




$$
\begin{gathered}
Q_{12}=Q_{21}=C_{12}-\frac{C_{23} C_{12}}{C_{22}} \\
Q_{22}=C_{22}-\frac{C_{23}^{2}}{C_{22}} \\
Q_{66}=C_{66}
\end{gathered}
$$

A typical pultruded FRP section can be simulated as laminated configuration mainly consisting of combinations of three types of layers: (1) Continuous Strand Mats (CSM); (2) angle-ply Stitched Fabrics (SF); and (3) rovings or unidirectional fiber bundles. The SF and roving layers are usually modeled as unidirectional composites with different orientations, and their reduced stiffness coefficients $Q$ are then obtained directly from Eq. (2.11). Furthermore, the transformed reduced stiffness coefficients $\bar{Q}$ of SF and roving layers are obtained by multiplying $Q$ by the appropriate transformation matrix [18].

The CSM layer is assumed to be isotropic in the plane and the following reduced relaxation coefficients $(Q)_{C S M}$ of CSM layer are given explicitly in Harris [29] as

$$
\begin{gathered}
\left(Q_{11}\right)_{C S M}=\frac{3}{8} Q_{11}+\frac{1}{4} Q_{12}+\frac{3}{8} Q_{22}+\frac{1}{2} Q_{66} \\
\left(Q_{12}\right)_{C S M}=\left(Q_{21}\right)_{C S M}=\frac{1}{8} Q_{11}+\frac{3}{4} Q_{12}+\frac{1}{8} Q_{22}-\frac{1}{2} Q_{66} \\
\left(Q_{22}\right)_{C S M}=\frac{3}{8} Q_{11}+\frac{1}{4} Q_{12}+\frac{3}{8} Q_{22}+\frac{1}{2} Q_{66}
\end{gathered}
$$




$$
\left(Q_{66}\right)_{C S M}=\frac{1}{8} Q_{11}-\frac{1}{4} Q_{12}+\frac{1}{8} Q_{22}+\frac{1}{2} Q_{66}
$$

where all other coefficients are equal to zero.

Table 2.2 Ply material properties of box section (Figure 2.1) computed by micromechanics model [25]

\begin{tabular}{|c|c|c|c|c|}
\hline Lamina & $\mathrm{E}_{1}\left(\times 10^{6} \mathrm{psi}\right)$ & $\mathrm{E}_{2}\left({\left.\mathrm{x} 10^{6} \mathrm{psi}\right)}^{v_{12}}\right.$ & $\mathrm{G}_{12}\left({\left.\mathrm{x} 10^{6} \mathrm{psi}\right)}\right.$ \\
\hline $1 / 2 \mathrm{oz} \mathrm{CSM}$ & 2.093 & 2.093 & 0.407 & 0.744 \\
\hline $1 \mathrm{oz} \mathrm{CSM}$ & 1.710 & 1.710 & 0.402 & 0.610 \\
\hline $15.5 \mathrm{oz} 90^{\circ} \mathrm{SF}$ & 4.118 & 1.183 & 0.389 & 0.457 \\
\hline $12 \mathrm{oz}+/-45^{\circ} \mathrm{SF}$ & 3.505 & 1.056 & 0.396 & 0.405 \\
\hline 61 yield roving & 8.469 & 3.374 & 0.343 & 1.429 \\
\hline
\end{tabular}

Table 2.3 Ply material properties of wide-flange section (Figure 2.2) computed by micromechanics model [25]

\begin{tabular}{|c|c|c|c|c|}
\hline Lamina & $\mathrm{E}_{1}\left(\mathrm{x} \mathrm{10} 0^{6} \mathrm{psi}\right)$ & $\mathrm{E}_{2}\left(\mathrm{x} \mathrm{10}^{6} \mathrm{psi}\right)$ & $v_{12}$ & $\mathrm{G}_{12}\left(\times 10^{6} \mathrm{psi}\right)$ \\
\hline $3 / 4 \mathrm{oz} \mathrm{CSM}$ & 1.710 & 1.710 & 0.402 & 0.610 \\
\hline $17.7 \mathrm{oz}+/-45^{\circ} \mathrm{SF}$ & 4.157 & 1.191 & 0.294 & 0.460 \\
\hline 62 yield roving & 6.732 & 2.077 & 0.278 & 0.826 \\
\hline
\end{tabular}




\subsubsection{Macromechanics of Laminate and Prediction of Panel Stiffnesses}

Once the reduced stiffness coefficients of corresponding layers are computed, the stiffness

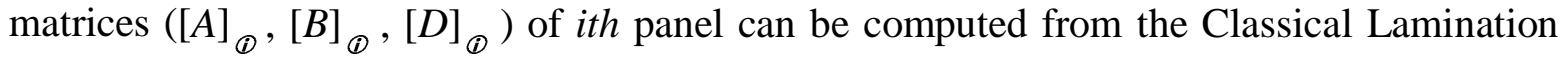
Theory (CLT) [18]. In particular, the panel compliance matrix $[\alpha]_{\mathscr{O}}$ which is obtained by inverting of the extentional relaxation matrix $[A]_{\mathscr{\oplus}}$, is used to compute the compliance coefficients and elastic properties $\left(E_{x}, E_{y}, v_{x y}, G_{x y}\right)$ of the ith panels as

$$
E_{x}=1 /\left(t \alpha_{11}\right), \quad E_{y}=1 /\left(t \alpha_{22}\right), \quad v_{x y}=-\alpha_{12} / \alpha_{11}, \quad G_{x y}=1 /\left(t \alpha_{66}\right)
$$

where $t$ is the thickness of the $i t h$ panel.

The panel properties $\left(E_{x}, E_{y}, v_{x y}, G_{x y}\right)$ can also be directly obtained from the panel coupon tests, i.e., the tensile tests in longitudinal $\left(E_{x}\right)$ and transverse $\left(E_{y}\right)$ directions, and torsion tests $\left(G_{x y}\right)$. For example, the laminate properties of the box section shown in Fig. 2.1 predicted by micro/mechanics approach compare well with coupon tests [30] of the same box section (Table 2.4). Table 2.5 also shows good correlation between predicted values and laminate samples of the WF 12"x12"x1/2" beam (Fig. 2.2). 
Table 2.4 Panel properties of box section (4" x 8" x 1/4")

\begin{tabular}{|c|c|c|c|c|}
\hline & $\mathrm{E}_{\mathrm{x}}$ & $\mathrm{E}_{\mathrm{y}}$ & $v_{\mathrm{xy}}$ & $\mathrm{G}_{\mathrm{xy}}$ \\
\hline Experimental & $3.293 \times 10^{6} \mathrm{psi}^{(\mathrm{a})}$ & $2.491 \times 10^{6} \mathrm{psi}^{(\mathrm{a})}$ & $0.269^{(\mathrm{a})}$ & $8.599 \times 10^{5} \mathrm{psi}^{(\mathrm{b})}$ \\
\hline $\begin{array}{c}\text { Micro/ } \\
\text { macromechanics }\end{array}$ & $3.377 \times 10^{6} \mathrm{psi}$ & $2.620 \times 10^{6} \mathrm{psi}$ & 0.285 & $8.760 \times 10^{5} \mathrm{psi}$ \\
\hline$\%$ Difference & $+2.6 \%$ & $+5.2 \%$ & $+5.9 \%$ & $+1.9 \%$ \\
\hline
\end{tabular}

${ }^{(a)}$ From tension tests; ${ }^{(b)}$ From torsion tests.

Table 2.5 Panel properties of WF-A section (12" x 12” x 1/2”)

\begin{tabular}{|c|c|c|c|c|}
\hline & $\mathrm{E}_{\mathrm{x}}$ & $\mathrm{E}_{\mathrm{y}}$ & $v_{\mathrm{xy}}$ & $\mathrm{G}_{\mathrm{xy}}$ \\
\hline Experimental & $4.141 \times 10^{6} \mathrm{psi}$ & $2.102 \times 10^{6} \mathrm{psi}$ & 0.351 & $9.180 \times 10^{5} \mathrm{psi}$ \\
\hline $\begin{array}{c}\text { Micro/ } \\
\text { macromechanics }\end{array}$ & $3.876 \times 10^{6} \mathrm{psi}$ & $1.905 \times 10^{6} \mathrm{psi}$ & 0.393 & $9.660 \times 10^{5} \mathrm{psi}$ \\
\hline$\%$ Difference & $-6.4 \%$ & $-9.4 \%$ & $+12.0 \%$ & $+5.2 \%$ \\
\hline
\end{tabular}

\subsubsection{Beam Deflection and Strain Predictions}

Beam displacement and rotation functions can be obtained by solving the equilibrium equations in Timoshenko beam theory. Deflections at discrete locations can be computed by employing energy methods that incorporate the beam bending and shear stiffnesses. General formulas for maximum bending and shear deflections for typical beam loading and boundary conditions are available in manuals. For example, the maximum deflections: 
1) for concentrated load cases:

$$
\delta_{\text {Total }}=\delta_{\text {Bending }}+\delta_{\text {Shear }}=C_{B} \frac{P L^{3}}{D}+C_{S} \frac{P L}{K F}
$$

where $P$ is the concentrated load, $L$ is the span length, $C_{B}$ and $C_{S}$ are the bending and shear coefficients (Table 2.6), $K$ is the shear correction factor, and $D$ and $F$ are the beam bending and shear stiffnesses which will be discussed in Section 2.2.5.

2) for uniformly distributed loads:

$$
\delta_{\text {Total }}=\delta_{\text {Bending }}+\delta_{\text {Shear }}=C_{B} \frac{q L^{4}}{D}+C_{S} \frac{q L^{2}}{K F}
$$

where $q$ is the uniformly distributed load.

and, 3) for transverse bending only:

$$
\delta=C_{B} \frac{M L^{2}}{D}
$$

where $M$ is the transverse bending moment. 
Thus, in the present formulation, the deflection components due to bending and shear can be evaluated separately.

Table 2.6 $C_{B}$ and $C_{S}$ factors of Timosenko's beams

\begin{tabular}{|c|c|c|}
\hline Beam (Loading + B.C.) & $\mathrm{C}_{\mathrm{B}}$ & $\mathrm{C}_{\mathrm{S}}$ \\
\hline$\downarrow^{\mathrm{P}}$ & $1 / 48$ & $1 / 4$ \\
\hline$\downarrow^{\downarrow^{\mathrm{P}} \quad \downarrow^{\mathrm{P}}}$ & $23 / 648$ & $1 / 3$ \\
\hline$\lambda^{\prime}$ & $1 / 3$ & 1 \\
\hline$S^{\mathrm{q}}$ & $5 / 384$ & $1 / 8$ \\
\hline 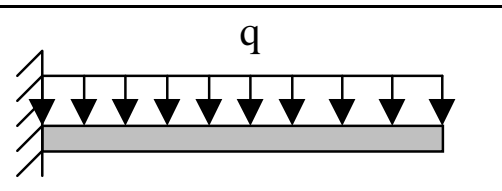 & $1 / 8$ & $1 / 2$ \\
\hline$\underbrace{M}$ & $1 / 8$ & - \\
\hline
\end{tabular}

Also, the maximum beam top-surface longitudinal strains and in-plane shear strains of the ith panel can be expressed as 


$$
\varepsilon_{z}=\frac{N_{Z}}{A_{Z}}+\left(Y_{i}+t_{i} \cos \phi_{i}\right) \frac{M_{Y}}{D_{Y}} \quad \text { and } \quad \gamma_{x y}=\frac{V_{Y}}{K_{Y} F_{Y}} \sin \phi_{i}
$$

where $N_{Z}, V_{Y}$, and $M_{Y}$ are, respectively, the resultant internal axial force, shear force, and bending moment acting on the beam; $Y_{i}$ is the transverse coordinate of a point measured from the neutral axis.

\subsubsection{Beam Stiffnesses}

The response of FRP shapes in bending is evaluated using the Mechanics of thin-walled Laminated Beams (MLB) [31]. In MLB, the stiffnesses of a beam are computed by adding the contribution of the stiffnesses of the component panels, which in turn are obtained from the effective beam moduli. Based on MLB, engineering design equations for FRP beams under bending have been formulated [32], and they can be easily adopted by practicing engineers and composite manufacturers for the analysis, design, and optimization of structural FRP beams or bridge stringers. MLB is suitable for straight FRP beams or columns with at least one axis of geometric symmetry. However, the analysis with MLB may still be complicated for engineering practitioners. Thus, in the following, we simplify the MLB formulations and present explicit design equations in terms of panel engineering properties for beam stiffness properties of FRP shapes.

For each laminated wall (e.g., a flange or a web), the stiffness values are obtained either by the micro/macromechanics approach or from coupon tests (Section 2.2.3). If we incorporate 
stress resultant assumptions compatible with beam theory (without torsion), and we assume that the off-axis plies of pultruded panels are balanced symmetric (no extension-shear and bending-twist couplings are present), then the extensional, bending, and shear stiffnesses of the ith panel are expressed as:

$$
\bar{A}_{i}=\left(E_{x}\right)_{i} t_{i}, \quad \bar{D}_{i}=\left(E_{x}\right)_{i} t_{i}^{3} / 12, \quad \overline{F_{i}}=\left(G_{x y}\right)_{i} t_{i}
$$

where the engineering properties $\left(E_{x}, E_{y}, v_{x y}\right.$, and $\left.G_{x y}\right)$ of the panel are computed by assembling the transformed stiffness coefficients into the extensional stiffness matrix $A$ [as described in Eq. (2.13)] or directly obtained from coupon sample tests.

Assuming that the beam centroid is the neutral axis of bending (no beam bendingextension coupling), general expressions for the beam stiffness coefficients are derived from the beam variational problem. Therefore the axial $(A)$, bending $(D)$, and shear $(F)$ stiffnesses of the beam (that account for the contribution of all the panels) can be further simplified from MLB [31] as

$$
A=\sum_{i=1}^{n} \bar{A}_{i} b_{i}, \quad D=\sum_{i=1}^{n}\left[\bar{A}_{i}\left(\frac{b_{i}^{2}}{12} \sin ^{2} \phi_{i}\right)+\bar{D}_{i} \cos ^{2} \phi_{i}\right] b_{i}, \quad F=\sum_{i=1}^{n} \bar{F}_{i} b_{i} \sin ^{2} \phi_{i}
$$

where $b_{i}$ is the panel width, and $\phi_{i}$ is the cross-sectional orientation of the ith panel. 
The preceding design equations are readily applied in engineering design to various structural shapes. For example, the beam stiffnesses [as shown in Eq. (2.18)] are simplified for the wide-flange beam (about the strong axis y-y, Fig. 2.3) as:

$$
\begin{gathered}
A_{Z}=2 E_{f} t_{f} b_{f}+E_{w} t_{w} b_{w} \\
D_{Y}=\frac{1}{2} E_{f} t_{f} b_{w}{ }^{2} b_{f}+\frac{1}{12} E_{w} t_{w} b_{w}{ }^{3}+\frac{1}{6} E_{f} t_{f}{ }^{3} b_{f} \\
F_{Y}=G_{w} t_{w} b_{w}
\end{gathered}
$$

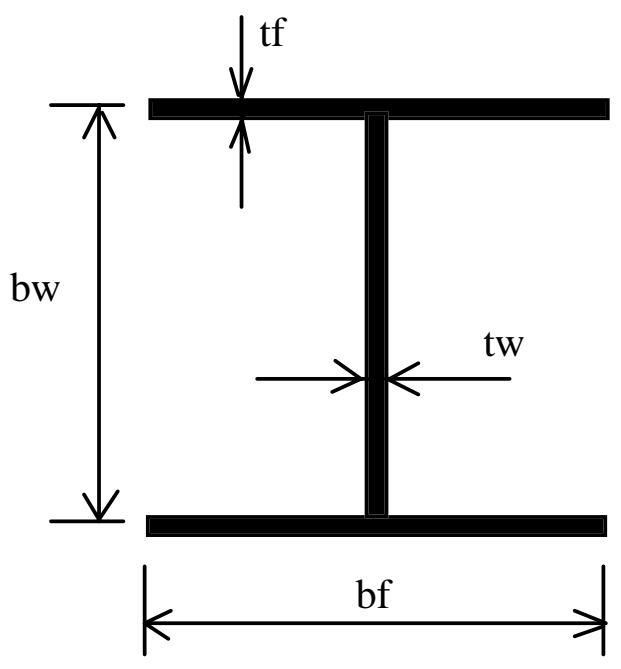

Fig. 2.3 Dimensions of I or wide-flange beam

Similarly, for the box section (about the strong axis x-x, Fig. 2.4):

$$
A_{Z}=2 E_{f} t_{f} b_{f}+2 E_{w} t_{w} b_{w}
$$




$$
\begin{gathered}
D_{Y}=\frac{1}{2} E_{f} t_{f} b_{w}{ }^{2} b_{f}+\frac{1}{6} E_{w} t_{w} b_{w}{ }^{3}+\frac{1}{6} E_{f} t_{f}{ }^{3} b_{f} \\
F_{Y}=2 G_{w} t_{w} b_{w}
\end{gathered}
$$

where the subscripts $f$ and $w$ identify flange and web components. Using the beam stiffnesses, the deflection [Eqs. (2.14 - 2.16)] and the panel strains [Eq. (2.17)] can be obtained.

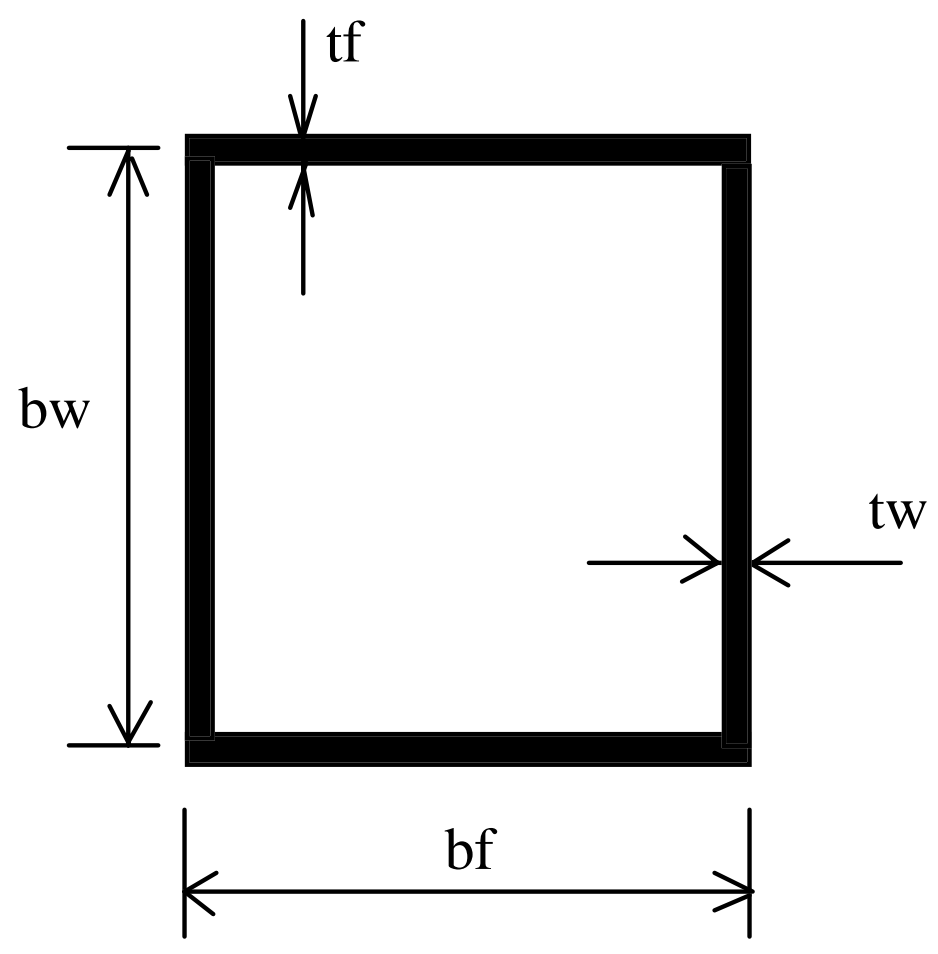

Fig. 2.4 Dimensions of box beam

As an example, the bending $(D)$ and shear $(F)$ stiffnesses of a box beam (Fig. 2.1) and wideflange beam (Fig. 2.2) by MLB are listed in Table 2.7, and experimental results for deflections and strains compared favorably with MLB predictions [17, 33, 34]. 
Table 2.7 Strong-axis beam bending and shear stiffness coefficients by MLB

\begin{tabular}{|c|c|c|}
\hline Beam stiffness & $\mathrm{D}_{\mathrm{b}}\left(\mathrm{lb} / \mathrm{in}^{2}-\mathrm{in}^{4}\right)$ & $\mathrm{F}_{\mathrm{b}}\left(\mathrm{lb} / \mathrm{in}^{2}-\mathrm{in}^{2}\right)$ \\
\hline Box 4" $\times 8$ 8" $\times 1 / 4 "$ & $1.795 \times 10^{8}$ & $3.474 \times 10^{6}$ \\
\hline WF 12" $\times 12^{\prime \prime} \times 1 / 2 "$ & $1.706 \times 10^{9}$ & $5.026 \times 10^{6}$ \\
\hline
\end{tabular}

\subsubsection{Application to Design of FRP Beams}

To validate the simplified equations for beam stiffnesses, the experimental data of box [30] and WF sections [34] are compared with the proposed displacement and strain equations. Both box (Fig. 2.1) and WF (Fig. 2.2) were tested under 3-point (load at midspan) and also 4point (load at exactly third points) bending and for various span lengths [30, 34]. The deflection (Eq. 2.14) and strain (Eq. 2.17) comparisons between experimental results and simplified equations are shown in Table 2.8 for box section and Table 2.9 for WF section, respectively. The close agreement of simplified equations with the experimental results demonstrates the accuracy of the proposed explicit beam stiffness formula to predict displacement and strains for FRP beams. These beam stiffness equations are later used in computing the FRP deck and stringer stiffness properties. 
Table 2.8 Experimental and analytical predictions of deflections and strains for 4" x 8" $x$ 1/4" box section (span $L=9.0$ ft.)

\begin{tabular}{|c|c|c|c|c|c|c|}
\hline Loading & \multicolumn{2}{|c|}{ Max. Deflection (in/kip) } & \multicolumn{3}{c|}{ Max. Strain ( $\mu \varepsilon / \mathrm{kip})$} \\
\hline & Exp. & Eq. (2.14) & ratio & Exp. & Eq. (2.17) & ratio \\
\hline 4-point & 0.0202 & 0.0216 & 1.070 & 370.4 & 371.9 & 1.004 \\
\hline 3-point & 0.141 & 0.147 & 1.043 & 475.5 & 523.6 & 1.101 \\
\hline
\end{tabular}

Table 2.9 Experimental and analytical predictions of deflections and strains for 12" x 12" x 1/2" wide-flange section ( $\operatorname{span} L=9.0 \mathrm{ft}$.)

\begin{tabular}{|c|c|c|c|c|c|c|}
\hline Loading & \multicolumn{3}{|c|}{ Max. Deflection (in/kip) } & \multicolumn{3}{c|}{ Max. Strain $(\mu \varepsilon / \mathrm{kip})$} \\
\hline & Exp. & Eq. (2.14) & ratio & Exp. & Eq. (2.17) & ratio \\
\hline 4-point & 0.0166 & 0.0166 & 1.000 & 59.6 & 62.7 & 1.052 \\
\hline 3-point & 0.0211 & 0.0207 & 0.981 & 91.4 & 94.1 & 1.030 \\
\hline
\end{tabular}

\subsection{Conclusions}

This chapter briefly reviews the micro/macromechanics approach to design analysis of FRP beams under bending. Once ply stiffnesses are evaluated from micromechanics, the laminated panel properties are obtained from macromechanics and verified with experimental coupon tests. Simplified equations for beam stiffnesses are formulated based on MLB [31] and are used in the Timosenko's beam equations to predict beam deflections and also strains. The close correlations between experimental results and proposed analytical equations indicate that simplified design equations based on micro/macromechanics approach can be efficiently used in design analysis of FRP beams under bending and further design optimization of FRP shapes [35]. Also, the panel and beam stiffnesses properties can also be used in bridge system analysis as introduced in the following chapters. 


\section{Chapter 3}

\section{FRP CELLULAR COMPOSITE DECKS:}

\section{ELASTIC EQUIVALENCE}

\subsection{Introduction}

A multicellular FRP composite bridge deck can be modeled as an orthotropic plate, with equivalent stiffnesses that account for the size, shape, and constituent materials of the cellular deck. Thus, the complexity of material anisotropy of the panels and structural orthotropy of the deck system can be reduced to an equivalent orthotropic plate with global elastic properties in two orthogonal directions: parallel and transverse to the longitudinal axis of the deck cell. These equivalent orthotropic plate properties can be directly used in design and analysis of deck/stringer bridge system, as presented in Chapter 4, and they can also serve to simplify modeling procedures either in numerical or explicit formulations. The design equations necessary for such a model are presented in this section, along with numerical and experimental verification of the results. 
In this study, design equations for FRP composite decks consisting of multiple box beams are proposed. Multicell-box-beam bridges are commonly used in deck construction because of their light-weight, efficient geometry, and inherent stiffness in flexure and torsion. Another advantage is that the hollow sections may be used to accommodate services such as water mains, telephone cables, sewage pipes, etc. Also, the section has the advantage of being relatively easy to build. It can be either assembled from individual box-beams or manufactured as a complete section by pultrusion or vacuum assisted resin transfer molding (VARTM) process. And the section can be constructed with or without transverse diaphragm intermediate between the supports, depending on the need for stiffening.

In this study, the elastic equivalence approach [36] is used to perform the deck system analysis, with out-of-plane shear effects also considered. The results for a multicell box section are verified experimentally and by finite element analyses.

\subsection{Design Equations for Stiffness Properties of Cellular FRP Decks}

The first step in analyzing any deck is to determine its bending and shear stiffnesses based on its actual panel constituent properties and geometries. The following derivations for deck stiffness assumptions are based on a deck composed of multiple box sections (Fig. 3.1) with panel properties as described in Chapter 2. 


\subsubsection{Longitudinal Stiffnesses of Cellular FRP Decks}

The bending stiffness of the deck in the longitudinal direction, or $x$-axis in Figure 3.1, is expressed as the sum of the bending stiffness of individual box beams $\left(D_{b}\right.$, see Table 2.7):

$$
D_{x}=n_{c} D_{b}
$$

where $n_{c}=$ number of cells. For the section shown in Figure 3.1, $b=$ width of a cell, $h=$ height of a cell, $t_{f}=$ thickness of the flange, and $t_{w}=$ thickness of the web. If all panels have identical material lay-up and $t_{f}=t_{w}=t$, Eq. (3.1) becomes

$$
D_{x}=n_{c} E_{x}\left(h^{2}+t^{2}+3(h) b\right) \frac{(h)(t)}{6}
$$

where $E_{x}=$ modulus of elasticity of a panel in the $x$-direction computed by micro/macromechanics or obtained experimentally (Table 2.4).

The out-of-plane shear stiffness of the deck in the longitudinal direction, $F_{x}$, is expressed as a function of the stiffness for the individual beams $\left(F_{b}\right)$ :

$$
F_{x}=n_{c} F_{b}
$$


where $F_{b}$ is given in Table 2.7, and $n_{c}=$ number of cells. This expression can be further approximated in terms of the in-plane shear modulus of the panel, $G_{x y}$, (see Table 2.4) and crosssectional area of the beam webs:

$$
F_{x}=n_{c} G_{x y}(2 t) h
$$

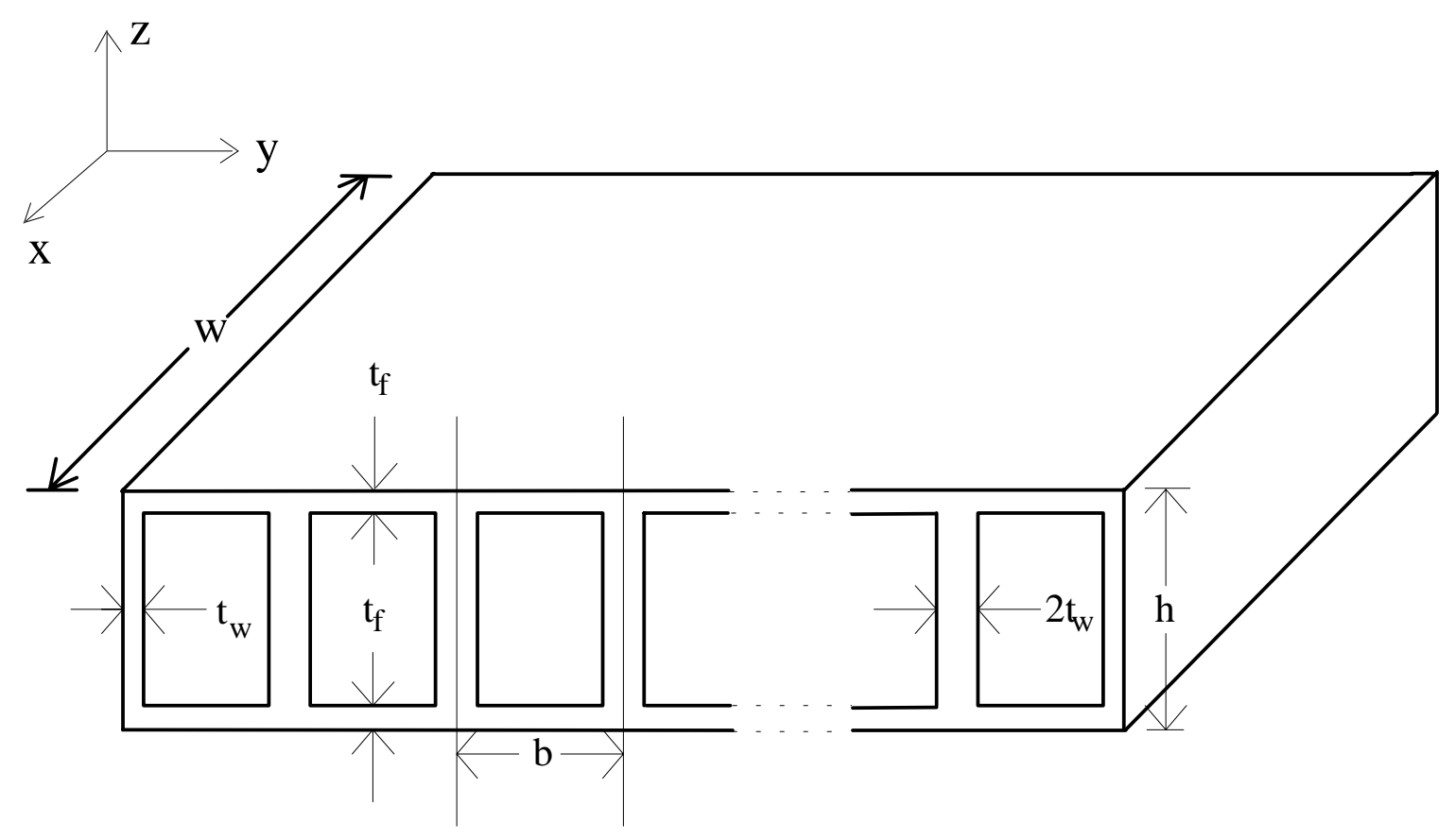

Figure 3.1 Geometric parameters of multi-cell box deck 


\subsubsection{Transverse Stiffnesses of Cellular FRP Decks}

An approximate value for the deck bending stiffness in the transverse direction, $D_{y}$, may be obtained by neglecting the effect of the transverse diaphragms and the second moment of area of the flanges about their own centroids. For a deck as shown in Figure 3.1 with $t_{f}=t$ :

$$
D_{y}=\frac{1}{2} E_{y}(w)(t) h^{2}
$$

where $w$ is the length of the deck in the longitudinal direction and $E_{y}$ is the modulus of elasticity of the panel in the $y$-direction (Table 2.4).

For multiple box sections, the simplest way to obtain the deck's out-of-plane transverse shear stiffness is to treat the structure as a Vierendeel frame in the transverse direction [37]. For the Vierendeel frame (Figure 3.2), the inflection points are assumed at the midway of top and bottom flanges between the webs. The shear stiffness in the transverse direction, $F_{y}$, for the cross-section shown in Figure 4 may be written as

$$
F_{y}=\frac{V}{\theta}=\frac{12 E_{y}}{b\left(\frac{h}{I_{w}}+\frac{b}{2 I_{f}}\right)}
$$




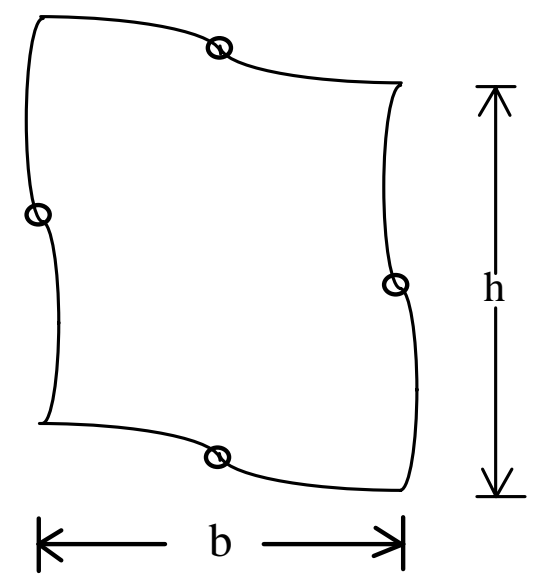

(a) cell distortion

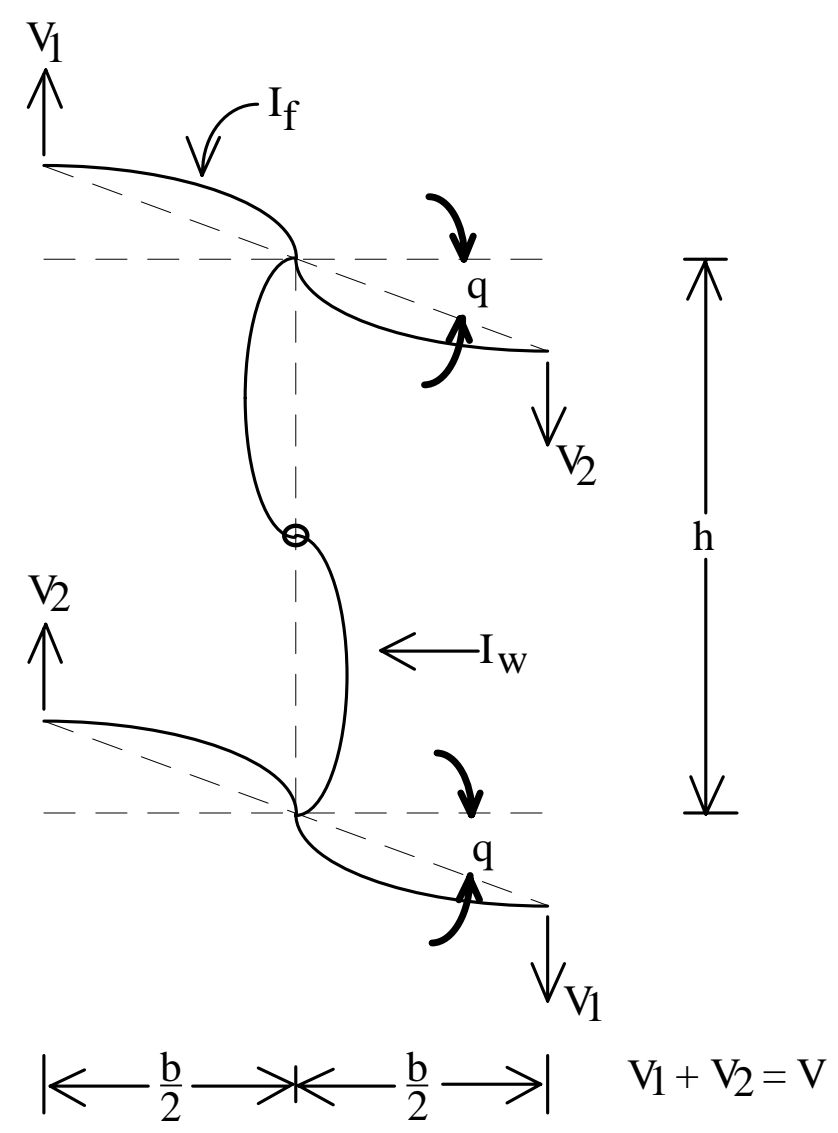

(b) distortion parameters 
Figure 3.2 Vierendeel distortion in multi-cell box-beam [37]

where the moments of inertia $I$ are defined as:

$$
I_{f}=\frac{w t_{f}^{3}}{12} ; \quad I_{w}=\frac{w\left(2 t_{w}\right)^{3}}{12}
$$

For $t_{f}=t_{w}=t$, Eq. (3.6) can be simplified as

$$
F_{y}=\frac{2 E_{y} w t^{3}}{b\left(b+\frac{h}{4}\right)}
$$

where $E_{y}$ is the modulus of elasticity of a panel in the $y$-direction (Table 2.4).

\subsubsection{Torsional Stiffness of Cellular FRP Decks}

The torsional rigidity of a multi-cell section, $G J$, is evaluated by considering the shear flow around the cross-section of a multi-cell deck. For a structure where the webs and flanges are small compared with the overall dimensions of the section, Cusens and Pama [37] have shown that the torsional rigidity may be written as 


$$
G J=\frac{4 A^{2} G_{x y}}{\sum \frac{d s}{t}}+\sum G_{x y}(d s) \frac{t^{3}}{3}
$$

where $A=$ area of the deck section including the void area and is defined as $A=n_{c} b h$, and $\sum d s / t$ represents the summation of the length-to-thickness ratio taken around the median line of the outside contour of the deck cross-section. For a constant panel thickness $t$, the torsional rigidity can be simplified as

$$
G J=\frac{2\left(n_{c} b h\right)^{2} G_{x y} t}{\left(n_{c} b+h\right)}+\frac{2}{3}\left(n_{c} b+h\right) G_{x y} t^{3}
$$

The above approximate equation is justified by the fact that for a multi-cell deck, the net shear flows through interior webs are negligible and only the shear flows around the outer webs and top and bottom flanges are significant. The second term in Eq. (3.10) is relatively small compared to the first term and can be ignored.

If the deck is treated as an equivalent orthotropic plate, its torsional rigidities depend upon the twist in two orthogonal directions. Thus torsional stiffness $D_{x y}$ may be taken as one-half of the total torsional rigidity given by Eq. (3.10) divided by the total width of the deck:

$$
D_{x y}=\frac{G J}{2 n_{c} b}
$$


Substituting Eq. (3.10) into Eq. (3.11) and neglecting the second term in Eq. (10), we get:

$$
D_{x y}=\frac{n_{c} G_{x y} b h^{2} t}{\left(n_{c} b+h\right)}
$$

where, $D_{\mathrm{xy}}$ is the torsional stiffness per unit width $\left(\mathrm{lb}-\mathrm{in}^{3} / \mathrm{in}^{2}\right)$.

\subsection{Verification of Deck Stiffness Equations by Finite Element Analysis}

The formulas for bending and torsional stiffnesses obtained in section 3.2 are based on the assumption that the deck system behaves as a beam and do not account for the Poisson effects of the deck. To verify the accuracy of the above deck stiffness equations, a finite element analysis of the deck system is performed. The model is shown in Figure 3.1 and consists of box beams (Figure 2.1) bonded side-by-side to form an integral deck. The computer program NISA [38] is

used, and the panels are modeled with 8-node isoparametric layered shell elements. The cellular decks subject to line-loading for longitudinally supported and transversely supported conditions are shown in Figures 3.3 and 3.4, and the model for torsional loading is given in Figure 3.5.

\subsubsection{Verification of Bending and Shear Stiffnesses}


The deck bending and shear stiffnesses in the longitudinal and transverse directions are used to evaluate midspan deflections from the following:

$$
\begin{array}{r}
\delta_{3}=\frac{P L^{3}}{48 D_{i}}+\frac{P L}{4 \kappa F_{i}} \text { (3-point bending) } \\
\delta_{4}=\frac{23 P L^{3}}{1296 D_{i}}+\frac{P L}{6 \kappa F_{i}} \text { (4-point bending) }
\end{array}
$$

where $P=$ total applied load, $L=$ span length, $\kappa=$ shear correction factor $(\kappa \cong 1.0$ is assumed in the analysis), and $D_{i}$ and $F_{i}=$ bending and shear stiffness $(i=x$ for longitudinal or $y$ for transverse directions). The deflections computed from Eqs. (3.13) and (3.14) in terms of stiffness properties are compared with results from the finite element model for actual cellular systems under line loading (Figures 3.3 and 3.4). For the longitudinal stiffness verification, the length of the decks is kept constant ( $L=108$ in.), and the deflection in terms of bending and shear stiffnesses is a function of the number of cells. Each deck is simply supported and subjected to either three-point or four-point bending due to uniformly distributed line loads. The comparisons between the numerical predictions, based on the simplified stiffness formulas of Eqs. (3.13) and (3.14), and the finite element results for actual decks are presented in Table 3.1 and graphically in Figure 3.5.

Similarly, the midspan deflections in the transverse direction are found by modeling several multicellular decks comprised of 4"x 8"x 1/4" box sections (Figure 3.4). For these models, the 
width $(w)$ is kept constant ( $w=12$ in.), and the deflection is a function of the number of cells. The model is simply supported and subjected to either three-point or four-point bending due to uniformly distributed line loads. The results of the finite element models and theoretical predictions are shown in Table 3.2 and graphically in Figure 3.6. 


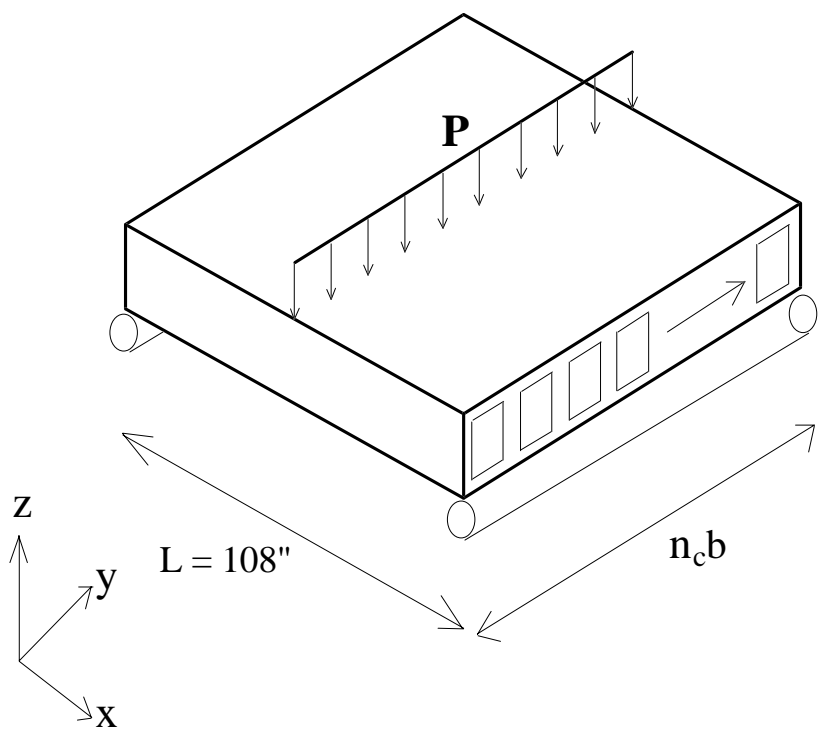

(a) Deck under 3-point bending

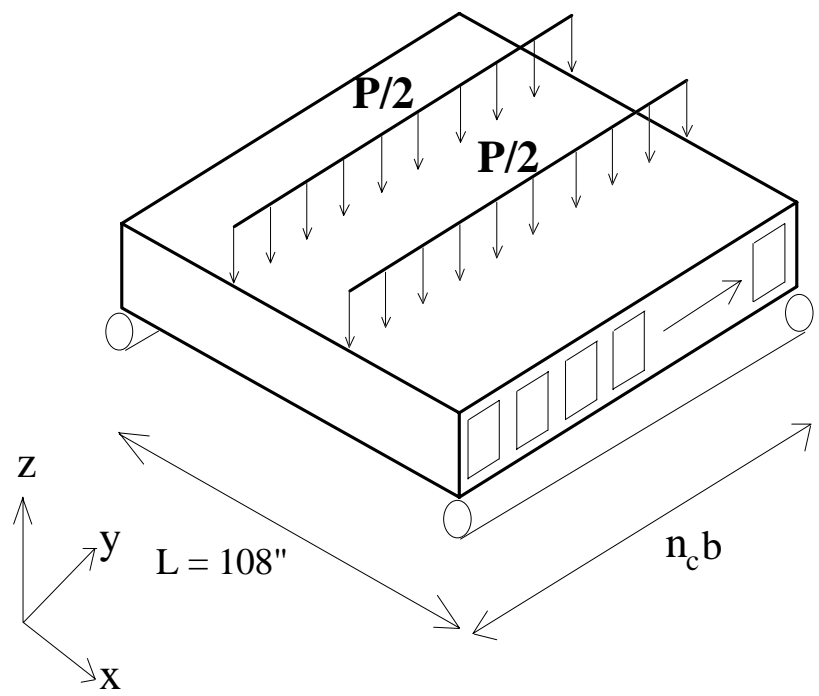

(b) Deck under 4-point bending

Figure 3.3 Conceptual model for verification of longitudinal stiffness equations 
Table 3.1 Center Deflections (in.) of longitudinally supported models for three-point and four-point bending

\begin{tabular}{|c|c|c|c|c|}
\hline \multirow{2}{*}{} & \multicolumn{2}{|c|}{$\delta$ (in) } & \multicolumn{2}{c|}{ 4-pt. bending } \\
\hline $\mathrm{n}$ cells & Eq. (3.13) & FE & Eq. (3.14) & FE \\
\hline 1 & 0.15467 & 0.15319 & 0.13022 & 0.13095 \\
\hline 2 & 0.07733 & 0.0762 & 0.06511 & 0.06454 \\
\hline 3 & 0.05156 & 0.05163 & 0.04341 & 0.0436 \\
\hline 5 & 0.03093 & 0.03037 & 0.02604 & 0.02569 \\
\hline 7 & 0.0221 & 0.02162 & 0.0186 & 0.01828 \\
\hline 9 & 0.01719 & 0.01675 & 0.01447 & 0.01416 \\
\hline 11 & 0.01406 & 0.01365 & 0.01184 & 0.01153 \\
\hline 13 & 0.0119 & 0.0115 & 0.01002 & 0.00971 \\
\hline 15 & 0.01031 & 0.00993 & 0.00868 & 0.00838 \\
\hline & & & & \\
\hline
\end{tabular}




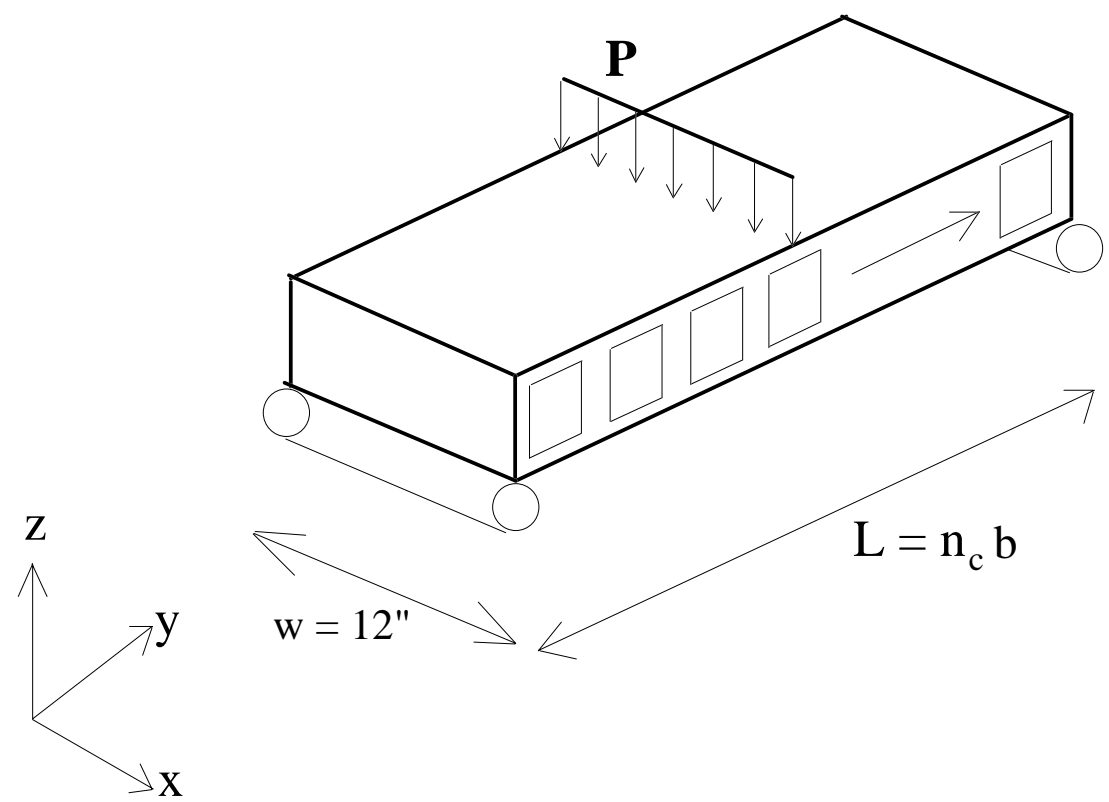

(a) Deck under 3-point bending

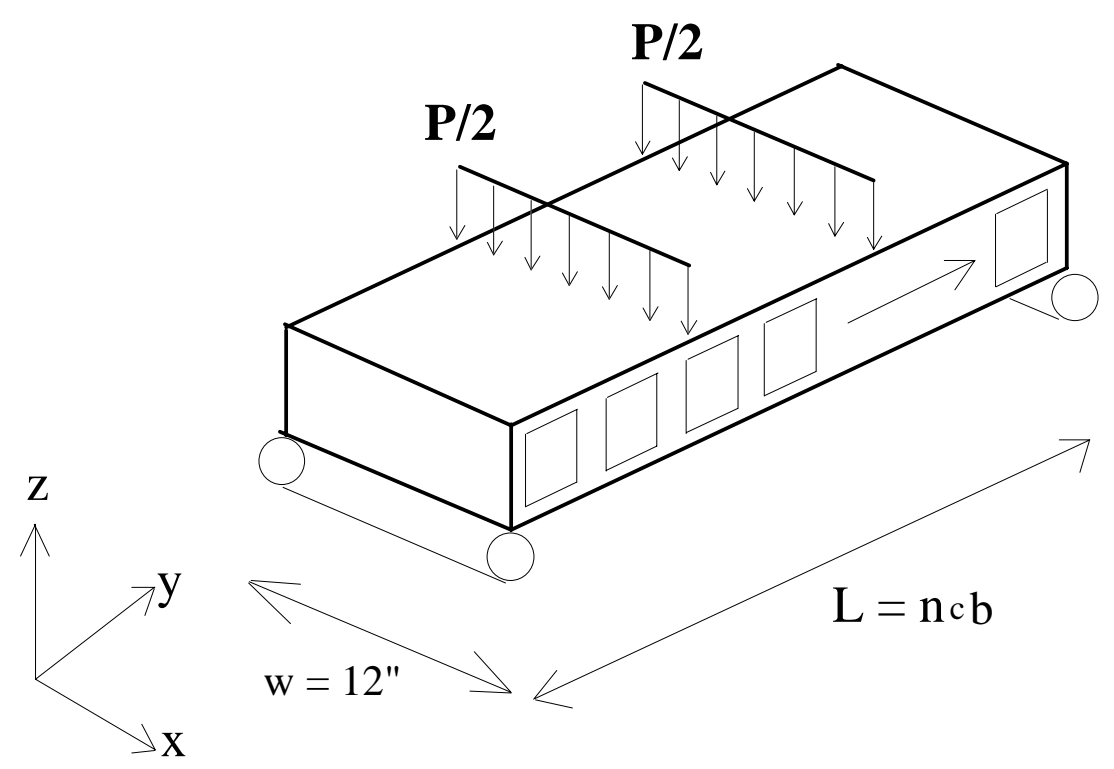

(b) Deck under 4-point bending

Figure 3.4 Conceptual model for verification of transverse stiffness equations

Table 3.2 Center deflections of multi-cell transversely-supported beam for three-point and four-point bending 


\begin{tabular}{|c|c|c|c|c|}
\hline & \multicolumn{2}{|c|}{$\delta$ (in) } & \multicolumn{2}{c|}{ 4-point bending } \\
\hline & \multicolumn{2}{|c|}{ 3-point bending } & Eq. (3.14) & FE \\
\hline $\mathrm{n}$ cells & Eq. (3.13) & FE & 0.09929 & 0.10357 \\
\hline 6 & 0.14862 & 0.13903 & 0.15078 & 0.14935 \\
\hline 9 & 0.22509 & 0.19064 & 0.18628 & 0.17346 \\
\hline 11 & 0.27745 & 0.23699 & 0.20447 & 0.19711 \\
\hline 12 & 0.30415 & 0.27659 & 0.24186 & 0.2229 \\
\hline 14 & 0.35872 & 0.32513 & 0.26111 & 0.24768 \\
\hline 15 & 0.38666 & 0.33409 & 0.32143 & 0.30186 \\
\hline 18 & 0.4735 & 0.42773 & 0.38616 & 0.36038 \\
\hline 21 & 0.56552 & 0.49452 & 0.45605 & 0.42395 \\
\hline 24 & 0.66359 & 0.59923 & & \\
\hline
\end{tabular}




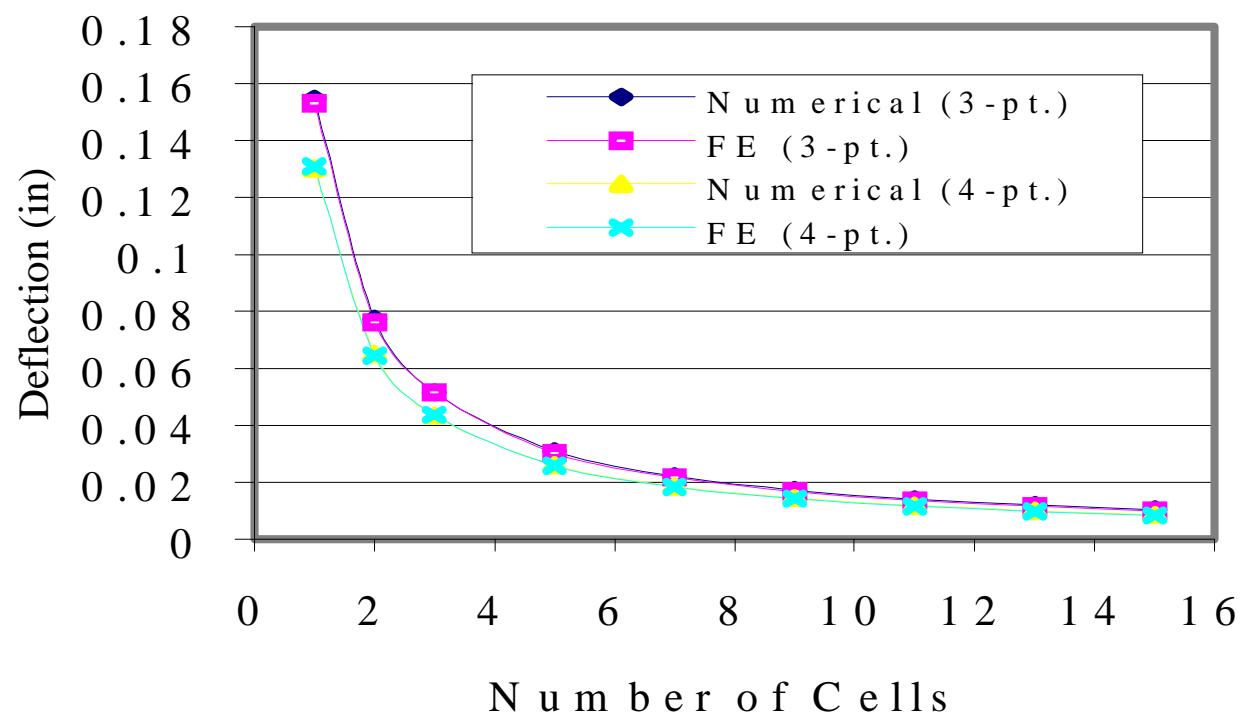

Fig. 3.5 Center deflections (in.) of multi-cell longitudinally-supported deck

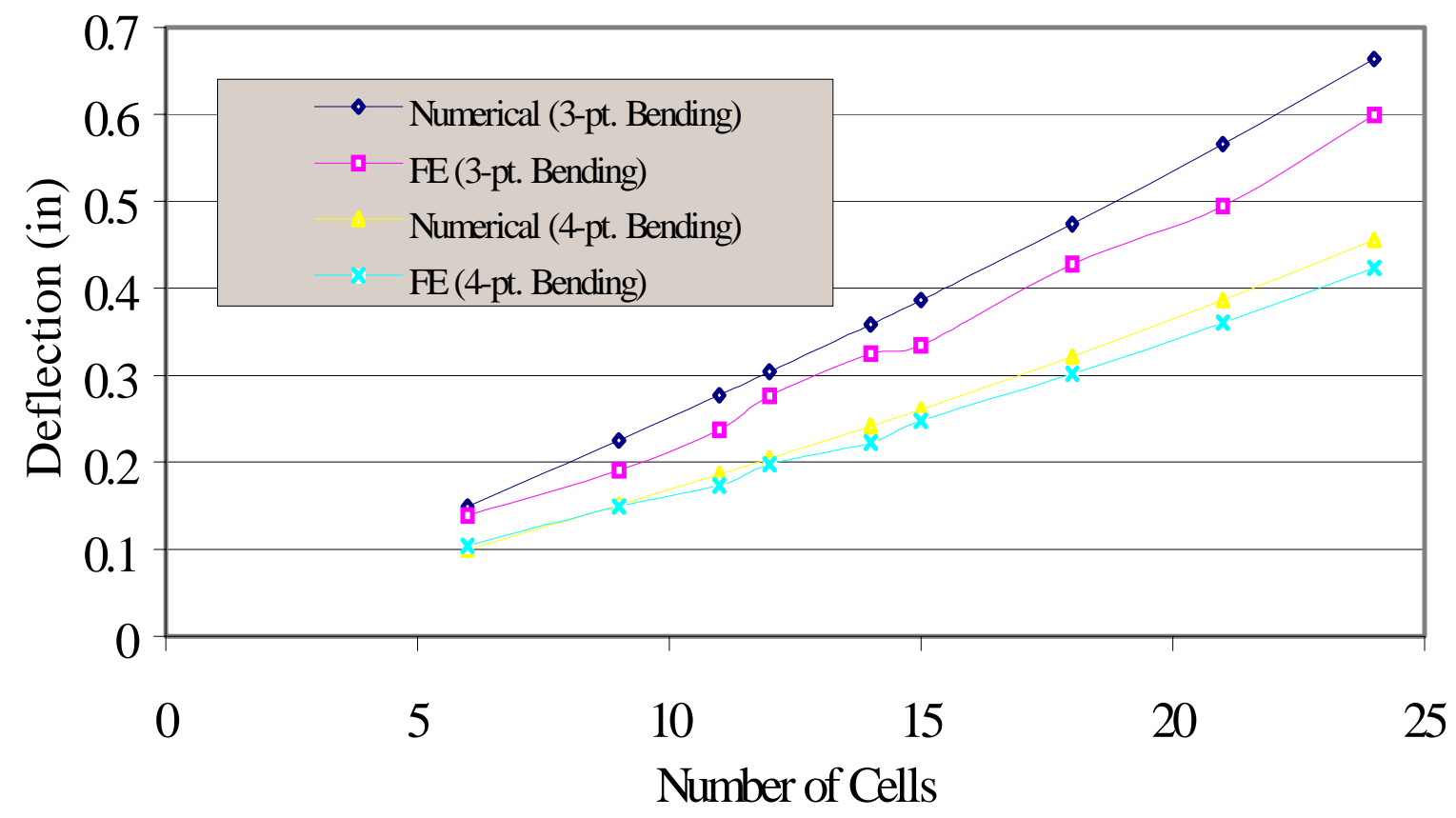

Fig. 3.6 Center deflections (in.) of multi-cell transversely-supported beam 


\subsubsection{Verification of Torsional Stiffness of the Deck}

The simplified formula for the torsional rigidity, $G J$, of the deck system was also verified using finite element analyses, which indirectly serve to verify the torsional stiffness of the deck $\left(D_{x y}\right)$. As shown in Figure 3.7, the model consisted of a multicellular deck with one end fixed, by constraining displacements and rotations in all three principal directions and all three rotations, and the other end subjected to a uniform torque. The longitudinal torsional rigidity of a deck is expressed in terms of the angle of twist $\phi$ and the torque applied at the end of the section as

$$
G J=\frac{T L}{\phi}
$$

where $T=2 q n_{c} b h$ (as shown in Figure 3.7) is the applied torque ( $q$ is the shear flow around the outside contour of the deck, lb/in). The specimen length $L$ is held constant $(L=108 \mathrm{in}$.), and the number of cells is used as the design variable. The finite element results are compared with the theoretical predictions of Eq. (3.10), and the results are presented in Table 3.3 and Figure 3.8. 


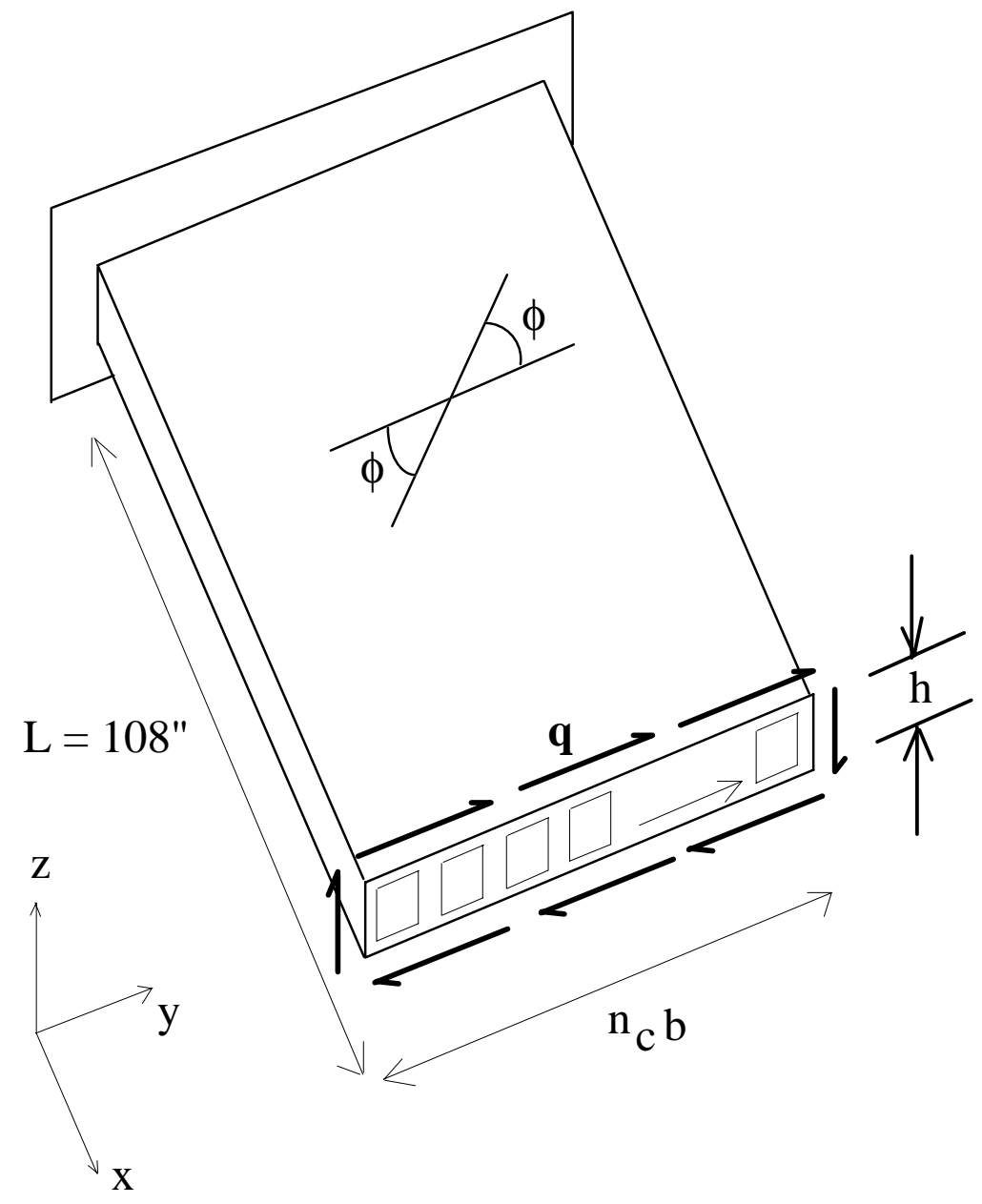

Figure 3.7 Conceptual model for verification of torsional rigidity equation 
Table 3.3 Torsional rigidity versus number of cells

\begin{tabular}{|c|c|c|c|}
\hline & \multicolumn{3}{|c|}{ Torsional Rigidity GJ (lb-in'/rad) } \\
\hline $\mathrm{n}$ cells & Eq. (3.15) & FE & Experimental \\
\hline 1 & 34816000 & 37024300 & 42969600 \\
\hline 2 & 104448000 & 111054000 & 127126800 \\
\hline 3 & 188006400 & 205518600 & - \\
\hline 5 & 373028600 & 416988400 & - \\
\hline 7 & 568661300 & 644391400 & - \\
\hline 9 & 769117100 & 888888900 & - \\
\hline 11 & 972169900 & 999888900 & - \\
\hline 13 & 1176780800 & 1448886500 & - \\
\hline 15 & 1382400000 & 1772235000 & - \\
\hline
\end{tabular}




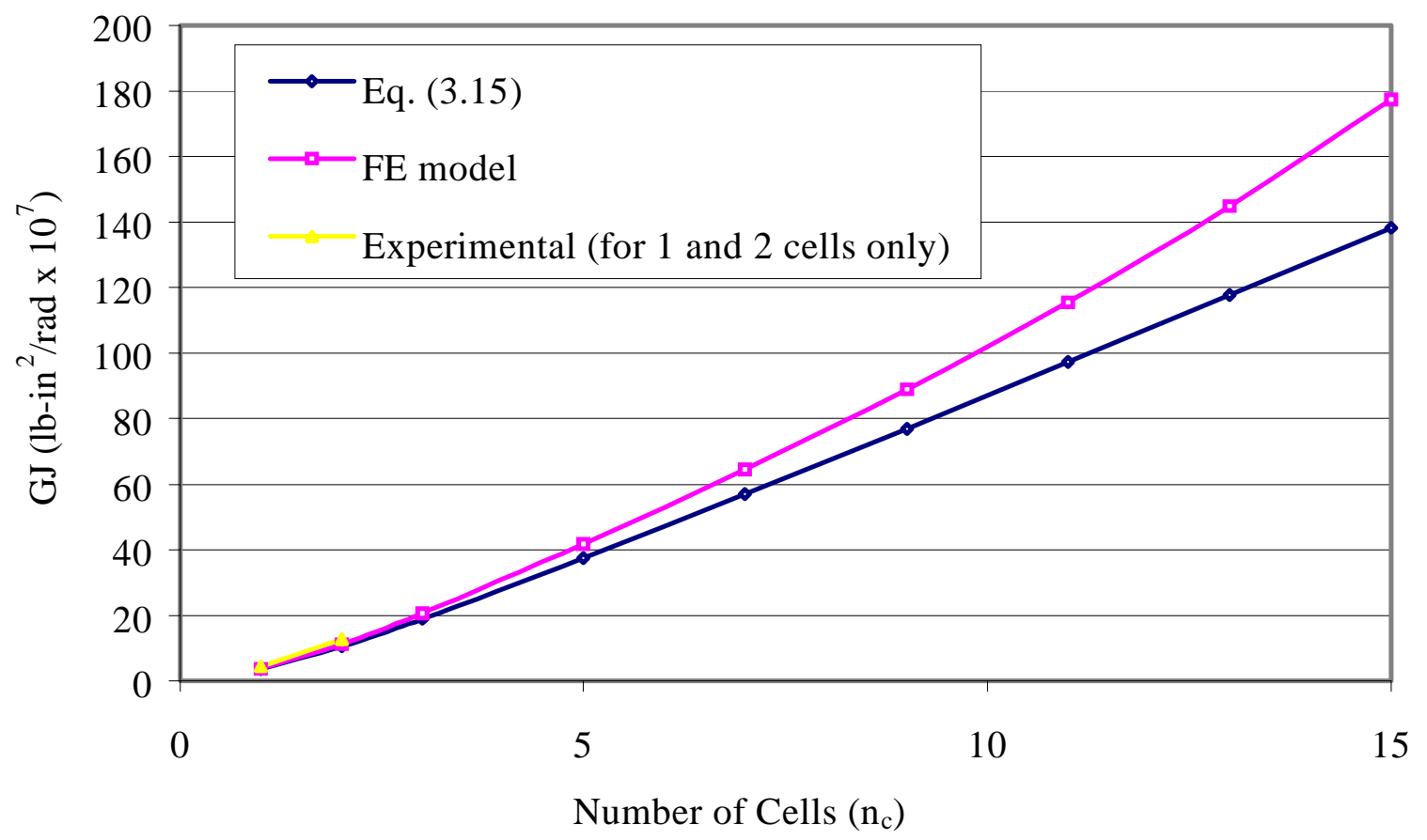

Fig. 3.8 Torsional rigidity (GJ) vs. number of cells

Remarks: As shown in Figures 3.5, 3.6, and 3.8, a good correlation is obtained between the theoretical predictions based on the simplified stiffness formulas and the finite element analyses of an actual deck. For the deflection in terms of longitudinal stiffnesses $\left(D_{x}\right.$ and $\left.F_{x}\right)$, the maximum percent difference is $4 \%$, and for the deflection in terms of transverse stiffnesses $\left(D_{y}\right.$ and $F_{y}$ ), the maximum difference is about $10 \%$. For the longitudinal torsional stiffness, the discrepancy of results increases steadily from $6 \%$ for one cell to $22 \%$ for 15 cells. Some limited experimental data available for one and two cells [30] match closely the analytical results. The favorable deflection comparisons between beam equations and finite element results indirectly verify the accuracy of the deck bending stiffness equations. Similarly, the torsion results 
indicate that the simplified torsional stiffness equations are acceptable for practical applications. Therefore, the proposed relatively simple stiffness equations account for both shape and material anisotropy of the deck and can be used with relative confidence in design analysis of cellular bridge deck systems.

\subsection{Equivalent Orthotropic Material Properties}

Once the stiffness properties of an actual deck are obtained, it is a simple matter to calculate effective material properties for an equivalent orthotropic plate. To obtain the equivalent orthotropic plate material properties for an actual deck can further simplify the design analysis of deck and deck/stringer bridge systems.

To calculate the moduli of elasticity $\left(E_{x}\right)_{p}$ and $\left(E_{y}\right)_{p}$ for the equivalent orthotropic plate, the relationship $D=E I$ is used, leading to

$$
\begin{aligned}
& \left(E_{x}\right)_{p}=12 \frac{D_{x}}{t_{p}^{3} b_{p}}\left(1-v_{x y} v_{y x}\right) \\
& \left(E_{y}\right)_{p}=12 \frac{D_{y}}{t_{p}^{3} l_{p}}\left(1-v_{x y} v_{y x}\right)
\end{aligned}
$$

where the subscript " $p$ " indicates property related to the equivalent orthotropic plate; $t_{p}=$ thickness of the plate ( $=h$ for the actual deck, Figure 3.1$), b_{p}=$ width of the plate $\left(=n_{c} b\right.$ for the actual deck), and $l_{p}=$ length of the plate ( $=w$ for the actual deck). 

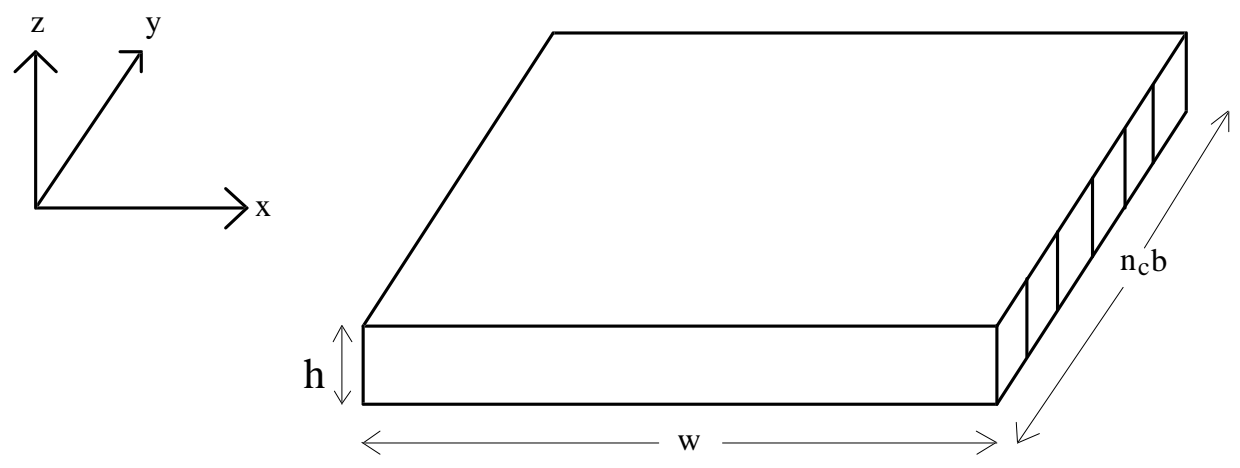

(a) actual cellular deck
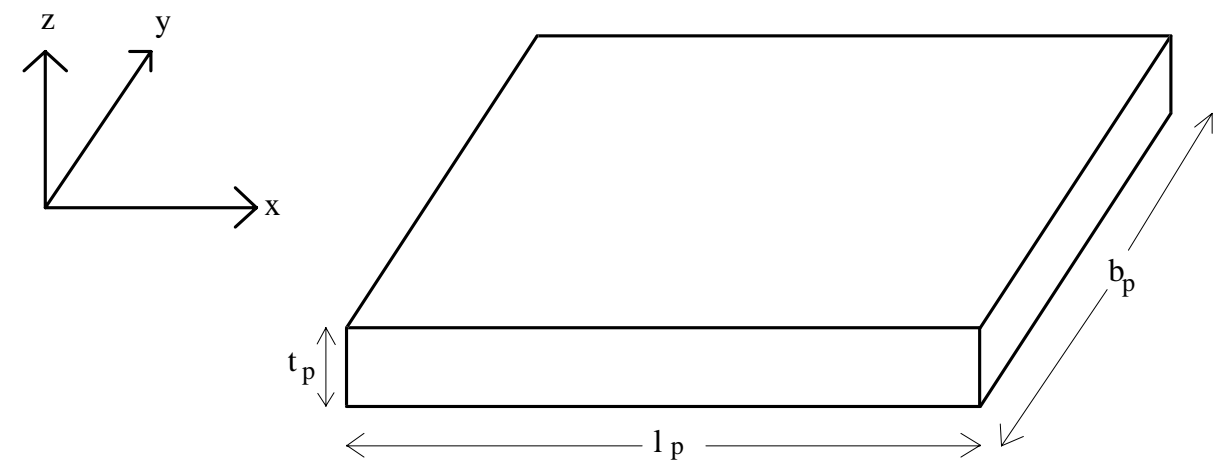

(b) equivalent orthotropic deck

Figure 3.9 Multi-cellular deck and equivalent orthotropic plate 
The Poisson's ratios $v_{i j}$ are defined as

$$
v_{i j}=\frac{-\varepsilon_{j}}{\varepsilon_{i}}
$$

where $\varepsilon$ is the strain in the $i$ or $j$ direction. For orthotropic materials, the Poisson's ratio must obey the following relationship:

$$
\frac{v_{i j}}{E_{i}}=\frac{v_{j i}}{E_{j}} \text { or } \frac{v_{x y}}{D_{x}}=\frac{v_{y x}}{D_{y}}
$$

In this study, we use the approximation $v_{x y}=0.3$, which is typically used for pultruded composites.

To calculate the out-of-plane shear moduli $\left(G_{x z}\right)_{p}$ and $\left(G_{y z}\right)_{p}$, the relationship $F=G A$ is used, leading to

$$
\begin{aligned}
& \left(G_{x z}\right)_{p}=\frac{F_{x}}{t_{p} b_{p}} \\
& \left(G_{y z}\right)_{p}=\frac{F_{y}}{t_{p} l_{p}}
\end{aligned}
$$


Finally, to calculate the in-plane shear modulus $\left(G_{x y}\right)_{p}$, we use

$$
\left(G_{x y}\right)_{p}=6 \frac{D_{x y}}{t_{p}^{3}}
$$

With these equivalent material properties, it is now easy to use explicit plate solutions (see Chapter 4) for analysis and design of cellular decks.

\subsection{Numerical Verification of Equivalent Orthotropic Material Properties}

The equations for developing the material properties of an orthotropic plate equivalent to a given actual multi-cellular FRP deck are verified again using finite element modeling. Each model consists of a 5' x 9' x 8' actual deck and its equivalent orthotropic plate with same dimensions. Effective material properties of the plate are given in Table 3.4. The models are analyzed using the NISA composite shell element.

Table 3.4 Equivalent deck stiffness properties and orthotropic material properties for cellular deck 5'x9'x8',

\begin{tabular}{|c|c|c|c|c|c|}
\hline $\begin{array}{c}\mathrm{D}_{\mathrm{x}} \\
\left(\mathrm{lb}-\mathrm{in}^{4} / \mathrm{in}^{2}\right)\end{array}$ & $\begin{array}{c}\mathrm{D}_{\mathrm{y}} \\
\left(\mathrm{lb}-\mathrm{in}^{4} / \mathrm{in}^{2}\right)\end{array}$ & $\mathrm{v}_{\mathrm{xy}}$ & $\begin{array}{c}\mathrm{D}_{\mathrm{xy}} \\
\left(\mathrm{lb}-\mathrm{in}^{4} / \mathrm{in}^{2}\right)\end{array}$ & $\begin{array}{c}\mathrm{F}_{\mathrm{x}} \\
\left(\mathrm{lb}-\mathrm{in}^{2} / \mathrm{in}^{2}\right)\end{array}$ & $\begin{array}{c}\mathrm{F}_{\mathrm{y}} \\
\left(\mathrm{lb}-\mathrm{in}^{2} / \mathrm{in}^{2}\right)\end{array}$ \\
\hline $2.689 \times 10^{9}$ & $2.250 \times 10^{9}$ & 0.3 & $1.153 \times 10^{7}$ & $4.896 \times 10^{7}$ & $3.662 \times 10^{5}$ \\
\hline $\mathrm{E}_{\mathrm{x}}\left(\mathrm{lb} / \mathrm{in}^{2}\right)$ & $\mathrm{E}_{\mathrm{y}}\left(\mathrm{lb} / \mathrm{in}^{2}\right)$ & $\mathrm{v}_{\mathrm{yx}}$ & $\mathrm{G}_{\mathrm{xy}}\left(\mathrm{lb} / \mathrm{in}^{2}\right)$ & $\mathrm{G}_{\mathrm{xz}}\left(\mathrm{lb} / \mathrm{in}^{2}\right)$ & $\mathrm{G}_{\mathrm{yz}}\left(\mathrm{lb} / \mathrm{in}^{2}\right)$ \\
\hline $9.713 \times 10^{5}$ & $4.515 \times 10^{5}$ & 0.25 & $1.351 \times 10^{5}$ & $1.020 \times 10^{5}$ & $4.238 \times 10^{2}$ \\
\hline
\end{tabular}


To determine the accuracy of the longitudinal and transverse modulus of elasticity, both the equivalent plate and the actual deck models were subjected to three-point and four-point bending, with simple supports at each end (Figs. 3.10 and 3.11). Comparisons between the equivalent plate and actual deck deflections at various locations (Fig. 3.12) are given in Tables 3.5 and 3.6. Values for the longitudinally supported plate are within 5\% of the corresponding deck values. Thus the formula for $\left(E_{x}\right)_{p}$ is sufficiently accurate. Deflection values for the transversely supported plate are within $15 \%$ for three-point bending and $6 \%$ for four-point bending, indicating that the formula for $\left(E_{y}\right)_{p}$ is sufficiently accurate.

Table 3.5 Deflection of longitudinally-supported plate and deck

\begin{tabular}{|c|c|c|c|c|}
\hline & \multicolumn{2}{|c|}{$\delta$ (in) 3-point bending } & \multicolumn{2}{c|}{$\delta$ (in) 4-point bending } \\
\hline location & Actual Deck & Equivalent Plate & Actual Deck & Equivalent Plate \\
\hline 1 & 0.0106135 & 0.0107895 & 0.0089685 & 0.0087605 \\
\hline 2 & 0.0101003 & 0.0105955 & 0.0085297 & 0.0086227 \\
\hline 3 & 0.0099301 & 0.0105357 & 0.0083787 & 0.0085731 \\
\hline 4 & 0.0100961 & 0.0105955 & 0.008526 & 0.0086227 \\
\hline 5 & 0.0106031 & 0.0107895 & 0.0089594 & 0.0087605 \\
\hline 6 & 0.0069524 & 0.0071086 & 0.0061291 & 0.0062719 \\
\hline 7 & 0.0069524 & 0.0071086 & 0.0061291 & 0.0062719 \\
\hline
\end{tabular}


Table 3.6 Deflection of transversely-supported plate and deck

\begin{tabular}{|c|c|c|c|c|}
\hline & \multicolumn{2}{|c|}{$\delta$ (in) } & \multicolumn{2}{c|}{$\delta$ (in) } \\
& \multicolumn{2}{|c|}{ 3-point bending } & 4-point bending \\
\hline location & Actual Deck & Equivalent Plate & Actual Deck & Equivalent Plate \\
\hline 1 & 0.0375205 & 0.0435018 & 0.0278256 & 0.0294105 \\
\hline 2 & 0.0221223 & 0.0230568 & 0.0219525 & 0.022898 \\
\hline 3 & 0.0363812 & 0.0425966 & 0.0271006 & 0.0287347 \\
\hline 4 & 0.0221107 & 0.0230568 & 0.0219404 & 0.022898 \\
\hline 5 & 0.0375205 & 0.0435018 & 0.0278256 & 0.0294105 \\
\hline 6 & 0.03683 & 0.0428203 & 0.0272968 & 0.0289101 \\
\hline 7 & 0.03683 & 0.0428203 & 0.0272968 & 0.0289101 \\
\hline
\end{tabular}



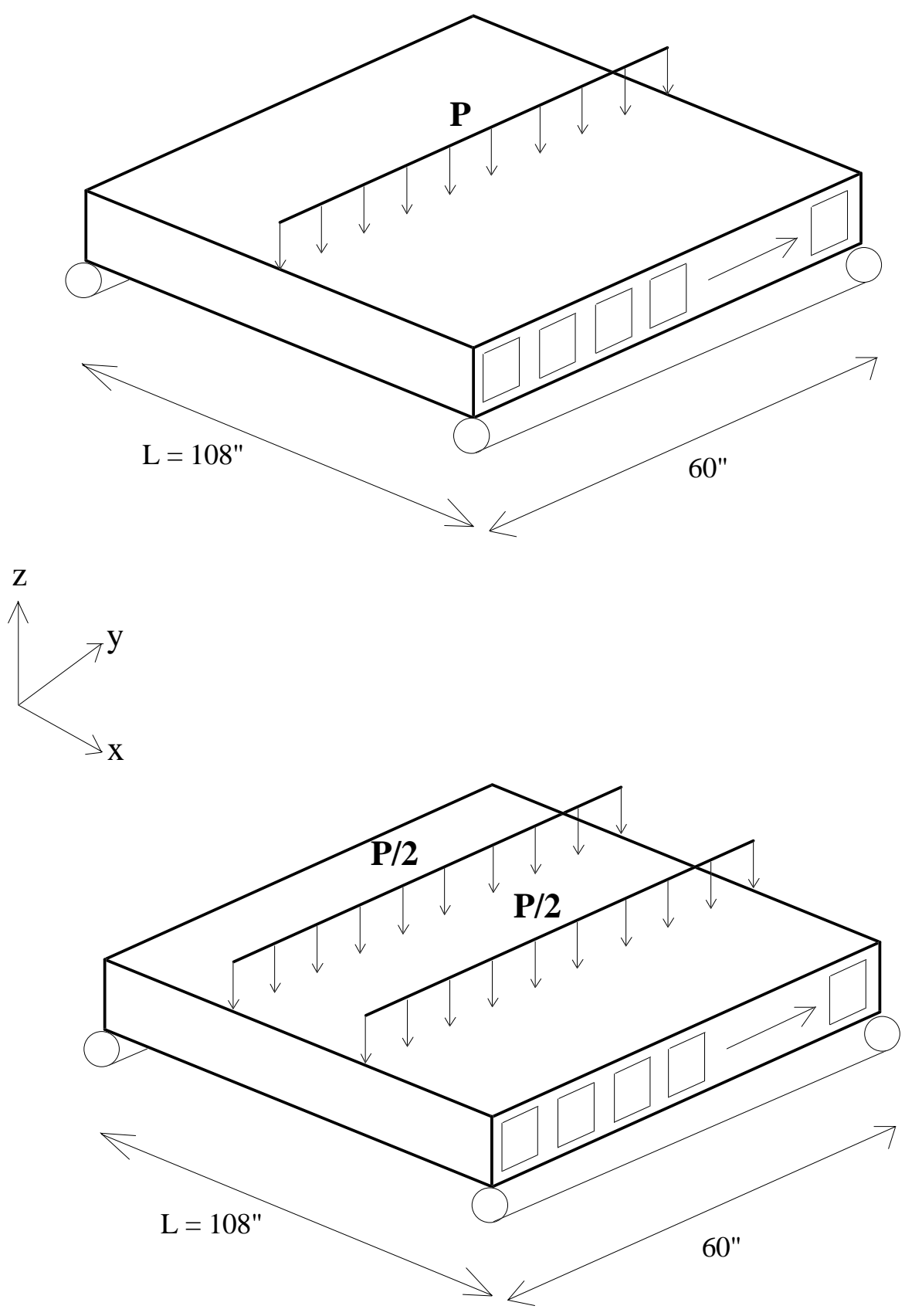

Fig. 3.10 Finite element model of multicellular deck for verification of $\mathbf{E}_{\mathbf{x}}$ 

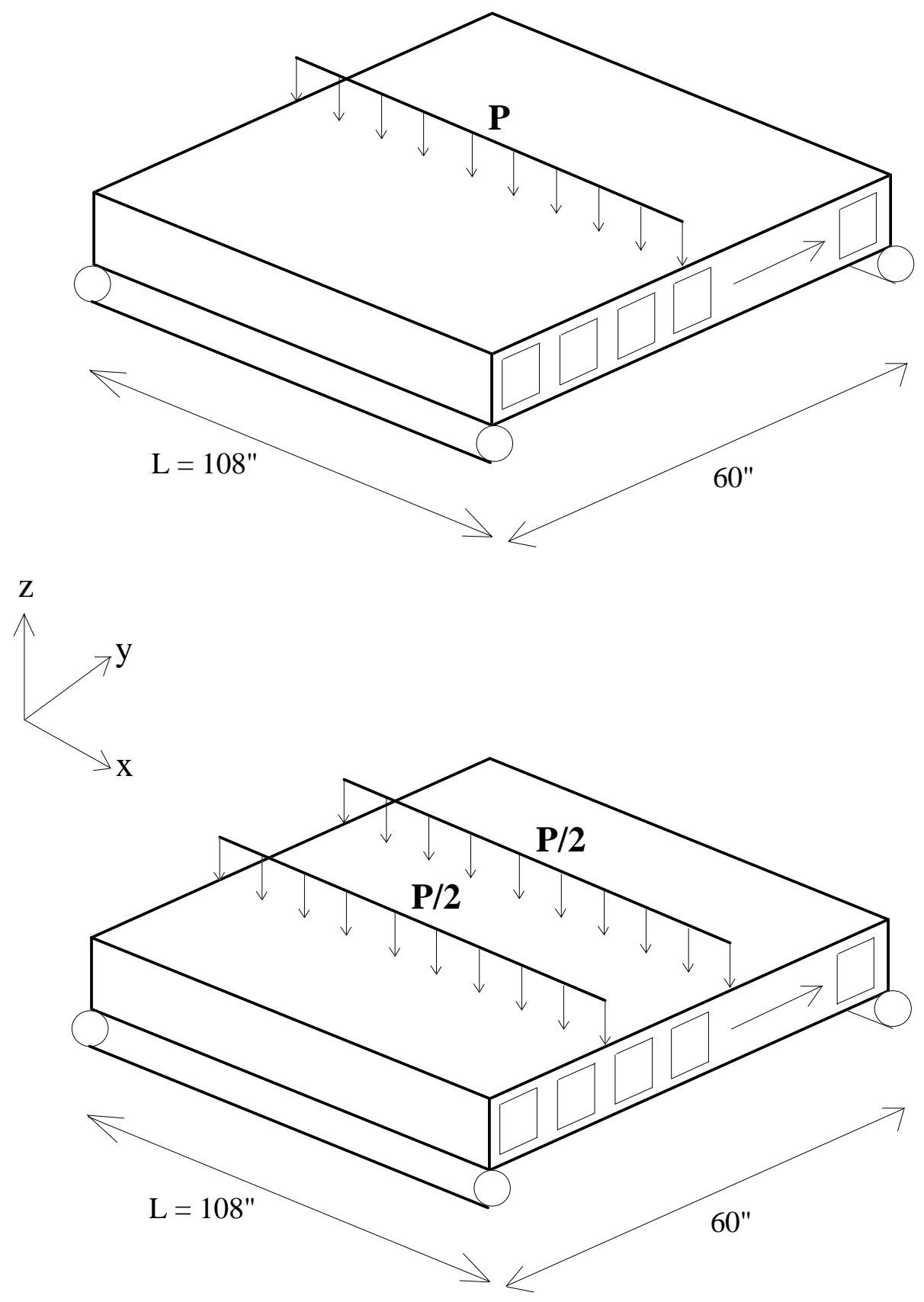

Fig. 3.11 Finite element model of multicellular deck for verification of $E_{y}$ 

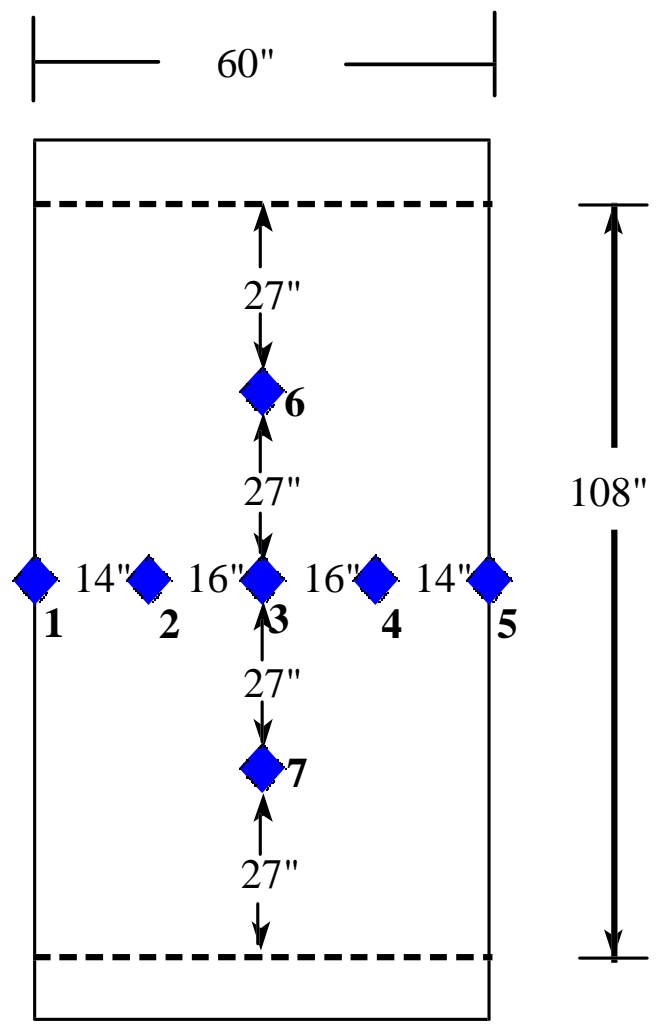

- Location of measurements

Fig. 3.12 Locations of displacement measurements in Tables 3.5 and 3.6

\subsection{Conclusions}

In this chapter, design equations of stiffnesses for multi-cellular box deck are formulated by elastic equivalence technique, and they are verified using finite element modeling. These design equations are further used to obtain the material properties of equivalent orthotropic plate, which can be directly input in the bridge system analysis as introduced in the next chapter. 


\section{Chapter 4}

\section{FRP COMPOSITE DECK-AND-STRINGER BRIDGE SYSTEMS: ANALYSIS AND DESIGN}

\subsection{Introduction}

For composite bridge decks to be more useful, simplification of design methods is necessary. Although Finite Element modeling can be used to perform numerical analysis of actual bridge systems, it is a time-consuming process requiring the user to be specially trained. Thus there is a need to develop an approximate series (closed form) technique for design and analysis of FRP composite deck-and-stringer bridges. Based on this approximation technique, a simple but accurate analysis procedure can be formed to predict the response of FRP composite deck-and-stringer bridge systems.

In this chapter, a series approximation solution accounting for first-order shear deformation and transverse interaction forces between the deck and stringers is developed. The solutions for symmetric and antisymmetric load cases are formulated; the asymmetric load case condition is solved based on superposition principles. The approximated interaction force function is then used to define load distribution factors that represent the overall behavior of the bridge superstructure. Consistent with design methods for highway bridges given in AASHTO, step-by-step design guidelines for FRP

deck panels and deck-and-stringer bridge systems are given, followed by three illustrative design examples of the complete design procedure. 


\subsection{First-order Shear Deformation Theory for FRP Composite Plate}

In this section, the first-order shear deformation theory [39] is applied to analyze the behavior of an orthotropic composite plate. Instead of direct modeling of the actual deck panel, an equivalent orthotropic plate is used to simplify the analysis. Plate orthotropic properties such as longitudinal, transverse, in-plane shears and out-of-plane shear stiffness are important to accurately model the superstructure. The derivation of these properties with respect to deck geometry and thin-walled panel material properties is given in Chapter 3.

For a rectangular plate element, the equilibrium forces and moments are shown in Figure 4.1a, and the sign convention for the deformations is shown in Figure 4.1b. Analogous to the Timoshenko beam theory, in the shear deformation theory it is assumed that plane sections originally perpendicular to the longitudinal plane of the plate remain plane, but not necessarily perpendicular to the longitudinal plane. The displacement field of the plate is

$$
\begin{gathered}
u(x, y, z)=u_{o}(x, y)+z \psi_{x}(x, y) \\
v(x, y, z)=v_{o}(x, y)+z \psi_{y}(x, y) \\
w(x, y, z)=w_{o}(x, y)
\end{gathered}
$$

where $u_{o}, v_{o}$, and $w_{o}$ denote displacement components of a point along the $\mathrm{x}, \mathrm{y}, \mathrm{z}$ coordinates; and $\psi_{x}$ and $\psi_{y}$ denote the rotations of a line element, originally perpendicular to the longitudinal plane, about the $\mathrm{y}$ and $\mathrm{x}$ axes respectively. 


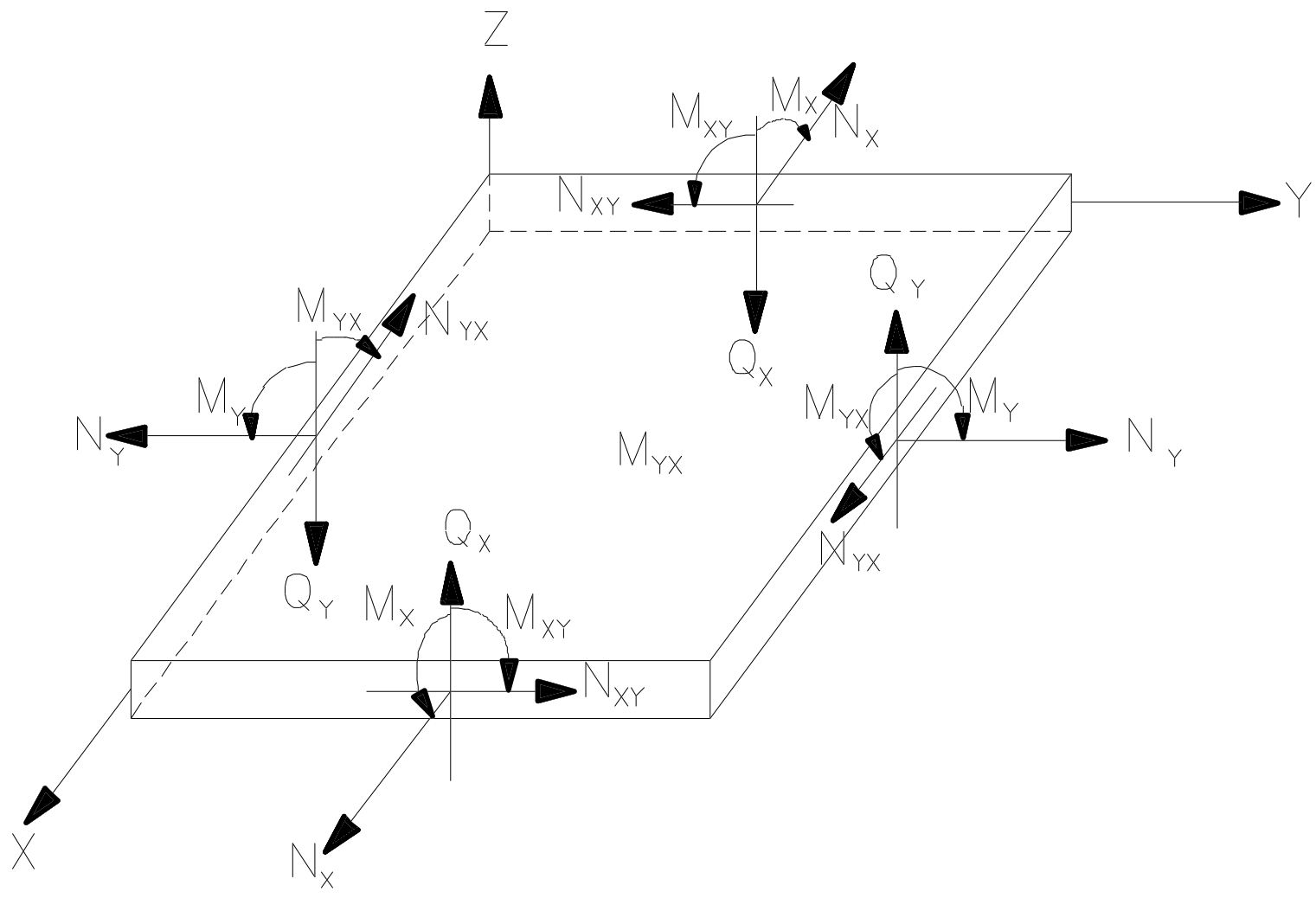

(a) forces and moments

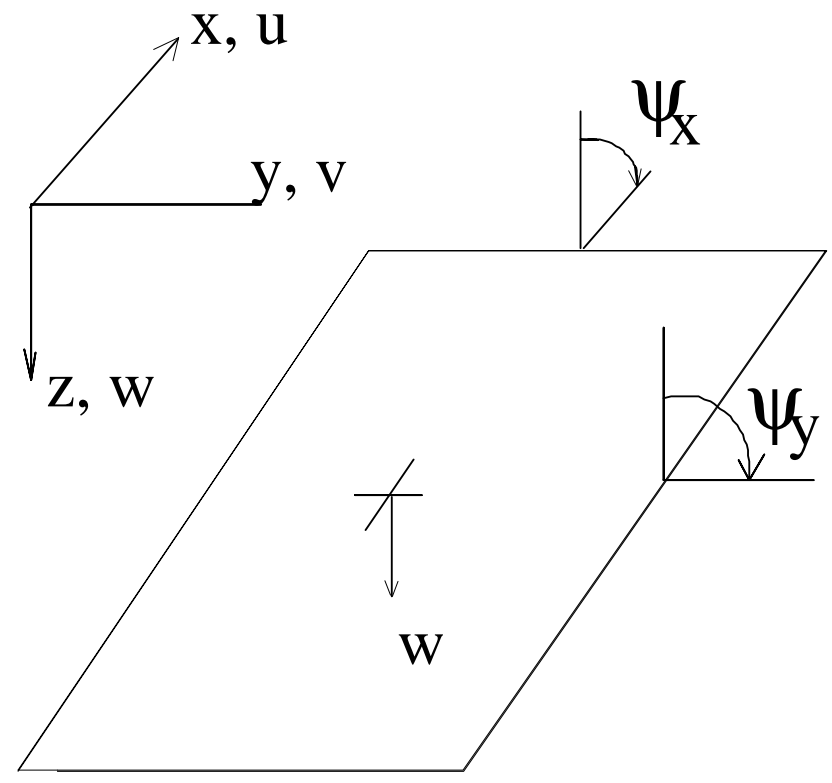

(b) deformation

Figure 4.1 Sign convention for deformation and plate stress resultants 
Using the total potential energy principle, the equilibrium equations of the firstorder shear theory can be obtained. For an orthotropic material, Hooke's law is written as

$$
\begin{aligned}
\left\{\begin{array}{l}
N_{x} \\
N_{y} \\
N_{x y}
\end{array}\right\} & =\left[\begin{array}{lll}
A_{11} & A_{12} & 0 \\
A_{12} & A_{22} & 0 \\
0 & 0 & A_{66}
\end{array}\right]\left\{\begin{array}{l}
\partial u_{o} / \partial x \\
\partial v_{o} / \partial y \\
\partial u_{o} / \partial y+\partial v_{o} / \partial x
\end{array}\right\} \\
\left\{\begin{array}{l}
M_{x} \\
M_{y} \\
M_{x y}
\end{array}\right\} & =\left[\begin{array}{lll}
D_{11} & D_{12} & 0 \\
D_{12} & D_{22} & 0 \\
0 & 0 & D_{66}
\end{array}\right]\left\{\begin{array}{l}
\partial \psi_{x} / \partial x \\
\partial \psi_{y} / \partial y \\
\partial \psi_{x} / \partial y+\partial \psi_{y} / \partial x
\end{array}\right\} \\
\left\{\begin{array}{l}
Q_{y} \\
Q_{x}
\end{array}\right\} & =\left[\begin{array}{ll}
A_{44} & 0 \\
0 & A_{55}
\end{array}\right]\left\{\begin{array}{l}
\psi_{y}+\partial w_{o} / \partial y \\
\psi_{x}+\partial w_{o} / \partial x
\end{array}\right\}
\end{aligned}
$$

where $A_{i j}(i, j=1,2,6)$ are the extensional stiffnesses, $A_{i j}(i, j=4,5)$ are the intralaminar shear coefficients, and $D_{i j}(i, j=1,2,6)$ are the bending stiffnesses for an orthotropic material, and they are defined in terms of orthotropic moduli (see Section 3.4 of Ch. 3):
$A_{11}=\frac{E_{x} t}{1-\frac{E_{y}}{E_{x}} v^{2}}$
$A_{22}=\frac{E_{y} t}{1-\frac{E_{y}}{E_{x}} v^{2}}$
$A_{12}=\frac{v E_{y} t}{1-\frac{E_{y}}{E_{x}} v^{2}}$
$A_{66}=G_{x y} t$
$A_{44}=\frac{5}{6} G_{x z} t$
$A_{55}=\frac{5}{6} G_{y z} t$ 


$$
\begin{aligned}
D_{11}=\frac{E_{x} t^{3}}{12\left(1-\frac{E_{y}}{E_{x}} v^{2}\right)} & D_{22}=\frac{E_{y} t^{3}}{12\left(1-\frac{E_{y}}{E_{x}} v^{2}\right)} \\
D_{12}=\frac{v E_{y} t^{3}}{12\left(1-\frac{E_{y}}{E_{x}} v^{2}\right)} & D_{66}=\frac{1}{12} G_{x y} t^{3}
\end{aligned}
$$

We are interested in solving for $w_{o}, \psi_{x}$, and $\psi_{y}$, which have been decoupled from $u_{o}$ and $v_{o}$. Therefore the equilibrium equations that contain these three unknowns [39] are

$$
\begin{gathered}
A_{55} \frac{\partial}{\partial x}\left(\psi_{x}+\frac{\partial w_{o}}{\partial x}\right)+A_{44} \frac{\partial}{\partial y}\left(\psi_{y}+\frac{\partial w_{o}}{\partial y}\right)+q(x, y)=0 \\
\frac{\partial}{\partial x}\left(D_{11} \frac{\partial \psi_{x}}{\partial x}+D_{12} \frac{\partial \psi_{y}}{\partial y}\right)+D_{66} \frac{\partial}{\partial y}\left(\frac{\partial \psi_{x}}{\partial y}+\frac{\partial \psi_{y}}{\partial x}\right)-A_{55}\left(\psi_{x}+\frac{\partial w_{o}}{\partial x}\right)=0 \\
D_{66} \frac{\partial}{\partial x}\left(\frac{\partial \psi_{x}}{\partial y}+\frac{\partial \psi_{y}}{\partial x}\right)+\frac{\partial}{\partial y}\left(D_{12} \frac{\partial \psi_{x}}{\partial x}+D_{22} \frac{\partial \psi_{y}}{\partial y}\right)-A_{44}\left(\psi_{y}+\frac{\partial w_{o}}{\partial y}\right)=0
\end{gathered}
$$

Eqs. 4.3, in general, can not be solved exactly. However, for certain boundary conditions, one can develop solutions by using double series expansions. The closedform approximate solution for the response of a bridge-type system (Figure 4.2) with two opposite sides simply supported and the other two stiffened by edge beams was developed by a macro-flexibility (MF) analysis [15], which is extended to include firstorder shear deformation for FRP deck-and-stringer bridges (SDMF). It is mainly based on approximate series solution approach, as introduced in the next section. 


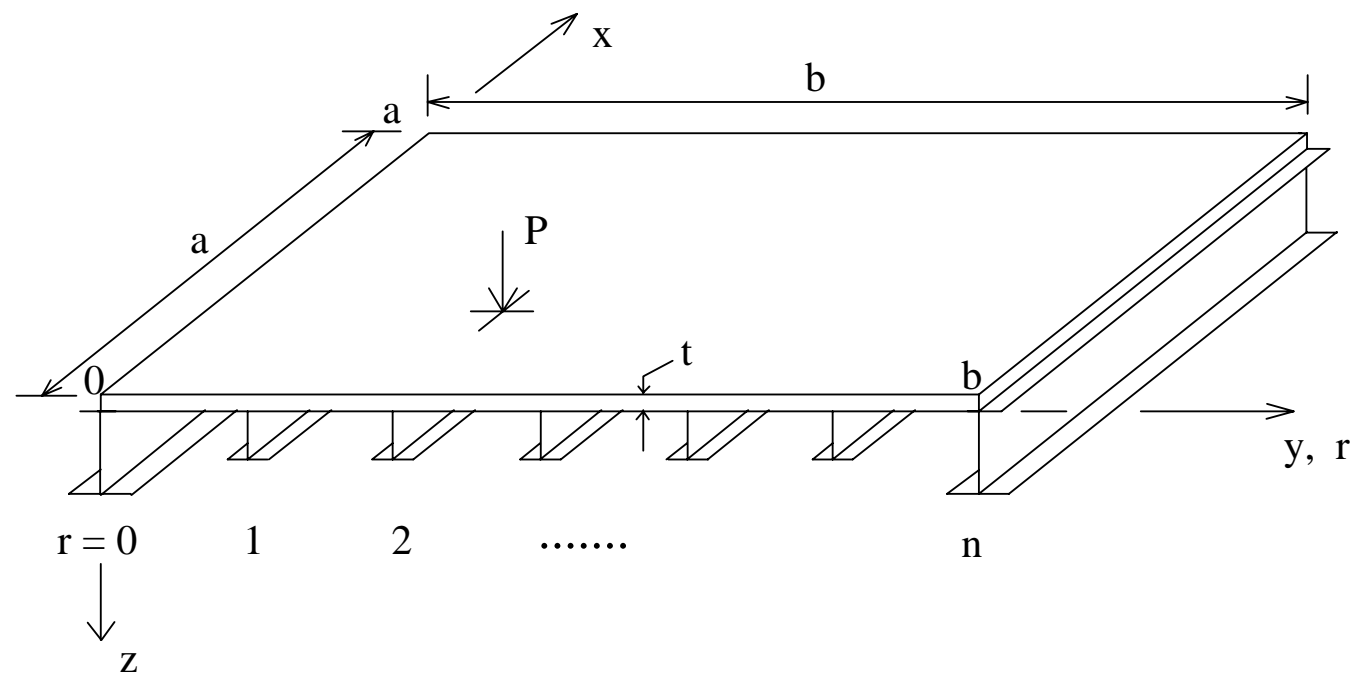

(a) Deck-and-Stringer system

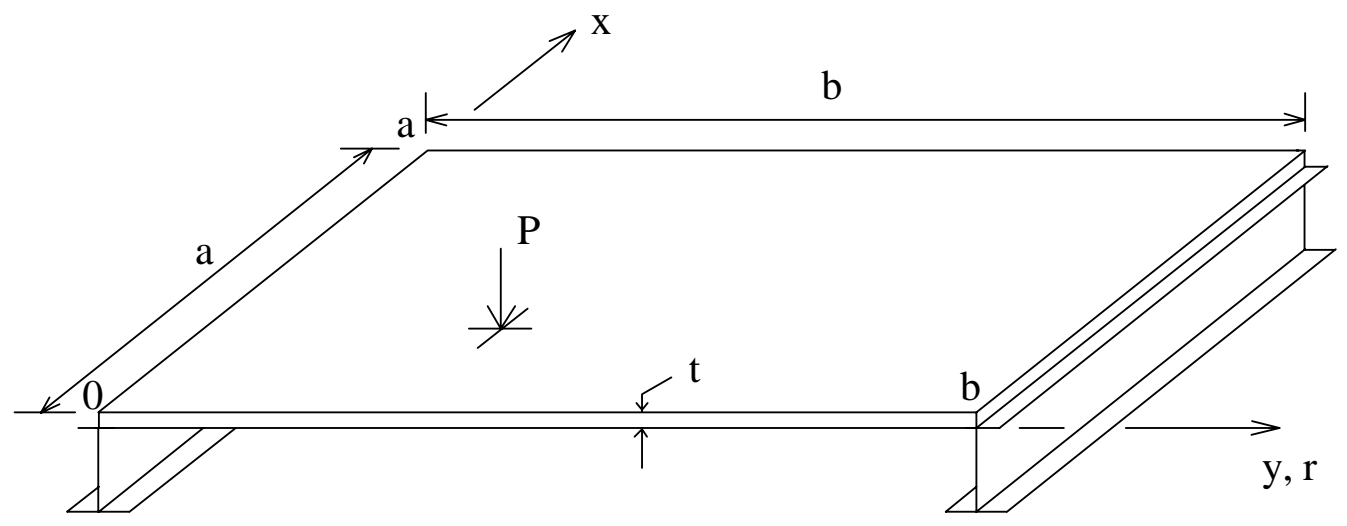

(b) Plate with exterior stringers only

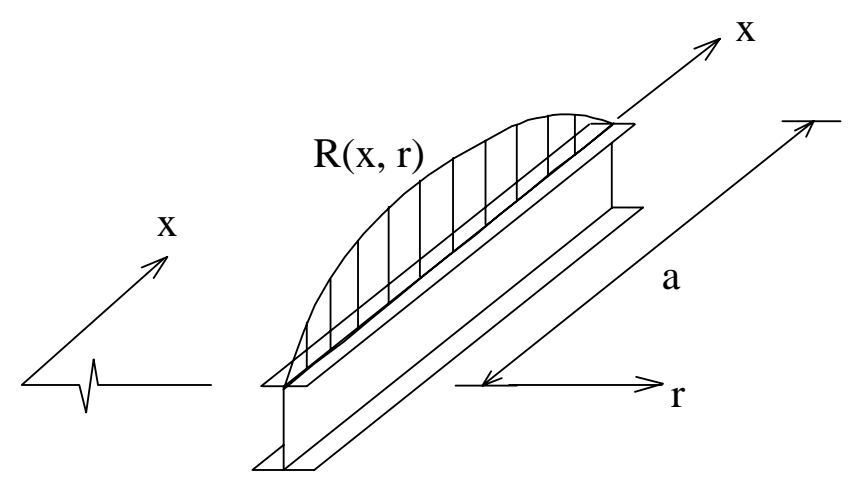

(c) Interior stringer

Figure 4.2 SDMF flexural analysis model 


\subsection{Approximate Series Solution}

The deck-and-stringer bridge system can be first analyzed as an orthotropic plate stiffened by edge stringers (or beams) using first-order shear deformation theory [40]. Then the effects of interior stringers are accounted in the formulation by applying the interaction forces and the comparability conditions along rib lines between the deck and stringers. The deck-and-stringer bridge systems under symmetric and antisymmetric loadings are solved separately in the following sections, and for asymmetric load case, the behavior of system is obtained using superposition principle.

The rectangular deck-and-stringer system can be subjected to arbitrary static transverse loads (no torsional moments and/or in-plane forces). The stringers are equally spaced and the interior stringers have identical cross-section and material properties. Other assumptions are stated as necessary while carrying out the derivations. The analysis is general with respect to: (1) size and stiffness of the deck; (2) type of loading (uniform and/or concentrated). The analysis will be derived first for the symmetric and antisymmetric loading conditions.

The basic steps in the flexural analysis of ribbed plates by the approximate series solution approach are:

(1) Following the formulation of Salim et al. [15], obtain the solution for the orthotropic composite plate stiffened by exterior stringers only (see Figure $4.2 \mathrm{~b}$ ).

(2) Obtain the solution for an interior rib (stringer) [30] subjected to the interaction forces $\mathrm{R}(\mathrm{x}, \mathrm{r})$ (Figure 4.2c). 
(3) Determine $\mathrm{R}(\mathrm{x}, \mathrm{r})$ by satisfying the compatibility conditions of the plate along the interior ribs.

(4) From the deflection functions derived for the plate and for the stringers, obtain moments for an isolated beam.

\subsubsection{Deck-and-stringer Bridge under Symmetric Loading}

\section{Solution for Orthotropic Deck with Exterior Edge Stiffeners}

A Fourier polynomial series is employed in this approach to obtain the solutions for the

plate equilibrium equations (Eqs. 4.3). The solution of Eqs. 4.3 for a symmetric loading is of the form

$$
\begin{gathered}
w_{o}(x, y)=\sum_{i, j=1}^{\infty} W_{i j} \sin \alpha x\left(\sin \beta y+W_{o}\right) \\
\psi_{x}(x, y)=\sum_{i, j=1}^{\infty} X_{i j} \cos \alpha x\left(\sin \beta y+X_{o}\right) \\
\psi_{y}(x, y)=\sum_{i, j=1}^{\infty} Y_{i j} \sin \alpha x \cos \beta y
\end{gathered}
$$

Note that these series approximations satisfy the essential boundary conditions. The generalized loading can be written as the following infinite double series 


$$
q(x, y)=\sum_{i, j=1}^{\infty} Q_{i j} \sin \alpha x \sin \beta y
$$

where $\alpha=i \pi / a$ and $\beta=j \pi / b$, and $W_{i j}, X_{i j}$, and $Y_{i j}$ are the coefficients to be determined to complete the solution. $Q_{i j}$ are the Fourier coefficients in the representation of the load $q(x, y)$. For a concentrated point load at $x=\xi$ and $y=\eta$ :

$$
Q_{i j}=\sum_{i, j=1}^{\infty} \frac{4 P}{a b} \sin \alpha \xi \sin \beta \eta
$$

By substituting the general solution Eqs. 4.4 into Eqs. 4.3 and reducing by orthogonality conditions [40], we obtain the following matrix of equations at any fixed $(i, j)$ for orthotropic deck under symmetric loading:

$$
\left[\begin{array}{lll}
K_{11} & K_{12} & K_{13} \\
K_{21} & K_{22} & K_{23} \\
K_{13} & K_{23} & K_{33}
\end{array}\right]\left\{\begin{array}{l}
W_{i j} \\
X_{i j} \\
Y_{i j}
\end{array}\right\}=\left\{\begin{array}{l}
Q_{i j} \\
0 \\
0
\end{array}\right\}
$$

where $K_{i j}$ are the deck stiffness coefficients (for a symmetric loading):

$$
\begin{gathered}
K_{11}=\alpha^{2} A_{55}+\beta^{2} A_{44}+\frac{4 \alpha^{2}}{\pi} A_{55} W_{o} \\
K_{12}=\alpha A_{55}+\frac{4 \alpha}{\pi} A_{55} X_{o} \\
K_{13}=\beta A_{44}
\end{gathered}
$$




$$
\begin{gathered}
K_{21}=\alpha A_{55}+\frac{4 \alpha}{\pi} A_{55} W_{o} \\
K_{22}=\alpha^{2} D_{11}+\beta^{2} D_{66}+A_{55}+\frac{4 \alpha^{2}}{\pi} D_{11} X_{o}+\frac{4}{\pi} A_{55} X_{o} \\
K_{23}=\alpha \beta\left(D_{12}+D_{66}\right) \\
K_{33}=\alpha^{2} D_{66}+\beta^{2} D_{22}+A_{44}
\end{gathered}
$$

The constants $W_{o}$ and $X_{o}$ represent the edge deformations and are found by satisfying the boundary conditions of the orthotropic plate (Figure $4.2 b$ ). The first of the two necessary equations for solving $W_{o}$ and $X_{o}$ is derived from force compatibility at the exterior stringers [30]. Interaction forces in an exterior stringer are equal to the shear forces in the plate at $y=0$ and $y=b$ :

$$
\frac{\partial}{\partial x}\left[\kappa F\left(\psi_{x}+\frac{\partial w_{o}}{\partial x}\right)\right]_{y=0, b}=\mp\left[A_{44}\left(\psi_{y}+\frac{\partial w_{o}}{\partial y}\right)\right]_{y=0, b}
$$

where $\kappa=$ shear correction factor and $F=$ shear stiffness of the stringer.

The second equation is the governing equation of a beam (the exterior stringer)

$$
D \frac{\partial^{2} \psi_{x}}{\partial x^{2}}-\kappa F\left(\psi_{x}+\frac{\partial w_{o}}{\partial x}\right)=0
$$


where $D=$ bending stiffness of the stringer. For a thin-wall laminated composite beam, $\kappa, F$, and $D$ are obtained from the Mechanics of Laminated Beam Theory $[31,32]$, and the details on their computation are presented in Chapter 2.

By substituting Eqs. 4.4 into Eqs. 4.8 and 4.9, applying orthogonality conditions and simplifying, we obtain the following one-term approximation $(i=j=1)$ for $W_{o}$ and $X_{o}$ :

$$
\begin{gathered}
W_{o}=A_{44} c\left(\frac{Y_{11}}{W_{11}}+\beta\right) \\
X_{o}=-\frac{A_{44}}{\alpha^{3} D}\left(\frac{Y_{11}+\beta W_{11}}{X_{11}}\right)
\end{gathered}
$$

where $\mathrm{c}$ is

$$
c=\frac{1}{\alpha^{2}}\left(\frac{1}{\kappa F}+\frac{1}{\alpha^{2} D}\right)
$$

For a bridge deck with no edge stringers, $W_{o}$ and $X_{o}$ are defined by

$$
\begin{gathered}
W_{o}=\frac{\pi}{4}\left[-1+\frac{A_{44} \beta^{2}}{A_{55} \alpha^{2} D_{12}}\left(\frac{\alpha^{2} D_{12}{ }^{2}\left(3 D_{66}+D_{12}\right)-D_{22}\left[\left(D_{11} \alpha^{2}+A_{55}\right)\left(D_{12}+2 D_{66}\right)+D_{12} D_{66} \beta^{2}\right.}{A_{44}\left(D_{12}+2 D_{66}\right)+D_{66}\left(D_{22} \beta^{2}-D_{12} \alpha^{2}\right)}\right)\right] \\
X_{o}=-\frac{\pi D_{66}}{2 D_{12}}\left(\frac{D_{12} \alpha^{2}-D_{22} \beta^{2}}{2 D_{66} \alpha^{2}+D_{22} \beta^{2}}\right)
\end{gathered}
$$


where $W_{1 l}, X_{11}$, and $Y_{11}$ are evaluated from Eq. 4.7. By examining Eqs. 4.10 and 4.11 we note that as expected they result in dimensionless quantities. At this stage, all of the constants in Eq. 4.4 have been determined to allow us to completely define the deflections and moments at any point in the plate of Figure $4.2 \mathrm{~b}$ for any symmetric type of loading. In the following section, the effect of the interior stringers will be added. Hence, the deflection function of any interior stringer will be determined.

\section{Solution for an Interior Stringer under Symmetric Loading}

For any interior stringer at any location $r(r=1,2, \ldots n$ see Fig. 4.2b), the governing differential equations are [39]

$$
\begin{gathered}
\frac{\partial}{\partial x}\left[\kappa F\left(\psi^{R}(x, r)+\frac{\partial w^{R}(x, r)}{\partial x}\right)\right]+R(x, r)=0 \\
D \frac{\partial^{2} \psi^{R}(x, r)}{\partial x^{2}}-\kappa F\left(\psi^{R}(x, r)+\frac{\partial w^{R}(x, r)}{\partial x}\right)=0
\end{gathered}
$$

where $w^{R}(x, r)$ is the generalized deflection function for any interior rib (stringer), $\psi^{R}(x, r)$ is the generalized rotation of any interior rib, and $R(x, r)$ is the generalized interaction force at the rib line (Figure 4.2c). Also in the formulation, the interior stringers are assumed to be identical to the exterior stringers. 
Since the compatibility and boundary conditions are only applicable at the rib lines, it is necessary to use infinite series forms for the approximation of $w^{R}(x, r), \psi^{R}(x, r)$, and $R(x, r)$. Therefore, the first term approximation results in

$$
\begin{aligned}
w^{R}(x, r) & =W_{11}^{R} \sin \alpha x\left(\sin \lambda r+W_{o}\right) \\
\psi^{R}(x, r) & =\Psi_{11}^{R} \cos \alpha x\left(\sin \lambda r+X_{o}\right) \\
R(x, r) & =R_{11} \sin \alpha x\left(\sin \lambda r+W_{o}\right)
\end{aligned}
$$

where $\lambda=\pi / n, r=1,2, \ldots n-1$, and $n=$ number of spacings $=$ number of stringers -1 . Substituting Eqs. 4.13 into Eqs. 4.12 and solving for $W_{11}^{R}$ and $\Psi_{11}^{R}$ we get

$$
\begin{aligned}
& W_{11}^{R}=\frac{R_{11}}{\alpha^{2}}\left(\frac{1}{\kappa F}+\frac{1}{\alpha^{2} D}\right) \\
& \Psi_{11}^{R}=-\frac{R_{11}}{\alpha^{3} D} \frac{\sin \lambda r+W_{o}}{\sin \lambda r+X_{o}}
\end{aligned}
$$

The only constant that remains to be defined is $R_{l l}$. To do so, the compatibility between the stringer and the plate are to be invoked. Therefore, the solution for the rib line deflection $w^{R}(x, r)$ is obtained by superimposing the solution of the plate subjected to load $q(x, y)$ and the solution due to the interaction forces $R(x, r)$. Referring to Figure 4.2, $w^{R}(x, r)$ can be expressed as 


$$
w^{R}(x, r)=w(x, r)-\sum_{\eta=1}^{n-1} \int_{0}^{a} R(\xi, \eta) K^{w}(x, r, \xi, \eta) \partial \xi
$$

where $w(x, r)$ is the deflection of the plate at the rib line $(y=r)$ due to $q(x \cdot y)$, and it is modified so as to be similar to Eq. 4.13:

$$
w(x, r)=W_{11} \sin \alpha x\left(\sin \lambda r+W_{o}\right)
$$

The term inside the summation in Eq. 4.16 represents the deflection due to the interaction forces at any interior rib (Eq. 4.13 modified for $x=\xi$ and $y=\eta$ ). The summation is carried over all interior ribs $(\eta=1, \ldots n-1)$, and $K^{w}(x, y, \xi, \eta)$ is the kernel function solution; i.e., the solution for an arbitrarily located unit load applied at $x=\xi$ and $y=\eta$. Similar to Eq. 4.13, the first-term approximation of $K^{w}(x, y, \xi, \eta)$ is

$$
K^{w}(x, y, \xi, \eta)=K_{11}^{w} \sin \alpha x\left(\sin \beta y+W_{o}\right)
$$

To obtain $K_{11}^{w}$, recall from Eq. 4.7 that $W_{11}=K_{11}{ }^{*} Q_{11}$, where $K_{11}{ }^{*}$ is the first term of the inverse $K$ matrix. Similarly we can write $K_{11}^{w}=K_{11}{ }^{*} Q_{11}{ }^{k}$, where $Q_{11}{ }^{k}$ is found by substituting $P=1$ into Eq. 4.6. Thus

$$
K_{11}^{w}=\frac{4 W_{11}}{a b Q_{11}} \sin \alpha \xi \sin \lambda \eta
$$


Substituting Eqs. 4.13, 4.17, and 4.18 into Eq. 4.16; performing the integration; applying orthogonality conditions; and solving for $R_{11}$, we get

$$
R_{11}=\frac{Q_{11}}{\frac{1}{\alpha^{2}}\left(\frac{1}{\kappa F}+\frac{1}{\alpha^{2} D}\right) \frac{Q_{11}}{W_{11}}+\frac{n}{b}\left(1+\frac{4 W_{o}}{\pi}\right)}
$$

Therefore, the generalized deflection function of any interior stringer is completely defined under any symmetric loading, and can be written as

$$
w^{R}(x, r)=R_{11} \frac{1}{\alpha^{2}}\left(\frac{1}{\kappa F}+\frac{1}{\alpha^{2} D}\right) \sin \frac{\pi x}{a}\left(\sin \frac{\pi r}{n}+W_{o}\right)
$$

where $r=1,2, \ldots n-1$ (see Fig. 4.4b). As an approximation, the deflection function of the deck can be written in a similar fashion as:

$$
w_{o}(x, y)=R_{11} \frac{1}{\alpha^{2}}\left(\frac{1}{\kappa F}+\frac{1}{\alpha^{2} D}\right) \sin \frac{\pi x}{a}\left(\sin \frac{\pi y}{b}+W_{o}\right)
$$

Remarks: Using a series approximation technique, the interaction forces (Eq. 4.20) between deck and stringer, and the corresponding deflections of stringers (Eq. 4.21) and deck (Eq. 4.22) under symmetric loading are simply expressed. The ultimate goal for this analysis is to obtain the interaction forces acting on individual stringers, from which the load distribution factors can be derived. 


\subsubsection{Deck-and-stringer Bridge under Anti-symmetric Loading}

\section{Solution for Orthotropic Deck with Exterior Edge Stiffeners}

Analogous to the symmetric case, Eqs. 4.4 and 4.5 are modified for a first term approximation of an antisymmetric loading as

$$
\begin{gathered}
w_{o}(x, y)=W_{12} \sin \alpha x\left(\sin 2 \beta y+W_{1}\left(1-\frac{2 y}{b}\right)\right) \\
\psi_{x}(x, y)=X_{12} \cos \alpha x\left(\sin 2 \beta y+X_{1}\left(1-\frac{2 y}{b}\right)\right) \\
\psi_{y}(x, y)=Y_{12} \sin \alpha x \cos 2 \beta y \\
q(x, y)=Q_{12} \sin \alpha x \sin 2 \beta y
\end{gathered}
$$

The antisymmetric concentrated loading $Q_{12}$ can be written as

$$
Q_{12}=\frac{4 P}{a b} \sin \alpha \xi \sin 2 \beta \eta
$$

Substituting Eqs. 4.23 into Eqs. 4.3 yields the following matrix (for the antisymmetric case) 


$$
\left[\begin{array}{lll}
K_{11} & K_{12} & K_{13} \\
K_{21} & K_{22} & K_{23} \\
K_{31} & K_{32} & K_{33}
\end{array}\right]\left\{\begin{array}{l}
W_{12} \\
X_{12} \\
Y_{12}
\end{array}\right\}=\left\{\begin{array}{l}
Q_{12} \\
0 \\
0
\end{array}\right\}
$$

where $K_{i j}$ are defined as follows:

$$
\begin{gathered}
K_{11}=\alpha^{2} A_{55}+4 \beta^{2} A_{44}+\frac{2 \alpha^{2}}{\pi} A_{55} W_{1} \\
K_{12}=\alpha A_{55}+\frac{2 \alpha}{\pi} A_{55} X_{1} \\
K_{13}=2 \beta A_{44} \\
K_{21}=\alpha A_{55}+\frac{2 \alpha}{\pi} A_{55} W_{1} \\
K_{22}=\alpha^{2} D_{11}+4 \beta^{2} D_{66}+A_{55}+\frac{2}{\pi}\left(\alpha^{2} D_{11}+A_{55}\right) \\
K_{23}=2 \alpha \beta\left(D_{12}+D_{66}\right) \\
K_{31}=2 \beta A_{44}\left(1+\frac{3}{\pi} W_{1}\right) \\
K_{32}=2 \alpha \beta\left(D_{12}+D_{66}\right)\left(1+\frac{3}{\pi} X_{1}\right) \\
K_{33}=\alpha^{2} D_{66}+4 \beta^{2} D_{22}+A_{44}
\end{gathered}
$$

The constants $W_{l}$ and $X_{l}$ are determined by substituting Eqs. 4.23 into Eqs. 4.8 and 4.9 


$$
\begin{gathered}
W_{1}=A_{44} c\left(\frac{Y_{12}}{W_{12}}+2 \beta\right)\left(\frac{1}{1+\frac{2}{b} A_{44} c}\right) \\
X_{1}=-\frac{A_{44}}{\alpha^{3} D}\left(\frac{Y_{12}+2 \beta W_{12}}{X_{12}}\right)
\end{gathered}
$$

where $\mathrm{c}$ is shown in Eq. 4.10c.

\section{Solution for an Interior Stringer for Under Antisymmetric Loading}

The first term approximations of the displacement functions of the interior stringers for the antisymmetric load case are as follows:

$$
\begin{gathered}
w^{R}(x, r)=W_{12}^{R} \sin \alpha x\left(\sin 2 \lambda r+W_{1}\left(1-\frac{2 r}{n}\right)\right) \\
\psi^{R}(x, r)=\Psi_{12}^{R} \cos \alpha x\left(\sin 2 \lambda r+X_{1}\left(1-\frac{2 r}{n}\right)\right) \\
R(x, r)=R_{12} \sin \alpha x\left(\sin 2 \lambda r+W_{1}\left(1-\frac{2 r}{n}\right)\right)
\end{gathered}
$$

Substituting Eqs. 4.27 into Eqs. 4.12 and solving for $W_{12}^{R}$ and $\Psi_{12}^{R}$ yields 


$$
\begin{gathered}
W_{12}^{R}=\frac{R_{12}}{\alpha^{2}}\left(\frac{1}{\mathrm{~K} F}+\frac{1}{\alpha^{2} D}\right) \\
\Psi_{12}^{R}=-\frac{R_{12}}{\alpha^{3} D} \frac{\sin 2 \lambda r+W_{1}\left(1-\frac{2 r}{n}\right)}{\sin 2 \lambda r+X_{1}\left(1-\frac{2 r}{n}\right)}
\end{gathered}
$$

As in the symmetric case, the only constant that remains to be defined is $R_{12}$. Again, Eq. 4.16 is applied with the following modifications:

$$
\begin{gathered}
w(x, r)=W_{12} \sin \alpha x\left(\sin 2 \lambda r+W_{1}\left(1-\frac{2 r}{n}\right)\right) \\
K^{w}(x, r, \xi, \eta)=K_{12}^{w} \sin \alpha x\left(\sin 2 \lambda r+W_{1}\left(1-\frac{2 r}{n}\right)\right) \\
K_{12}^{w}=\frac{4 W_{12}}{a b Q_{12}}(\sin \alpha \xi)(\sin 2 \lambda \eta)
\end{gathered}
$$

Substituting Eqs. 4.27 - 4.30 into Eq. 4.16; performing the integration; applying orthogonality conditions; and solving for $R_{12}$, we get

$$
R_{12}=\frac{Q_{12}}{\frac{1}{\alpha^{2}}\left(\frac{1}{\mathrm{~K} F}+\frac{1}{\alpha^{2} D}\right) \frac{Q_{12}}{W_{12}}+\frac{4 n}{b}\left(1+\frac{2 W_{1}}{3 \pi}\right)}
$$

Finally, the generalized approximate deflection function of any interior stringer is completely defined under any antisymmetric loading, and can be written as 


$$
w^{R}(x, r)=R_{12} \frac{1}{\alpha^{2}}\left(\frac{1}{\mathrm{~K} F}+\frac{1}{\alpha^{2} D}\right) \sin \frac{\pi x}{a}\left(\sin \frac{2 \pi r}{n}+W_{1} \cos \frac{\pi r}{n}\right)
$$

where $r=1,2, \ldots n-1$. An approximate deflection function of the deck can be written in a similar fashion as

$$
w_{o}(x, y)=R_{12} \frac{1}{\alpha^{2}}\left(\frac{1}{\mathrm{~K} F}+\frac{1}{\alpha^{2} D}\right) \sin \frac{\pi x}{a}\left(\sin \frac{2 \pi y}{b}+W_{1} \cos \frac{\pi y}{b}\right)
$$

Remarks: As similar to the symmetric loading case, the interaction forces (Eq. 4.31) on the stringers are obtained for the antisymmetric case. The intention of this formulation is not for practical use; rather it is a numerical exercise. The antisymmetric case can be superposed with the symmetric case to obtain the asymmetric case as presented next.

\subsubsection{Deck-and-stringer Bridge under Asymmetric Loading}

The asymmetric case is obtained by applying superposition principles to the symmetric and antisymmetric load conditions. By simply adding the symmetric and antisymmetric responses, the generalized function for an interior stringer under an asymmetric load is written as

$$
w^{R}(x, r)_{A s y m}=w^{R}(x, r)_{S y m}+w^{R}(x, r)_{A n t i s y m}
$$




$$
w^{R}(x, r)=\left[R_{11}\left(\sin \frac{\pi r}{n}+W_{o}\right)+R_{12}\left(\sin \frac{2 \pi r}{n}+W_{1} \cos \frac{\pi r}{n}\right)\right] \frac{1}{\alpha^{2}}\left(\frac{1}{\mathrm{~K} F}+\frac{1}{\alpha^{2} D}\right) \sin \frac{\pi x}{a}
$$

where $r=1,2, \ldots n-1$. The approximate deflection function of the deck can be written as

$$
\begin{gathered}
w_{o}(x, y)=w_{o}(x, y)_{\text {Sym }}+w_{o}(x, y)_{\text {Antisym }} \\
\text { or } \\
w_{o}(x, y)=\left[R_{11}\left(\sin \frac{\pi y}{b}+W_{o}\right)+R_{12}\left(\sin \frac{2 \pi y}{b}+W_{1}\left(1-\frac{2 y}{b}\right)\right)\right] \frac{1}{\alpha^{2}}\left(\frac{1}{\mathrm{~K} F}+\frac{1}{\alpha^{2} D}\right) \sin \frac{\pi x}{a}
\end{gathered}
$$

Similarly, the interaction forces $R(x, r)$ for any stringer can be written as

$$
\begin{gathered}
R(x, r)=R(x, r)_{S y m}+R(x, r)_{\text {Antisym }} \\
\text { or } \\
R(x, r)=\left[R_{11}\left(\sin \frac{\pi r}{n}+W_{o}\right)+R_{12}\left(\sin \frac{2 \pi r}{n}+W_{1}\left(1-\frac{2 r}{n}\right)\right)\right] \sin \frac{\pi x}{a}
\end{gathered}
$$

where $R_{11}, R_{12}, W_{o}$, and $W_{1}$ are defined in sections 4.3.1 and 4.3.2.

Remarks: The one-term series approximate solution for symmetric, antisymmetric, and asymmetric cases can now be employed to derive wheel-load distribution factors that are useful in the design of highway bridges. 


\subsubsection{Comparison with Finite Element Modeling}

To validate the accuracy of the approximate series solution, a finite element model of all-FRP deck-and-stringer bridges by NISA is used and the predicted deflections of the bridge system under various loading cases are compared. A bridge system (Fig. 5.6a and 5.8a) consisting of four 12"x12"x1/2" WF I-beams and a 10' x 10' deck composed of 30 bonded 4"x8"x1/4" box sections is modeled. Table 4.1 and Fig. 4.3 present a comparison between the FE model of the actual deck supported by four stringers (Fig. 5.8a) and the theoretical predictions. The results indicate that the approximate central stringer deflections by series solution compare favorably with the FE modeling, particularly for the symmetric load case.

Table 4.1 Comparison of series solution and FE model

\begin{tabular}{|c|c|c|c|c|c|c|}
\hline Stringer & $\begin{array}{c}\mathrm{FE} \\
\text { (sym) }\end{array}$ & $\begin{array}{l}\text { Theory } \\
\text { (sym) }\end{array}$ & $\begin{array}{c}\text { FE } \\
\text { (antisym) }\end{array}$ & $\begin{array}{l}\text { Theory } \\
\text { (antisym) }\end{array}$ & $\begin{array}{c}\text { FE } \\
\text { (asym) }\end{array}$ & $\begin{array}{l}\text { Theory } \\
\text { (asym) }\end{array}$ \\
\hline 1 & 0.0033 & 0.0032 & 0.0025 & 0.0003 & 0.0058 & 0.0035 \\
\hline 2 & 0.0061 & 0.006 & 0.0016 & 0.0018 & 0.0077 & 0.0078 \\
\hline 3 & 0.0061 & 0.006 & -0.002 & -0.002 & 0.0045 & 0.0042 \\
\hline 4 & 0.0033 & 0.0032 & -0.002 & $-3 \mathrm{E}-04$ & 0.0008 & 0.0029 \\
\hline
\end{tabular}




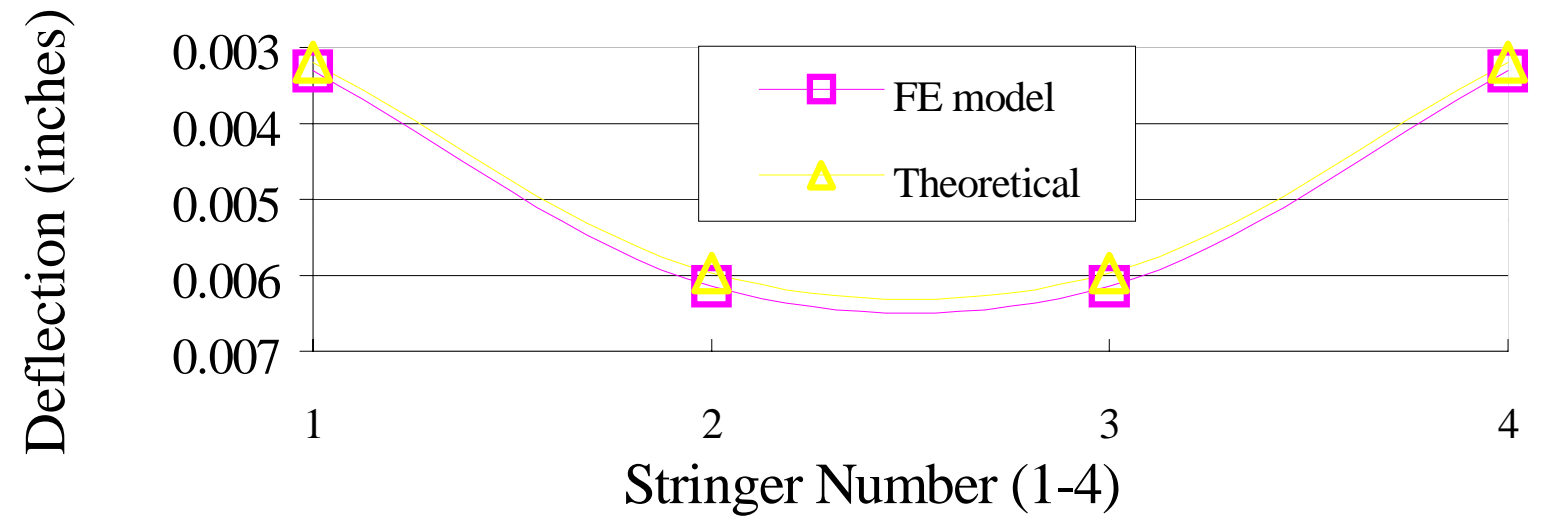

(a) Symmetric

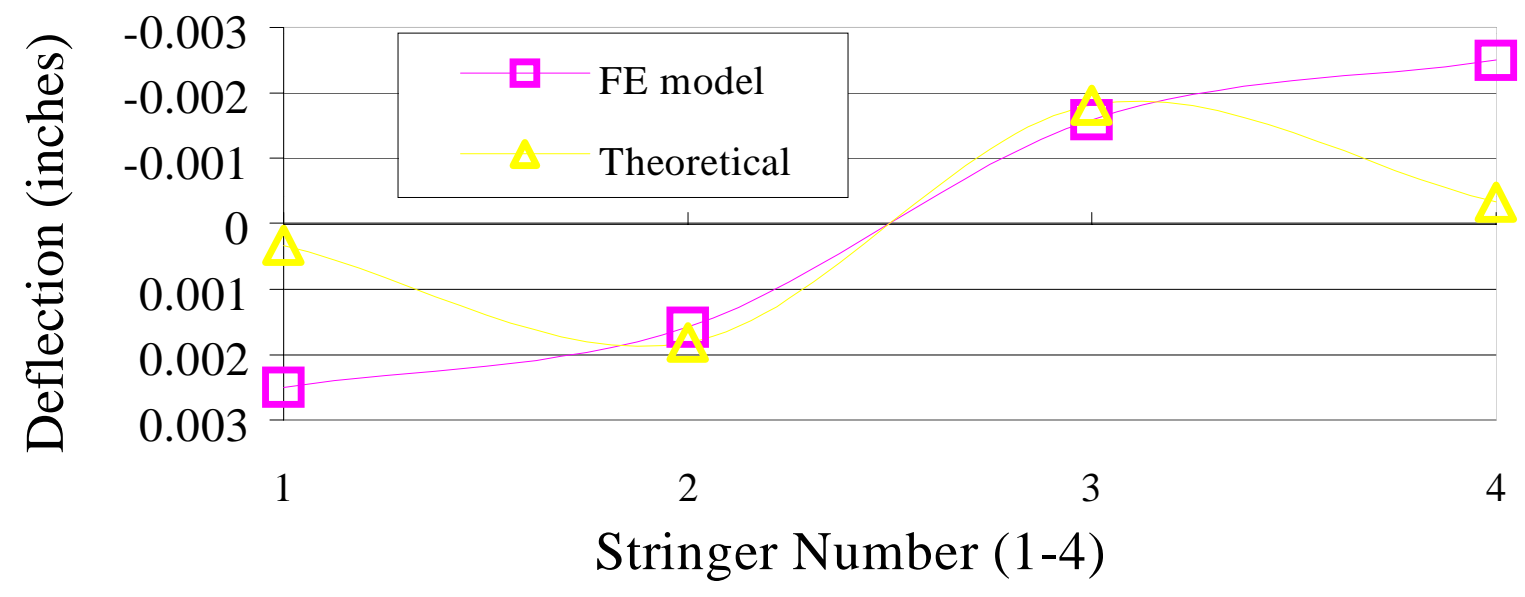

(b) Antisymmetric

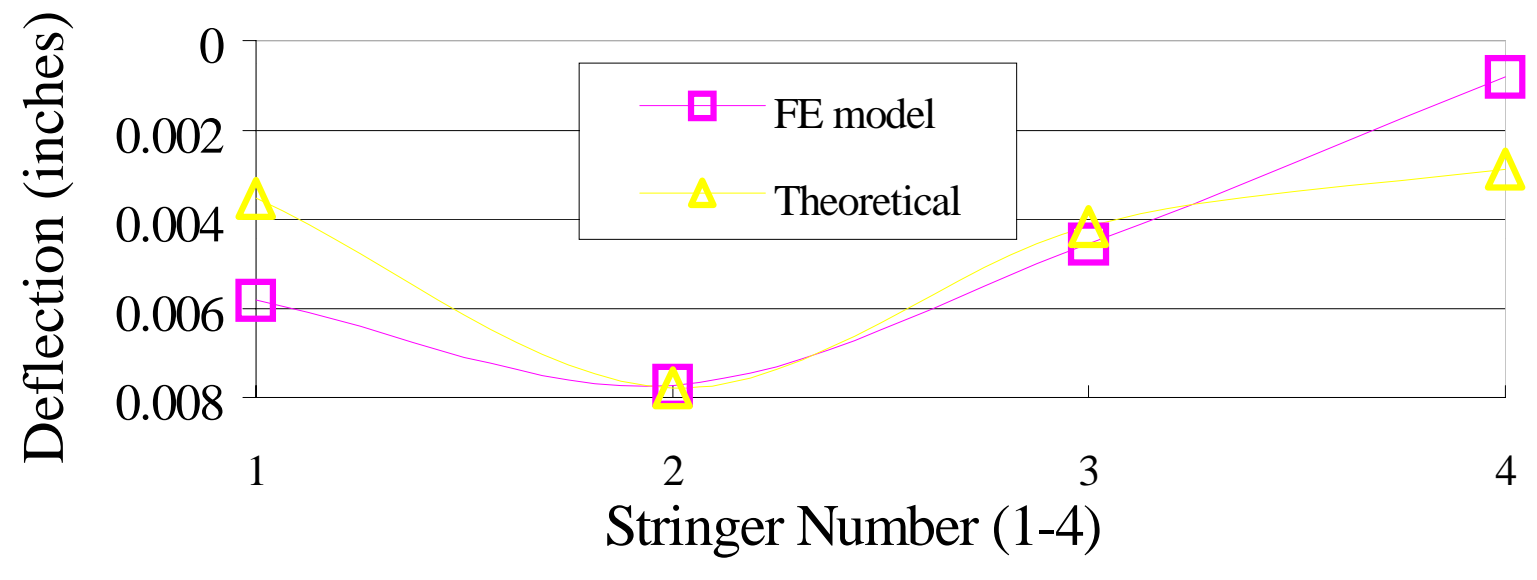

(c) Asymmetric

Fig. 4.3 Comparison of series solution and FE model 
The following tables present more detailed comparisons of stringer deflections for the 3-stringer and 4-stringer systems (Fig. 5.6a and 5.8a) subjected to loads at L/3 and L/4. Distinction is also made between FE results for models of the actual decks and models of the equivalent orthotropic plates. The asymmetric case results may be obtained by simply adding the symmetric and antisymmetric results for a given stringer.

Table 4.2 Center deflections (in.) of stringers for 3-stringer system

\begin{tabular}{|c|c|c|c|c|c|c|}
\hline \multirow{2}{*}{} & \multicolumn{2}{|c|}{ Symmetric Load at L/3 } & \multicolumn{2}{c|}{ Antisymmetric Load at L/3 } \\
\hline Stringer & Deck & Plate & Theoretical & Deck & Plate & Theoretical \\
\hline 1 & 0.004808 & 0.004717 & 0.004074 & 0.002959 & 0.002948 & 0.000337 \\
\hline 2 & 0.008734 & 0.008930 & 0.008152 & 0.0 & 0.0 & 0.0 \\
\hline 3 & 0.004808 & 0.004717 & 0.004074 & -0.002959 & -0.002948 & -0.000337 \\
\hline & \multicolumn{5}{|c|}{ Symmetric Load at L/4 } & Antisymmetric Load at L/4 \\
\hline Stringer & Deck & Plate & Theoretical & Deck & Plate & Theoretical \\
\hline 1 & 0.005301 & 0.005163 & 0.003326 & 0.004463 & 0.004432 & 0.000390 \\
\hline 2 & 0.007849 & 0.008122 & 0.0066564 & 0.0 & 0.0 & 0.0 \\
\hline 3 & 0.005301 & 0.005163 & 0.0033263 & -0.004463 & -0.004432 & -0.000390 \\
\hline
\end{tabular}


Table 4.3 Center deflections (in.) of stringers for 4-stringer system

\begin{tabular}{|c|c|c|c|c|c|c|}
\hline & \multicolumn{3}{|c|}{ Symmetric Load at L/3 } & \multicolumn{3}{|c|}{ Antisymmetric Load at L/3 } \\
\hline Stringer & Deck & Plate & Theoretical & Deck & Plate & Theoretical \\
\hline 1 & 0.003305 & 0.003217 & 0.003197 & 0.002506 & 0.002496 & 0.000325 \\
\hline 2 & 0.006140 & 0.006237 & 0.005969 & 0.001580 & 0.001582 & 0.001816 \\
\hline 3 & 0.006140 & 0.006237 & 0.005969 & -0.001591 & -0.001582 & -0.001816 \\
\hline 4 & 0.003305 & 0.003217 & 0.003197 & -0.002498 & -0.002496 & -0.000325 \\
\hline & \multicolumn{3}{|c|}{ Symmetric Load at L/4 } & \multicolumn{3}{|c|}{ Antisymmetric Load at L/4 } \\
\hline Stringer & Deck & Plate & Theoretical & Deck & Plate & Theoretical \\
\hline 1 & 0.003878 & 0.003732 & 0.002611 & 0.003879 & 0.003843 & 0.000376 \\
\hline 2 & 0.005607 & 0.005755 & 0.004874 & 0.002009 & 0.002074 & 0.002096 \\
\hline 3 & 0.005607 & 0.005755 & 0.004874 & -0.002009 & -0.002074 & -0.002100 \\
\hline 4 & 0.003878 & 0.003732 & 0.002611 & -0.003879 & -0.003843 & -0.000376 \\
\hline
\end{tabular}

\subsection{Wheel-load Distribution Factors}

The approximate solution is used to define a wheel-load distribution factor for any of the stringers. Once the edge deflection coefficients $W_{o}$ and $W_{l}$ are found from Eqs. 4.10 and 4.26, the distribution factor for any interior stringer $i^{\text {th }}$ is defined as the ratio of the interaction forces $R(x, r)$ for the $i^{\text {th }}$ stringer to the sum of interaction forces for all stringers 
[15]. Using Eq. 4.13, the wheel-load distribution factor under symmetric loading becomes

$$
W_{f}^{S y m}(r)=\frac{R_{11} \sin \frac{\pi x}{a}\left(\sin \frac{\pi r}{n}+W_{o}\right)}{\sum_{\alpha=0}^{n} R_{11} \sin \frac{\pi x}{a}\left(\sin \frac{\pi \alpha}{n}+W_{o}\right)}
$$

Eq. 4.37 can be reduced to

$$
W_{f}^{\text {Sym }}(r)=\frac{\sin \frac{\pi r}{n}+W_{o}}{\frac{2}{\pi} n+(n+1) W_{o}}
$$

where $n$ is the number of stringer-spacings and $r=0,1, \ldots n$. By defining $m$ as the number of stringers $(m=n+1$; and $r=1,2, \ldots m)$ Eq. 4.38 can be written in terms of $m$ as:

$$
W_{f}^{\text {Sym }}(r)=\frac{\sin \frac{r-1}{m-1} \pi+W_{o}}{\frac{2}{\pi}(m-1)+m W_{o}}
$$

The maximum wheel-load distribution factor under symmetric loading occurs when $(r-1) /(m-1)=1 / 2$; i.e., $\sin (\pi / 2)=1$. Therefore

$$
\left(W_{f}^{\text {Sym }}\right)_{\max }=\frac{1+W_{o}}{m W_{o}+\frac{2}{\pi}(m-1)}
$$


Similarly, using Eq. 4.27, the wheel-load factor for antisymmetric loading is

$$
W_{f}^{\text {Antisym }}(r)=\frac{R_{12} \sin \frac{\pi x}{a}\left(\sin \frac{2 \pi r}{n}+W_{1}\left(1-\frac{2 r}{n}\right)\right)}{\sum_{\alpha=0}^{n / 2} R_{12} \sin \frac{\pi x}{a}\left(\sin \frac{2 \pi \alpha}{n}+W_{1}\left(1-\frac{2 \alpha}{n}\right)\right)}
$$

where the summation is modified to account for the curvature of the antisymmetric deformed shape. Using $m=n+1$; and $r=1,2, \ldots m$ Eq. 4.41 can be reduced to

$$
W_{f}^{\text {Antisym }}(r)=\frac{\sin \frac{r-1}{m-1} 2 \pi+W_{1}\left(1-2 \frac{r-1}{m-1}\right)}{(m-1)\left(\frac{1}{\pi}+\frac{W_{1}}{4}\right)}
$$

It is seen from Eq. 4.42 that $W_{f}^{\text {Antisym }}$ depends on the values of $r($ or $m)$ and $W_{l}$. As the value of the edge-deflection coefficient $W_{l}$ increases, the location of the maximum wheel-load distribution shifts to the edges. However, for a practical range of $W_{l}$ values $\left(W_{l} \leq 0.5\right)$, the maxima of $W_{f}^{\text {Antisym }}$ that can be considered in design occurs around $r=n / 4$. Using this approximation, the maximum value of $W_{f}^{\text {Antisym }}$ becomes

$$
\left(W_{f}^{\text {Antisym }}\right)_{\text {Maxima }}=\frac{1+0.5 W_{1}}{(m-1)\left(\frac{1}{\pi}+\frac{W_{1}}{4}\right)}
$$


In general it would not be correct to add the wheel-load factors from symmetric and antisymmetric conditions to obtain the asymmetric wheel-load factor. Therefore the wheel-load factor for asymmetric load must be obtained using definition given previously for wheel-load distribution as the ratio of interaction forces for a stringer over the interaction forces for all stringers, and $W_{f}^{\text {Asym }}$ is defined using the interaction forces given in Eq. 4.36 leading to:

$$
W_{f}^{A s y m}(r)=\frac{\left[R_{11}\left(\sin \pi \frac{r-1}{m-1}+W_{o}\right)+R_{12}\left(\sin 2 \pi \frac{r-1}{m-1}+W_{1}\left(1-2 \frac{r-1}{m-1}\right)\right)\right]}{\sum_{r=1}^{m}\left[R_{11}\left(\sin \pi \frac{r-1}{m-1}+W_{o}\right)+R_{12}\left(\sin 2 \pi \frac{r-1}{m-1}+W_{1}\left(1-2 \frac{r-1}{m-1}\right)\right)\right]}
$$

Thus for a specific bridge configuration, the interaction forces and corresponding wheel-load distribution factors under symmetric, antisymmetric, and asymmetric load conditions can be evaluated. Note that while the symmetric and antisymmetric forces can be superimposed to obtain the asymmetric condition, Eq. 4.44 should be used to find the asymmetric wheel-load factors. However, Eq. 4.44 is too complex to be used in design since it depends on combinations of $r, m, W_{o}, W_{1}, R_{11}$, and $R_{12}$. Therefore it is convenient to define for every stringer an eccentricity ratio, $E_{R}(r)$, as $W_{f}^{A s y m}$ divided by $W_{f}^{\text {Sym }}$. Then the maximum $E_{R}$ ratio is used to obtain a general formula for the maximum wheel-load factor, $\left(W_{f}^{\text {Asym }}\right)_{\max }$ as a function of the maximum symmetric load factor:

$$
\left(W_{f}^{\text {Asym }}\right)_{\max }=E_{R} \times\left(W_{f}^{\text {Sym }}\right)_{\max }
$$




\subsection{Design procedure}

\subsubsection{General guideline}

The goal of this design procedure is to determine the number of stringers necessary for a given bridge deck subjected to a symmetric loading. The dimensions of the deck are used to evaluate the maximum allowable moment per lane $\left(M_{\max }\right)$ according to AASHTO. Then an equivalent concentrated load $\left(P_{e}\right)$ is calculated as

$$
P_{e}=\frac{4 M_{\max }}{L}
$$

where $L$ is the length of a stringer (span of the bridge).

The equivalent deck properties (calculated as shown in Chapter 3) and the bending and shear stiffnesses $(D$ and $F$ ) for a selected type of stringer are then used to calculate the edge deflection coefficient $W_{o}$ as shown in Section 4.3.1.

Next a design load $\left(P_{d}\right)$ is found from

$$
P_{d}=P_{e} N_{L}\left(W_{f}\right)_{\max }
$$

where $N_{L}$ is the number of lanes and $\left(W_{f}\right)_{\max }$ is found from Eq. 4.40 as a function of number of stringers $m$. 
Two design criteria based on the performance of the stringers and deck are used to confirm that the system will be effective and will satisfy the strength and deformation requirements.

Design criterion based on performance of stringer: The midspan deflection $\delta_{L L}$ of a stringer is evaluated as

$$
\delta_{L L}=P_{d}\left(\frac{L^{3}}{48 D}+\frac{L}{4 \kappa F}\right)(1+D L A)
$$

where $D L A$ is the dynamic load allowance factor, and for short-span bridges $D L A \cong 0.2$. Equation 4.48 is then set equal to the maximum allowable deflection (from AASHTO) to determine the number of stringers required for the bridge deck. Once a suitable system is chosen, the maximum moment due to live load $\left(M_{L L}\right)$ is calculated from

$$
M_{L L}=\frac{P_{d} L}{4}(1+D L A)
$$

Finally, the approximate maximum compression (or tensile) stress $\left(\sigma_{c}\right)$ in the stringer can be found from

$$
\sigma_{c}=\frac{M_{L L} y^{\prime}}{I}
$$


where $y^{\prime}$ is the distance from the neutral axis of the stringer to the top surface of the stringer and $I$ is the moment of inertia of the stringer. This stress can then be compared with the material compressive or tensile strength to confirm that the system will be effective. Also, as an approximation, shear stress in the stringer can be estimated as:

$$
\tau=\frac{P_{d}}{2 A_{w}}(1+D L A)
$$

where $A_{w}$ is the area of the web panels. The shear stress in Eq. 4.51 should be less than the shear strength of the stringer.

Design criterion based on performance of deck: Excessive local deck deformation and punch shear failure may be observed in FRP bridge applications. Thus it is necessary in the design process to check the local deck deflection, and bending and shear stress in a deck section between two adjacent stringers [41, 42]. Further research is needed to address these issues.

\subsubsection{Design Summary}

Based on the design guidelines developed, the following step-by-step design procedures are summarized as: 
1) Define bridge dimensions.

2) Obtain deck and stringer equivalent material properties.

3) Perform the series approximation analysis and determine the number of stringers $m$ based on the required deflection limit.

4) Check the stress level of the stringers.

5) Check the local deck effects: local deformation and bending and shear stresses.

6) Finalize the design.

\subsubsection{Design Examples}

This section presents some examples to illustrate the design procedures.

\section{Example 1:}

A single-lane short-span bridge of $15 \mathrm{ft}$. width and $25 \mathrm{ft}$. span is designed using the 4"x8"x1/4" box sections for the deck assembly and 12"x24" optimized FRP winged-box beams [35] for the stringers (see Fig. 4.4 for fiber lay-up). The material properties for the stringers are: $D=1.248 \times 10^{10} \mathrm{lb}-\mathrm{in}^{4} / \mathrm{in}^{2}$ and $F=1.940 \times 10^{7} \mathrm{lb}-\mathrm{in}^{2} / \mathrm{in}^{2}$. The deflection limit of L/500 and the loading of AASHTO HS-20 are considered, and the number of the stringers $(m)$ is used as the design variable. 
17 layers through the thickness of flanges

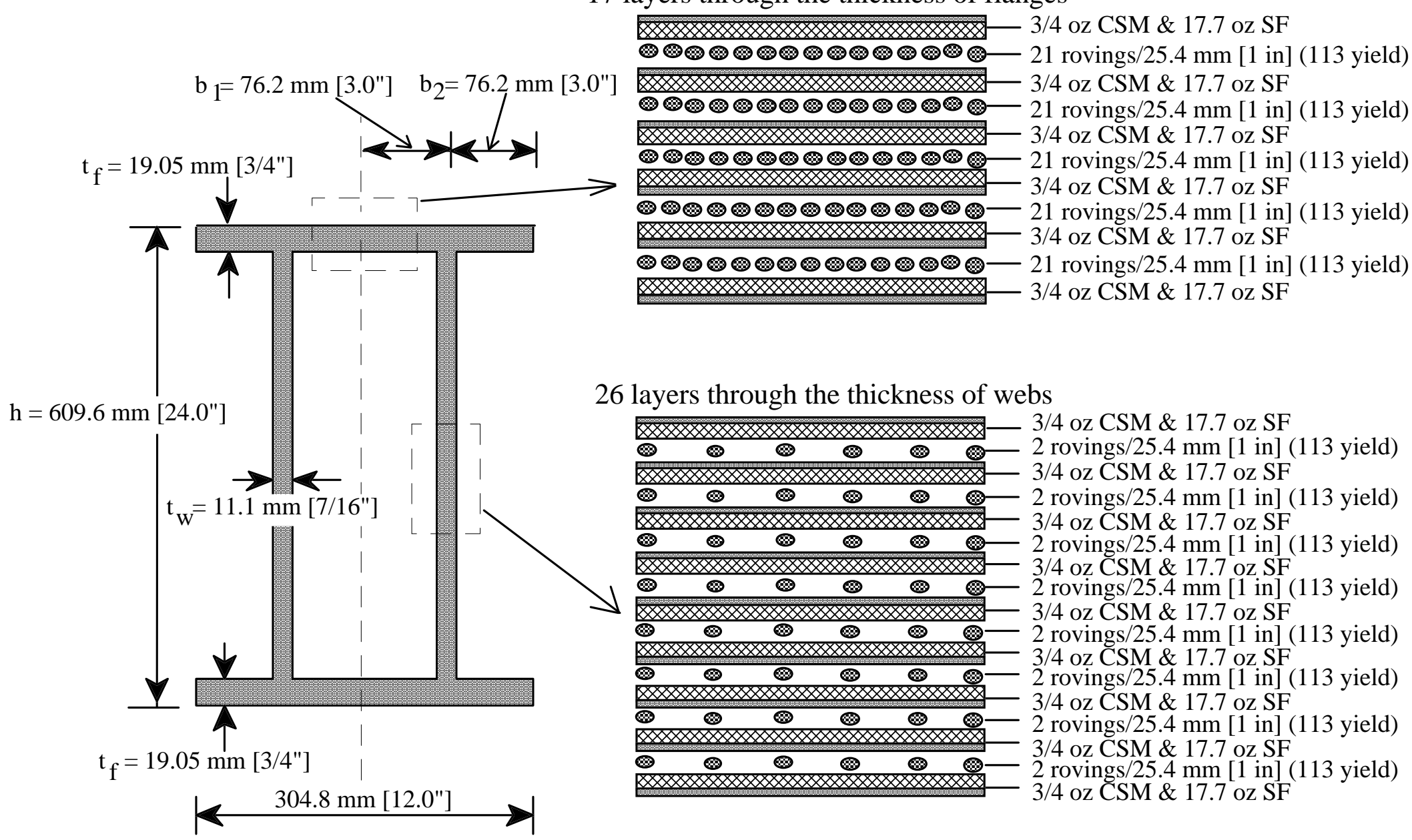

Figure 4.4 Dimensions and panel fiber architectures of optimized Winged-box beam [35] 
The edge deflection coefficient is evaluated from Eq. 4.10a as $W_{o}=1.691$, and the deflection limit from Eqs. $4.46-4.48$ is written in Eq. 4.51 as a function of the number of stringers $m$ :

$$
\delta_{L L}=\frac{L}{500}=M_{\max }\left(\frac{4}{L}\right) N_{L}\left(\frac{1+W_{o}}{m W_{o}+(m-1) \frac{2}{\pi}}\right)\left(\frac{L^{3}}{48 D}+\frac{L}{4 \mathrm{~K} F}\right)(1+D L A)
$$

The DLA factor is taken as 0.20 and the AASHTO maximum lane moment $M_{\max }=207.4$ kip-ft. In this case, $N_{L}=1.0$, and $\kappa$ is taken as 1.0. Solving for $m$, we get $m=6.15$, and therefore, we use $m=7$, which corresponds to 30 inches center-to-center spacing of the 7 longitudinal stringers.

We can now re-evaluate $P_{d}$ from Eq. 4.47, and subsequently, we compute the maximum moment for Eq. 4.49 as $M_{L L}=427.8$ kip-in. Based on this value, the maximum stress in the stringer becomes $\sigma_{\mathrm{c}}=1.48 \mathrm{ksi}$, which is below the allowable stress of $21.2 \mathrm{ksi}[35]$.

\section{Example 2}

These design procedures are applicable to stringers of any type, provided that the bending and shear stiffnesses are known. Consider a two-lane short-span bridge of $30 \mathrm{ft}$. width and $30 \mathrm{ft}$. span using 10"x10”x3/4” FRP box sections (Fig. 4.5) for the deck assembly. 


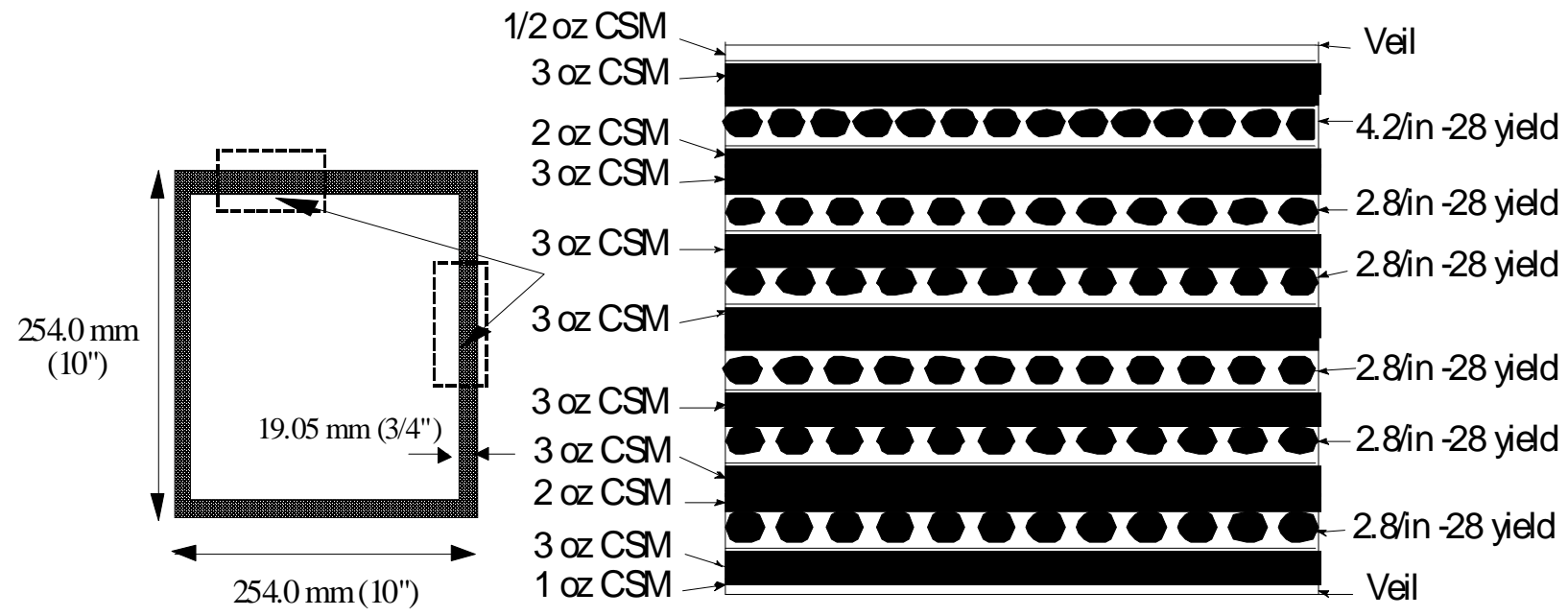

Figure 4.5 Dimensions and panel fiber architecture of 10"x10"x3/4" box beam [30]

The maximum allowable moment $\mathbf{M}_{\max }$, according to AASHTO, is $3385.6 \mathrm{kip}$-in (per lane) and the maximum allowable deflection $\delta_{\mathrm{LL}}$ is 0.72 in. If the 12 "x 24 " FRP wingedbox beams are used, $W_{o}$ is 2.0734 and $m$ is found to be 20 (stringers). The maximum wheel-load distribution factor $W_{f}$ becomes 0.0574 , the design load $P_{d}$ is $4.32 \mathrm{kips}$, the maximum moment $M_{L L}$ is 388.5 kip-in, and the maximum compression stress $\sigma_{\mathrm{c}}$ is 1.35 $\mathrm{ksi}(<21.2 \mathrm{ksi})$. The final mid-span deflection becomes 0.43 in.

Steel wide flange beams can also be used by simply using $D=E I_{x}$ (Young's modulus $E$ and moment of inertia $I_{x}$ ), and $F=G A_{w}$ (modulus of rigidity $G$ and area of

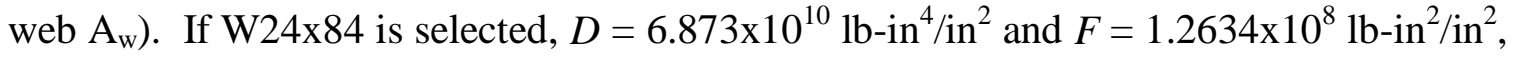
and $\sigma_{\max }=36 \mathrm{ksi}$. The edge deflection coefficient is then 0.4211 , and $m$ is found from Eq. 4.51 to be 5 (stringers). Then $W_{f}$ becomes $0.3055, P_{d}$ is $22.983 \mathrm{kips}, M_{L L}$ is 2068.5 kip-in, and $\sigma_{\mathrm{c}}$ is $10.5 \mathrm{ksi}(<36 \mathrm{ksi})$. The final mid-span deflection becomes $0.41 \mathrm{in}$. 


\subsection{Conclusions}

In this chapter, an analytical approach based on approximate series solution is developed to perform the design of FRP deck-and-stringer bridge system. A one-term series solution including transverse shear deformations is formulated to approximate the analysis of single-span, simply-supported, stiffened and un-stiffened FRP composite plates. The formulation is applied to FRP deck-and-stringer system under symmetric, anti-symmetric and asymmetric load cases, and is later used to define the wheel load distribution factors. The design guidelines of deck-and-bridge system are based on the derived wheel load distribution factors. To validate the present solution, the approximate deflections of the stringers compared with finite element studies for various load cases, and accepted results are achieved.

Based on the approximate series solution and design guidelines developed, two design examples of deck-and-stringer bridge systems are performed to illustrate the capability of the analytical and design procedures. The simplified design analysis procedure proposed in this chapter can be used for the analysis and design optimization of various cases of single-span FRP bridge systems. 


\section{Chapter 5}

\section{EXPERIMENTAL INVESTIGATIONS OF FRP}

\section{COMPOSITE DECKS AND DECK-AND-STRINGER}

\section{BRIDGES}

\subsection{Introduction}

An analytical and numerical prediction of the behavior of FRP composite decks and bridges can alleviate the necessity for an extensive also expensive experimental study. To validate the numerical (finite element) and analytical [the First-order Shear Deformation Macro-flexibility (SDMF)] models presented in the previous Chapters, an experimental program for the evaluation of FRP decks and deck-and-stringer bridges is presented in this chapter. The manufacturing and testing of FRP deck systems are introduced in Section 5.2. The experimental investigations of FRP deck-and-stringer bridges are presented in Section 5.3 with the experimental results being compared with analytical/numerical predictions. 


\subsection{FRP Decks}

In this study, two FRP cellular decks were tested under transverse loading and the deflections and strains were measured. Because of material limitation, the individual box beams were bonded together to form three multi-cellular FRP deck sections. Other possible deck shapes may include single-piece decks and honeycomb decks which are manufactured monolithically as a unit piece or connected several wide-sections by shearlock keys.

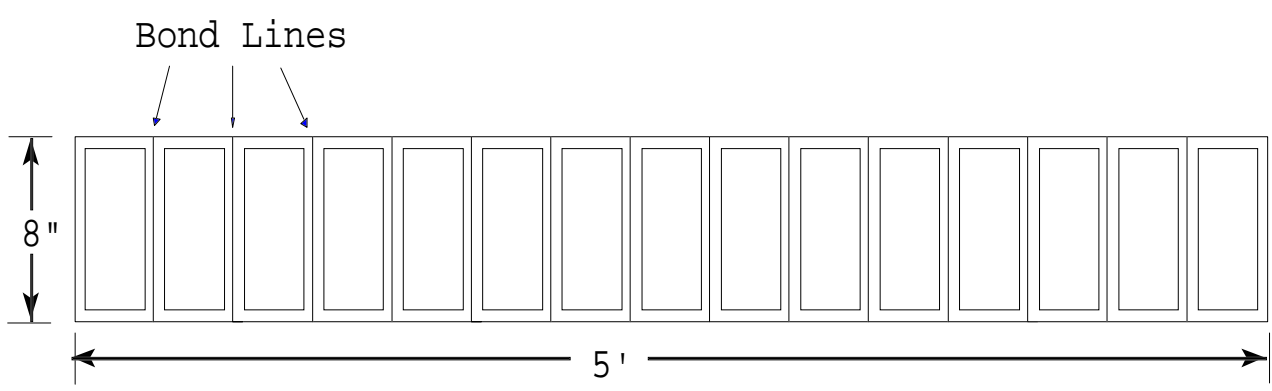

(A) Deck 1 (5'x10'x8")

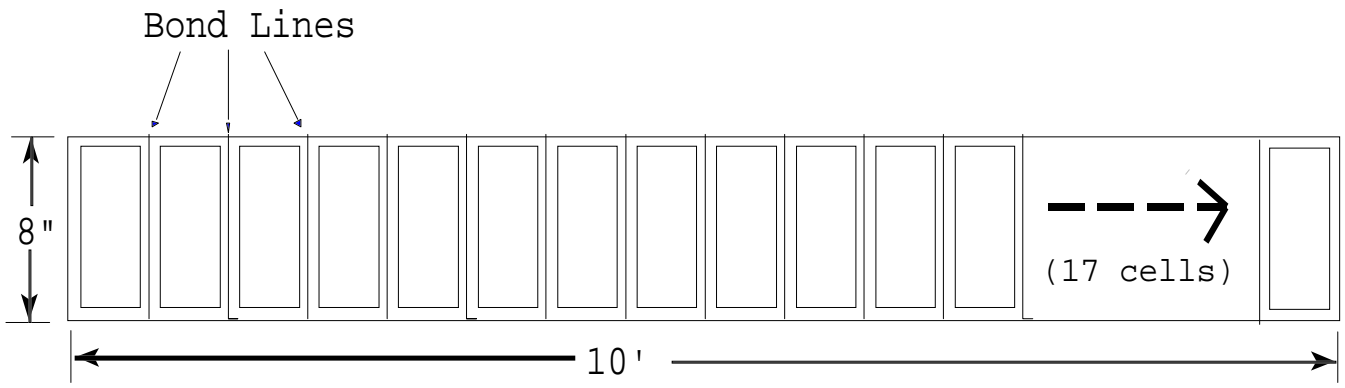

(B) Deck 2 (10'x10'x8")

Figure 5.1 Cross-sections of FRP decks 


\subsubsection{Manufacture of FRP decks}

Two FRP decks (Fig. 5.1) having dimensions of 5'x10'x8" (Deck 1) and 10'x10'x8" (Deck 2) were manufactured by bonding the pultruded FRP box beams together. Creative Pultrusions, Inc., Alum Bank, PA fabricated all of the beams, and each beam was made of E-glass fiber with vinylester resin. In Deck 1, 15 FRP box beams (4"x8"x1/4", see Fig. 2.1 in Chapter 2) of $10 \mathrm{ft}$. long were bonded edgewise with epoxy adhesives (approximately 1/16" thick used, and the bonded interface was allowed at least $24 \mathrm{hr}$. for curing). After Deck 1 had been tested, the original 5'x10'x8" section was further used in the construction of the full-size 10'x10'x8" section (Deck 2), which composed of 304 "x8"x1/4" box beams. During the bonding process, all deck systems were adjusted to insure that proper fit and even deck surfaces were achieved.

\subsubsection{Testing Program}

Both of the decks were tested under transverse loading, and Linear Voltage Differential Transducers (LVDTs) and strain gauges were installed to measure the deflections and strains of deformed decks. The detailed experimental setups and locations of the measured LVDTs and strain gauges for Deck 1 is shown in Figs. 5.2 and 5.3. The load was applied to the center of a 1.5 in thick steel plate using a 30-kip load cell with the 10 "x20" steel plate serving as a patch load. The data acquisition system was used to record the load, displacement and strain data, and these data were automatically tabulated for later input into a graphics program to generate the slope of the load vs. displacement 
curve. Both of the decks were tested under different loading conditions as introduced next.

Deck 1: Deck 1 (5'x10'x8') was tested under three-point bending with span length of $L$ $=9 \mathrm{ft}$ (see Fig. 5.2a). The following three different locations of concentrated loads were studied (Figure 5.3):

Case 1: Load applied at center of deck;

Case 2: Load applied at 16.0 in. to one side from center along the line AA'; Case 3: Load applied at 16.0 in. to other side from center along the line AA'.

For Deck 1, seven LVDTs and six standard 350-ohm strain gauges were bonded to the bottom surface of the deck (Fig. 5.2b and c). The vertical deflections and longitudinal and transverse strains were measured at the different loading and under three different loading cases.

Deck 2: Deck 2 (10'x10'x8') was placed on the top of FRP stringers and tested in a deck-and-stringer bridge system (see Section 5.3). 


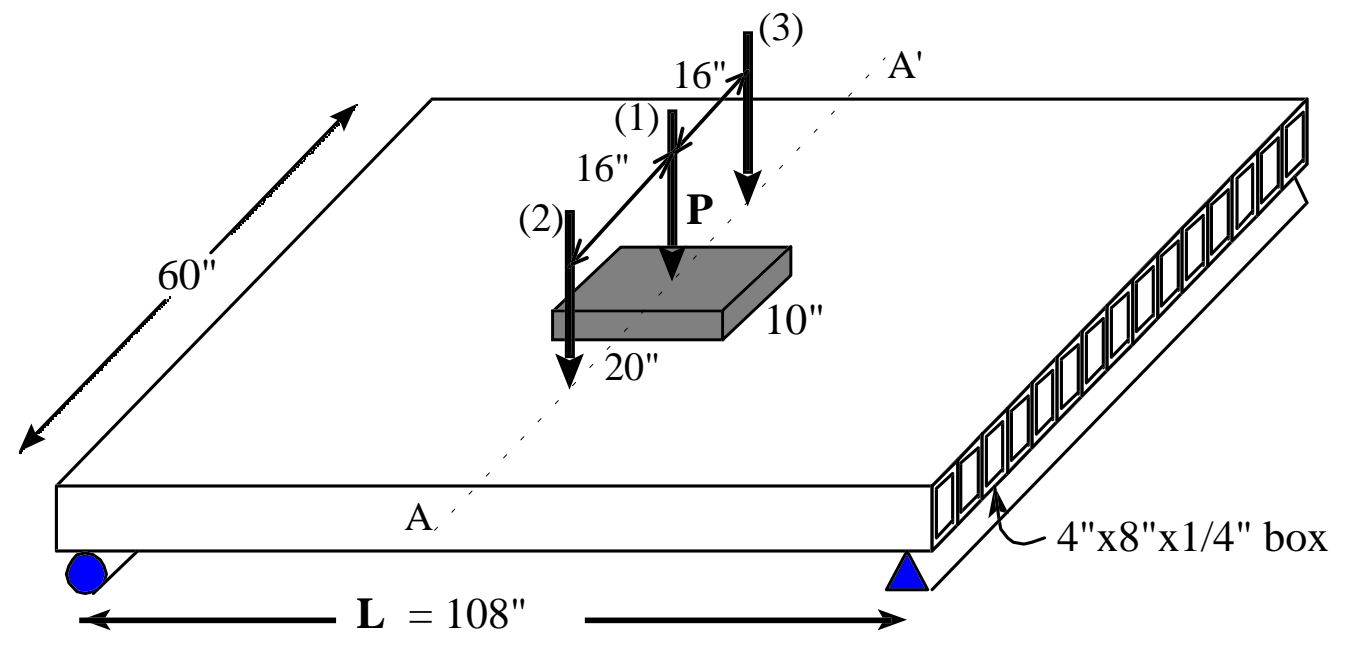

(a) Deck under patch loading

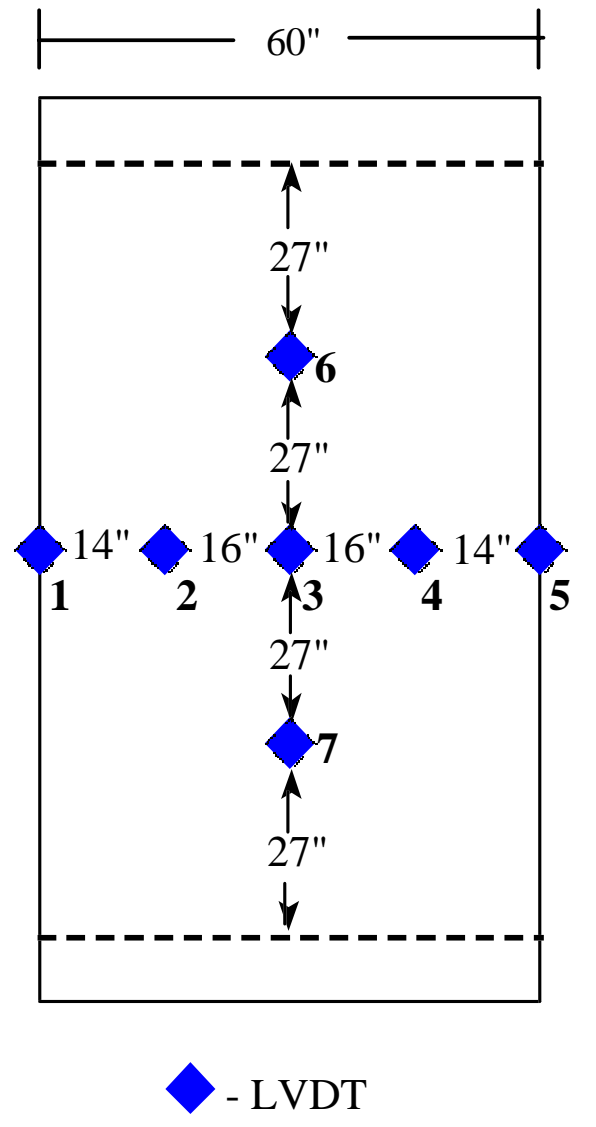

(b) Locations of LVDTs at bottom
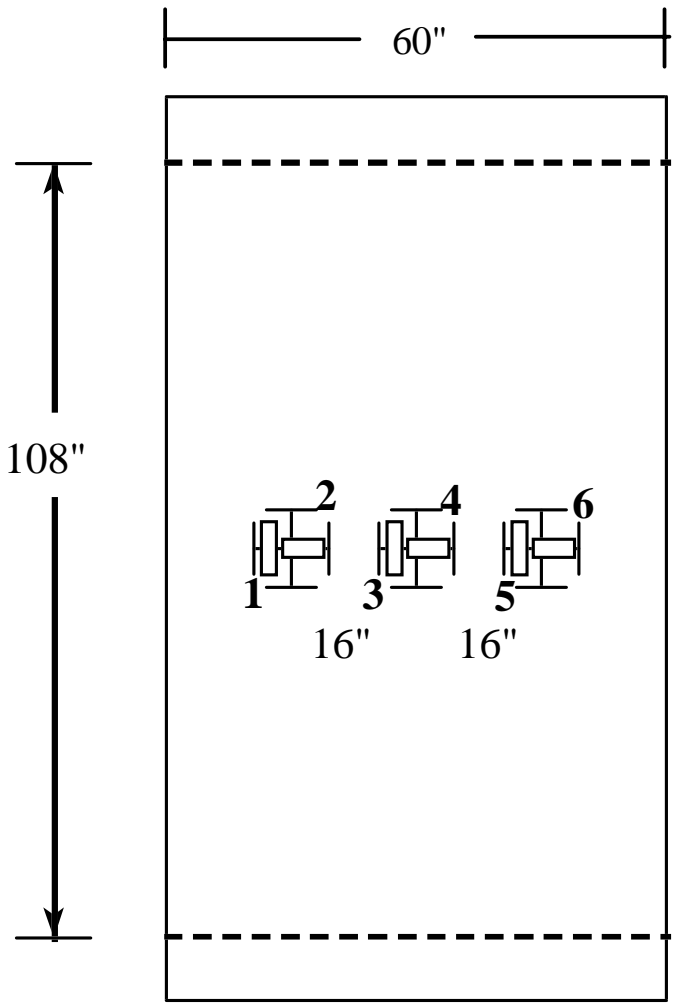

]- longitudinal strain gage

$\square$ - transverse strain gage

(c) Locations of strain gauges at bottom

Figure 5.2 Experimental setup of Deck 1 (5'x10'x8') 


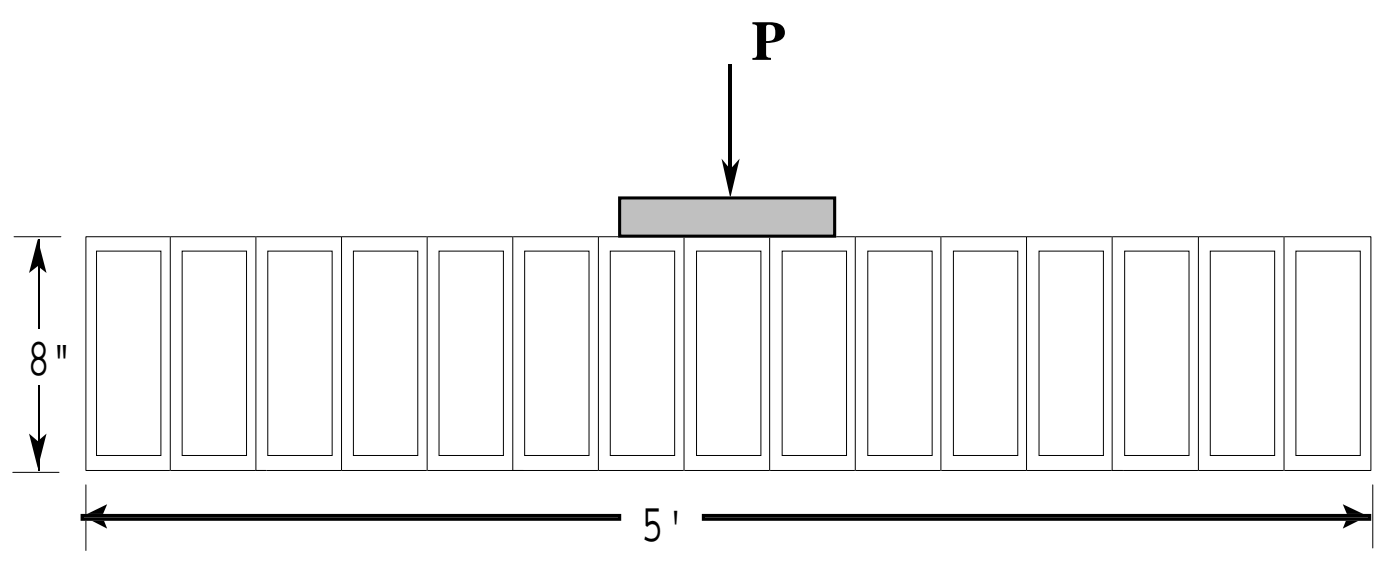

(A) Load Case 1

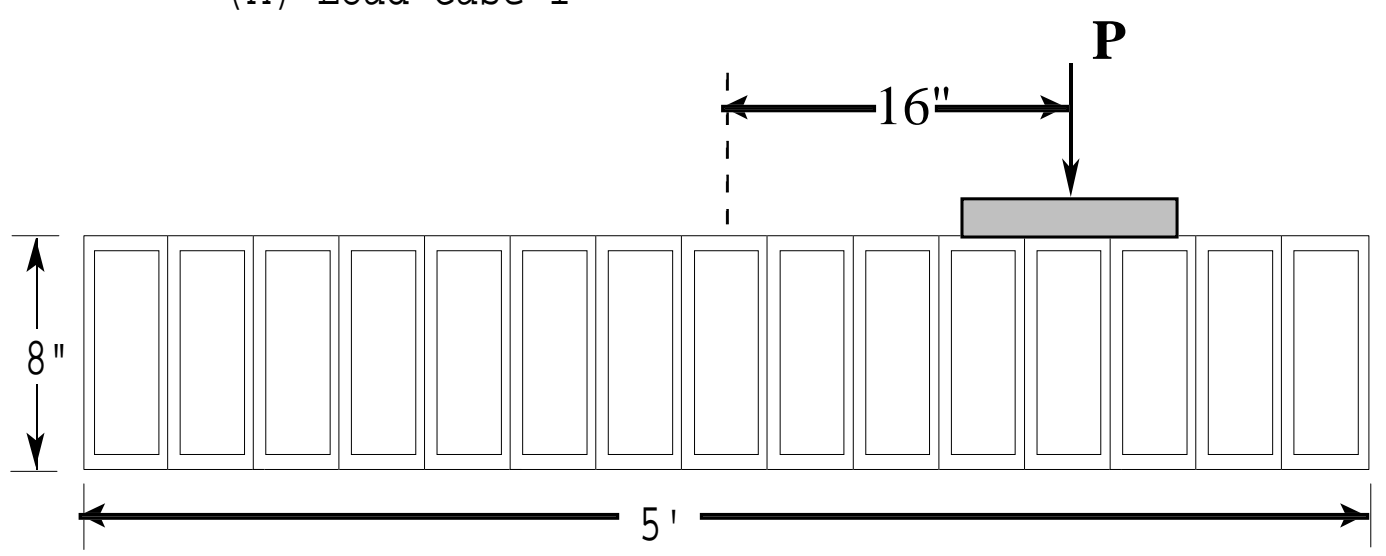

(B) Load Case 2

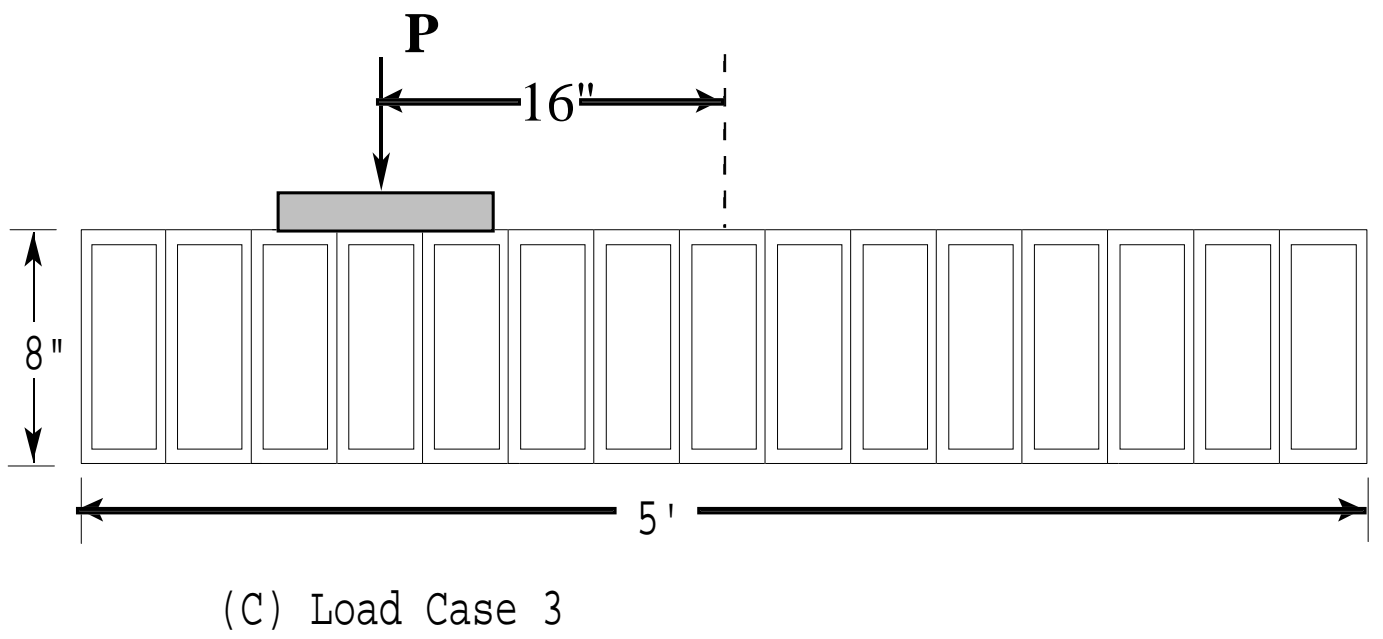

Figure 5.3 Three load cases for Deck 1 


\subsubsection{Testing Results for Deck 1}

In this section, the test results for Deck 1 are summarized; the test data for Deck 2 setting on the FRP stringers are given in Section 5.3 along with the data for the bridge system.

Various values of load vs. displacement and load vs. strain under elastic range were recorded during the tests, and these data were further analyzed using a linear regression program. Due to initial instability of the deck, the first several kilo-pounds (3 to 4 kips) of loading was ignored in the curve-fit of the load vs. displacement and load vs. strain relationships. The deck was tested several times at every loading case, and the average values were used as final results. Tables 5.1 and 5.2 list the displacements and strains for all three load cases.

Table 5.1: Displacement measurements $(\delta / P)$ for each load case

\begin{tabular}{|c|c|c|c|}
\hline Displacement & Load Case 1 & Load Case 2 & Load Case 3 \\
\hline$\delta 1$ (in/kip) & 0.00721 & -0.00191 & 0.01901 \\
\hline$\delta 2$ (in/kip) & 0.00971 & 0.00299 & 0.02330 \\
\hline$\delta 3$ (in/kip) & 0.02036 & 0.00895 & 0.01091 \\
\hline$\delta 4$ (in/kip) & 0.00964 & 0.02139 & 0.00412 \\
\hline$\delta 5$ (in/kip) & 0.00710 & 0.01865 & -0.05410 \\
\hline$\delta 6$ (in/kip) & 0.01544 & 0.00757 & 0.00996 \\
\hline$\delta 7$ (in/kip) & 0.01421 & 0.00798 & 0.00872 \\
\hline
\end{tabular}


Table 5.2 Strain measurements $(\varepsilon / P)$ for each load case

\begin{tabular}{|c|c|c|c|}
\hline Strain & Load Case 1 & Load Case 2 & Load Case 3 \\
\hline$\varepsilon 1(\mu \varepsilon / \mathrm{kip})$ & 28.111 & 24.652 & 83.287 \\
\hline$\varepsilon 2(\mu \varepsilon / \mathrm{kip})$ & -14.701 & -27.072 & -34.467 \\
\hline$\varepsilon 3(\mu \varepsilon / \mathrm{kip})$ & 68.584 & 27.868 & 29.289 \\
\hline$\varepsilon 4(\mu \varepsilon / \mathrm{kip})$ & -15.266 & -21.552 & -31.206 \\
\hline$\varepsilon 5(\mu \varepsilon / \mathrm{kip})$ & 28.361 & 80.044 & 23.750 \\
\hline$\varepsilon 6(\mu \varepsilon / \mathrm{kip})$ & -12.966 & -16.614 & -23.297 \\
\hline
\end{tabular}

As observed during the tests, an off-center loading (Case 2 or 3) caused the opposite side of the deck to deform upward, and thus induced negative deflection measurements at the outside edges of the deck. This effect was mainly due to the unconstrained boundary conditions and the warped nature of the deck. In order to assure that the results shown in Tables 5.1 and 5.2, which were obtained from the best-fit of curves are of sufficient accuracy, $R^{2}$ values were used to evaluate the validity of each test data. Only those values in Tables 5.1 and 5.2 obtained with $R^{2} \geq 0.8$ (where $R^{2}=1.0$ corresponds to a perfect fit) are considered to be adequate values in this study. As indicated in Tables 5.3 and 5.4, the test results for strains and deflections located away from the point of loading showed nonlinear behaviors for load vs. deformation and can not be used. Also, it was observed that the readings for strain \#4 are not valid since the $R^{2}$ value for each of the three load cases was very small. 
Table 5.3 Typical $\boldsymbol{R}^{2}$ values for displacement measurements under each load case.

\begin{tabular}{|c|c|c|c|}
\hline Displacements & Load Case 1 & Load Case 2 & Load Case 3 \\
\hline$\delta 1$ & $\mathbf{0 . 9 8 9}$ & 0.482 & $\mathbf{0 . 9 8 3}$ \\
\hline$\delta 2$ & $\mathbf{0 . 9 7 5}$ & $\mathbf{0 . 8 0 2}$ & $\mathbf{0 . 9 5 1}$ \\
\hline$\delta 3$ & $\mathbf{0 . 9 9 7}$ & $\mathbf{0 . 9 8 2}$ & $\mathbf{0 . 9 8 6}$ \\
\hline$\delta 4$ & $\mathbf{0 . 9 9 1}$ & $\mathbf{0 . 9 9 0}$ & 0.796 \\
\hline$\delta 5$ & $\mathbf{0 . 9 4 5}$ & $\mathbf{0 . 9 8 7}$ & 0.003 \\
\hline$\delta 6$ & $\mathbf{0 . 9 9 4}$ & $\mathbf{0 . 9 7 5}$ & $\mathbf{0 . 9 7 7}$ \\
\hline$\delta 7$ & $\mathbf{0 . 9 8 9}$ & $\mathbf{0 . 8 1 5}$ & $\mathbf{0 . 8 6 4}$ \\
\hline
\end{tabular}

Table 5.4 Typical $\boldsymbol{R}^{2}$ values for strain measurements under each load case.

\begin{tabular}{|c|c|c|c|}
\hline Strain & Load Case 1 & Load Case 2 & Load Case 3 \\
\hline$\varepsilon 1$ & $\mathbf{0 . 9 7 1}$ & 0.092 & $\mathbf{0 . 9 7 8}$ \\
\hline$\varepsilon 2$ & $\mathbf{0 . 8 9 6}$ & 0.112 & 0.689 \\
\hline$\varepsilon 3$ & $\mathbf{0 . 9 9 2}$ & $\mathbf{0 . 9 0 0}$ & $\mathbf{0 . 8 5 4}$ \\
\hline$\varepsilon 4$ & 0.162 & 0.380 & 0.405 \\
\hline$\varepsilon 5$ & $\mathbf{0 . 9 7 8}$ & $\mathbf{0 . 9 8 6}$ & 0.122 \\
\hline$\varepsilon 6$ & 0.799 & $\mathbf{0 . 8 6 4}$ & 0.115 \\
\hline
\end{tabular}

Due to the symmetry of Load Case 2 and Load Case 3 with respect to the center of the deck, the test results related to those two load cases should also be symmetric. In Tables 5.5 and 5.6, the ratios of corresponding deformations between Case 2 and Case 3 are computed and they indicate that the further a measurement is taken away from the center, the less equivalent it is toward to its corresponding measurements in the counterpart load case. This may be mainly due to the localized effects of the deck. 
Table 5.5 Displacement ratio for symmetric load cases

\begin{tabular}{|c|c|c|}
\hline $\begin{array}{c}\text { Displacement } \\
\text { Load Case 2 }\end{array}$ & $\begin{array}{c}\text { Load Case 3 } \\
\text { by Load Case 2 }\end{array}$ & $\begin{array}{c}\text { Displacement } \\
\text { Load Case 3 }\end{array}$ \\
\hline$\delta 1$ & 28.2831 & $\delta 5$ \\
\hline$\delta 2$ & 1.3760 & $\delta 4$ \\
\hline$\delta 3$ & 1.2198 & $\delta 3$ \\
\hline$\delta 4$ & 1.0895 & $\delta 2$ \\
\hline$\delta 5$ & 1.0189 & $\delta 1$ \\
\hline$\delta 6$ & 1.3161 & $\delta 6$ \\
\hline$\delta 7$ & 1.0928 & $\delta 7$ \\
\hline
\end{tabular}

Table 5.6 Strain ratio for symmetric load cases

\begin{tabular}{|c|c|c|}
\hline $\begin{array}{c}\text { Load Case 2 } \\
\text { measurement }\end{array}$ & $\begin{array}{c}\text { Load Case 3/ } \\
\text { Load Case 2 }\end{array}$ & $\begin{array}{c}\text { Load Case 3 } \\
\text { measurement }\end{array}$ \\
\hline$\varepsilon 1$ & 0.9634 & $\varepsilon 5$ \\
\hline$\varepsilon 2$ & 0.8606 & $\varepsilon 6$ \\
\hline$\varepsilon 3$ & 1.0510 & $\varepsilon 3$ \\
\hline$\varepsilon 4$ & 1.4480 & $\varepsilon 4$ \\
\hline$\varepsilon 5$ & 1.0405 & $\varepsilon 1$ \\
\hline$\varepsilon 6$ & 2.0746 & $\varepsilon 2$ \\
\hline
\end{tabular}




\subsubsection{Comparison with Finite Element Modeling}

Again, the finite element program NISA (described in Ch. 4) is used to model the actual FRP decks, and the FE predictions are compared with experimental results. Tables 5.7 and 5.8 indicate that the measured displacements and strains compare well with FE modeling for the symmetric loading case (Case 1) of Deck 1. As noted earlier, values for the asymmetric load cases (Cases 2 and 3) are most accurate close to the applied load. Graphic results of displacement from NISA are given in Figs. 5.4 and 5.5.

Table 5.7 Experimental and finite element comparison for multi-cell box deck under load case 1 (centric)

\begin{tabular}{|c|c|c|c|}
\hline Parameter & Experiment & FE (Actual Deck) & FE Equivalent Plate \\
\hline$\delta 1$ (in/kips) & 0.00721 & 0.00627 & 0.00602 \\
\hline$\delta 2$ (in/kips) & 0.00971 & 0.00861 & 0.00947 \\
\hline$\delta 3$ (in/kips) & 0.02036 & 0.01644 & 0.01900 \\
\hline$\delta 4$ (in/kips) & 0.00964 & 0.00861 & 0.00947 \\
\hline$\delta 5(\mathrm{in} / \mathrm{kips})$ & 0.0071 & 0.00625 & 0.00603 \\
\hline$\delta 6(\mathrm{in} / \mathrm{kips})$ & 0.01544 & 0.01033 & 0.01242 \\
\hline$\delta 7$ (in/kips) & 0.01421 & 0.01033 & 0.01242 \\
\hline$\varepsilon 1(\mu \varepsilon / \mathrm{kips})$ & 28.111 & 28.463 & 31.752 \\
\hline$\varepsilon 2(\mu \varepsilon / \mathrm{kips})$ & -14.701 & -5.832 & -7.813 \\
\hline$\varepsilon 3(\mu \varepsilon / \mathrm{kips})$ & 68.584 & 61.043 & 73.539 \\
\hline$\varepsilon 4(\mu \varepsilon / \mathrm{kips})$ & -15.266 & -26.522 & -23.643 \\
\hline$\varepsilon 5(\mu \varepsilon / \mathrm{kips})$ & 28.361 & 28.463 & 31.752 \\
\hline$\varepsilon 6(\mu \varepsilon / \mathrm{kips})$ & -12.966 & -5.832 & -7.813 \\
\hline
\end{tabular}




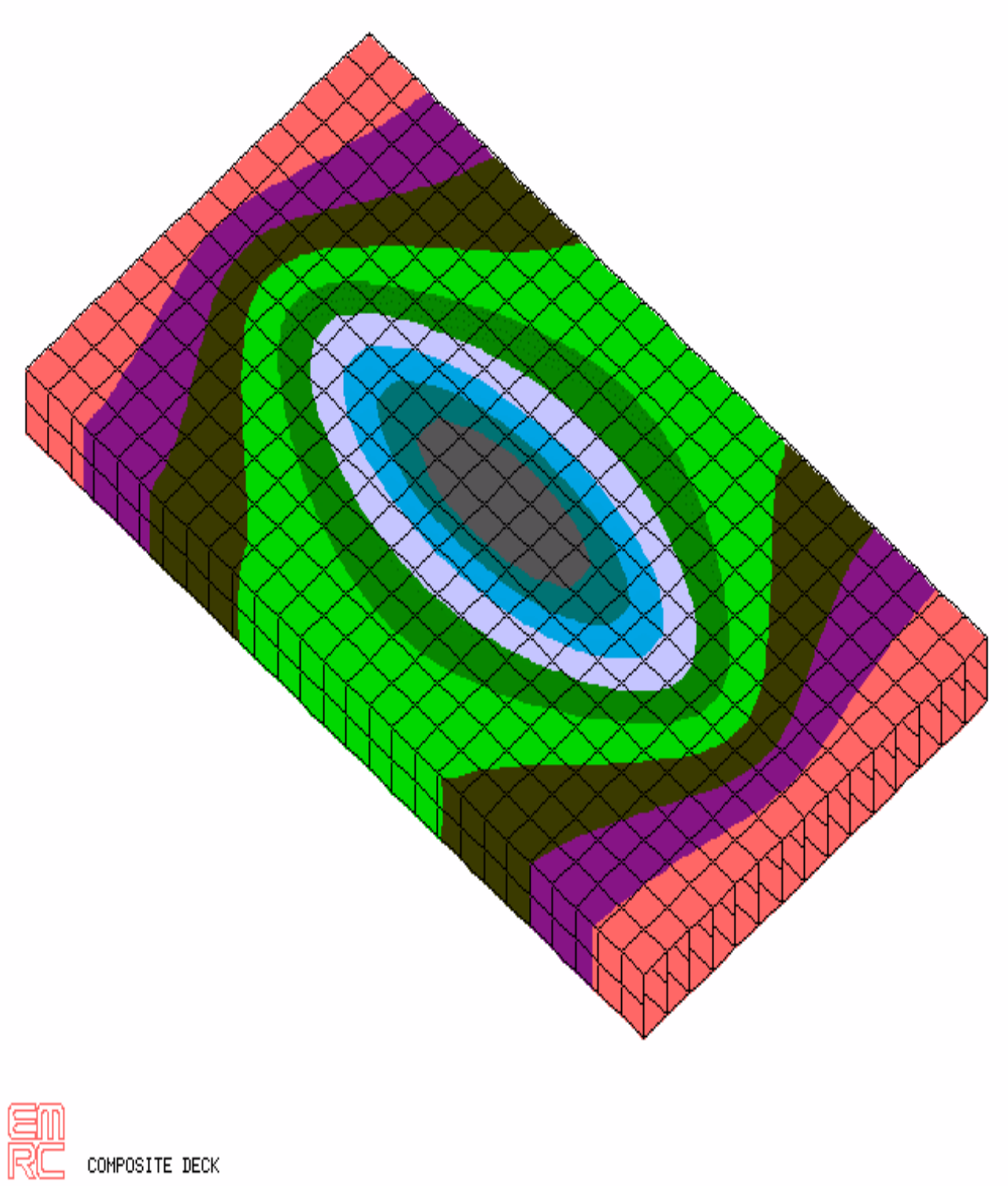

VIEW :,- 0165238

RANGEः 2,040E-05

(Band $* 1,0 \mathrm{E}-3$ )

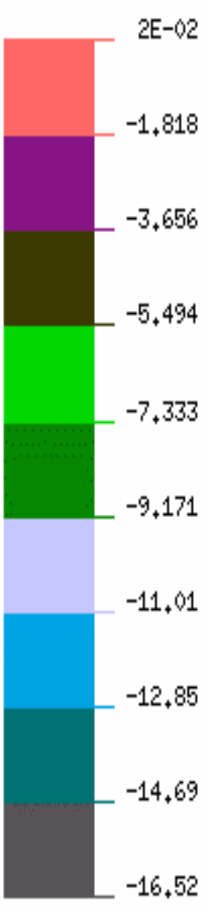

EMRC-NISA/DISPLAY JAN $/ 13 / 98 \quad 13 \div 45 \div 55$

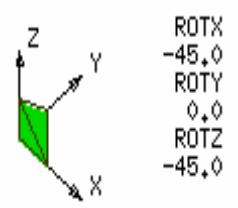

Fig. 5.4 Deck 1 deflections under symmetric loading. 


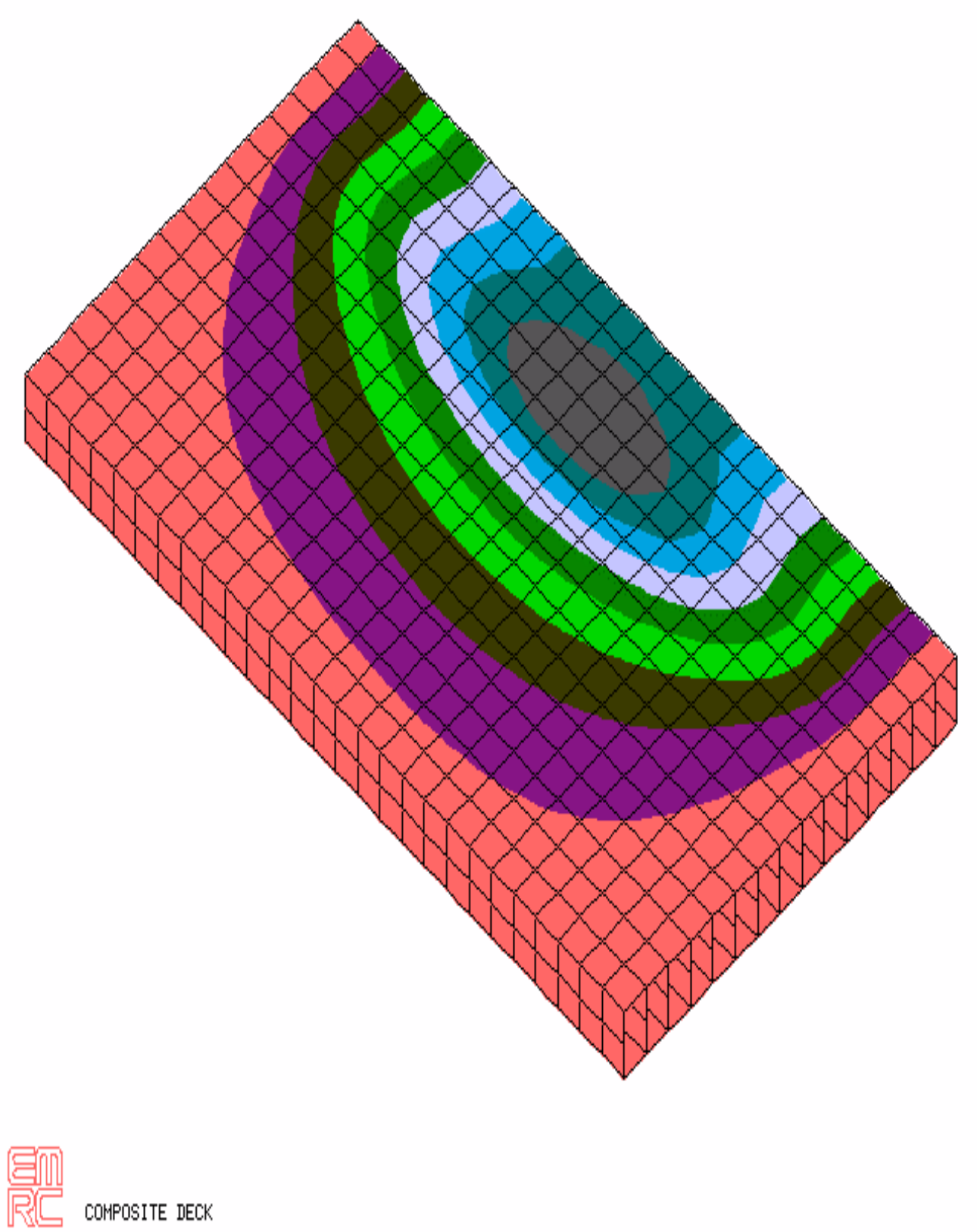

WIEW :,- 0198935

RANGE: 9,244E-05

(Band $* 1,0 E-3$ )

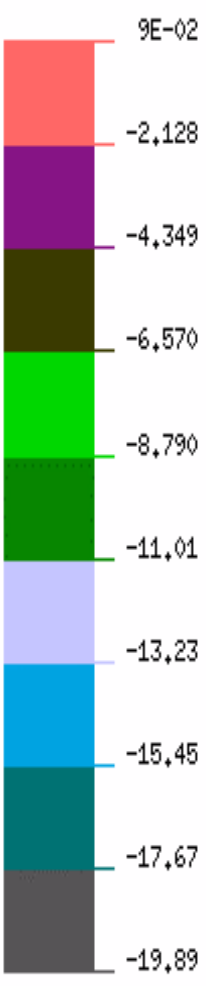

EMRC-NISA/DISPLAY JAN/ $13 / 98 \quad 14 \div 06 \div 46$

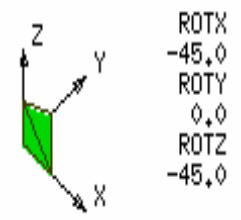

Fig. 5.5 Deck 1 deflections under asymmetric loading 
Table 5.8 Experimental and finite element comparison for multi-cell box deck under load cases 2 and 3 (asymmetric)

\begin{tabular}{|c|c|c|c|c|c|}
\hline $\begin{array}{c}\text { Parameter } \\
\text { Load Cases } 2 \text { and } 3\end{array}$ & $\begin{array}{l}\text { Experiment } \\
\text { Load Case } 2\end{array}$ & $\begin{array}{l}\text { Experiment } \\
\text { Load Case } 3\end{array}$ & $\begin{array}{c}\text { Average of } \\
\text { Load Cases } 2 \text { and } 3\end{array}$ & $\begin{array}{c}\text { FE } \\
\text { Actual Deck }\end{array}$ & $\begin{array}{c}\mathrm{FE} \\
\text { Equivalent Plate }\end{array}$ \\
\hline$\delta 1$ and $\delta 5$ (in/kips) & -0.00191 & -0.05410 & -0.02801 & 0.00094 & -0.00117 \\
\hline$\delta 2$ and $\delta 4$ (in/kips) & 0.00299 & 0.00412 & 0.00356 & 0.00352 & 0.00252 \\
\hline$\delta 3$ and $\delta 3$ (in/kips) & 0.00895 & 0.01091 & 0.00993 & 0.00860 & 0.00901 \\
\hline$\delta 4$ and $\delta 2$ (in/kips) & 0.02139 & 0.02330 & 0.02235 & 0.01940 & 0.02255 \\
\hline$\delta 5$ and $\delta 1$ (in/kips) & 0.01865 & 0.01901 & 0.01883 & 0.01729 & 0.02104 \\
\hline$\delta 6$ and $\delta 6$ (in/kips) & 0.00798 & 0.00996 & 0.00399 & 0.00610 & 0.00632 \\
\hline$\delta 7$ and $\delta 7$ (in/kips) & 0.00757 & 0.00872 & 0.00815 & 0.00566 & 0.00632 \\
\hline$\varepsilon 1$ and $\varepsilon 5(\mu \varepsilon / \mathrm{kips})$ & 24.652 & 23.75 & 24.201 & 12.826 & 8.3270 \\
\hline$\varepsilon 2$ and $\varepsilon 6$ ( $\mu \varepsilon /$ kips $)$ & -16.614 & -23.297 & -19.956 & -2.1760 & -0.6920 \\
\hline$\varepsilon 3$ and $\varepsilon 3$ ( $\mu \varepsilon /$ kips $)$ & 27.868 & 29.289 & 28.579 & 28.528 & 30.010 \\
\hline$\varepsilon 4$ and $\varepsilon 4(\mu \varepsilon /$ kips $)$ & -21.552 & -31.206 & -26.379 & -5.0860 & -6.1420 \\
\hline$\varepsilon 5$ and $\varepsilon 1$ ( $\mu \varepsilon /$ kips $)$ & 80.044 & 83.287 & 81.666 & 70.076 & 84.803 \\
\hline$\varepsilon 6$ and $\varepsilon 2(\mu \varepsilon /$ kips $)$ & -27.072 & -34.467 & -30.770 & -29.444 & -26.792 \\
\hline
\end{tabular}




\subsection{FRP Deck-and-Stringer Bridge System}

Deck 2 (10’x10’x8”) was placed on FRP I-beam stringers (12”x12”x1/2”, see Figure. 2.2 in Chapter 2 for detail lay-up) of $10 \mathrm{ft}$ long to form a deck-and-stringer bridge system. Two bridge systems with different number of stringers were studied: (1) System 1: Deck

2 with three stringers (see Figure 5.6), and (2) System 2: Deck 2 with four stringers (see Figure 5.8). These two bridge systems were tested under transverse loading, and the stringers were simply supported on each end with an effective span of $9 \mathrm{ft}$.

\subsubsection{Testing Program}

Similar to the experimental program for the FRP decks, the deck-and-stringer bridge systems were tested under transverse loading, and LVDTs and strain gauges were installed on the bottom flanges of supporting stringers to measure the deflections and strains of deformed bridge systems. The detailed experimental setups and locations of the measured LVDTs and strain gauges for bridge Systems 1 and 2 are shown in Figs. 5.6b and 5.8b, respectively. The load was applied at various locations of the deck surface by a 1.5 in thick steel plate using a 30-kip load cell. This 10"x20" steel plate served as a patch load with the longer side of the plate being aligned with the longitudinal orientation of the multi-cell deck. Both systems were tested under different loading conditions as introduced next. 
System 1: Bridge System 1 (Figure 5.6) consists of Deck 2 (10'x10'x8”) supported by three I-beam stringers (12"x12"x1/2"), with a stringer span length of $L=9 \mathrm{ft}$. Three strain gages and three LVDTs were attached at the midspan of the stringers on the bottom flange (Figure 5.6b), and they were used to measure the longitudinal strains of the stringers and the vertical deflections of the bridge system. The system was subjected to a concentrated patch load and the following three different locations of concentrated loads were studied (Figure 5.7):

Case 1:Load applied at center of deck;

Case 2:Load applied at 18 in. to one side from center along the deck center line;

Case 3: Load applied at 18 in. to other side from center along the deck center line.

System 2: Bridge System 2 (Figure 5.8) consists of Deck 2 (10'x10'x8') supported by four I-beam stringers (12"x12"x1/2"), with a stringer span length of $L=9 \mathrm{ft}$. Similar to Bridge System 1, four strain gages and four LVDTs were attached at the midspan of the stringers on the bottom flange (Figure 5.8b), and they were used to measure the longitudinal strains of the stringers and the vertical deflections of the bridge system. The system was subjected to the same concentrated patch load, and the following three different locations of concentrated loads were studied for System 2 (Figure 5.9):

Case 1:Load applied at center of deck;

Case 2:Load applied at 18 in. to one side from center along the deck center line;

Case 3: Load applied at 18 in. to other side from center along the deck center line 


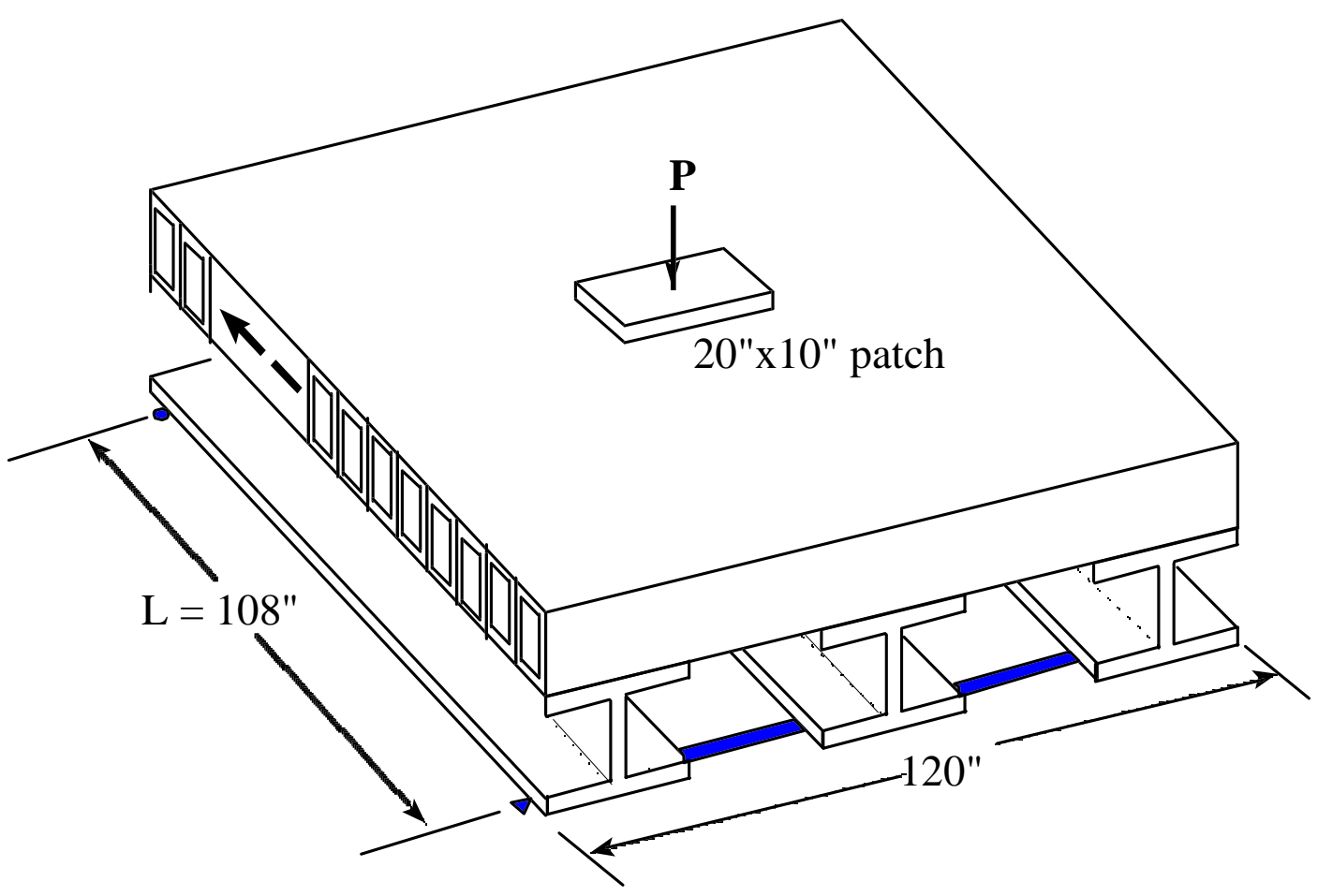

(a) Placement of Load and set-up of deck-and-stringer bridge

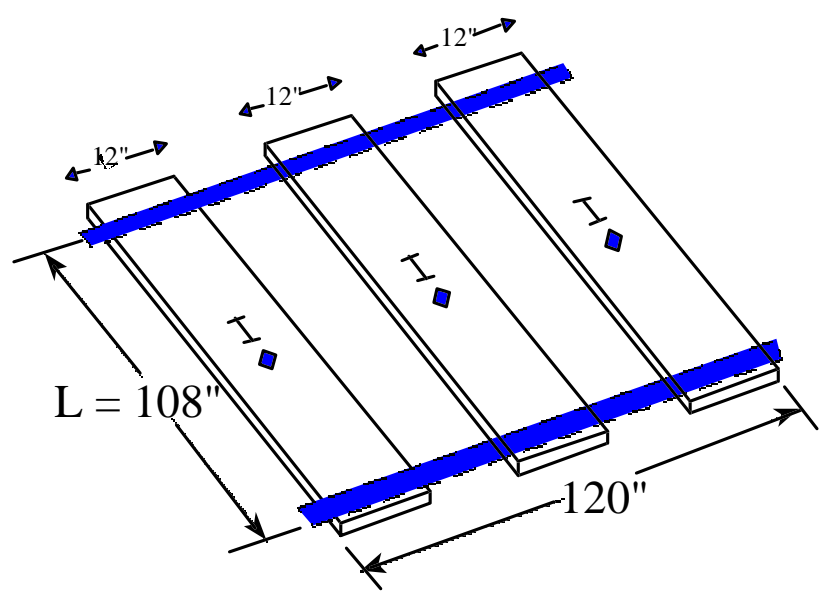

(b) Placement of LVDT's and Strain Gages

Figure. 5.6 Bridge System 1 with three stringers 


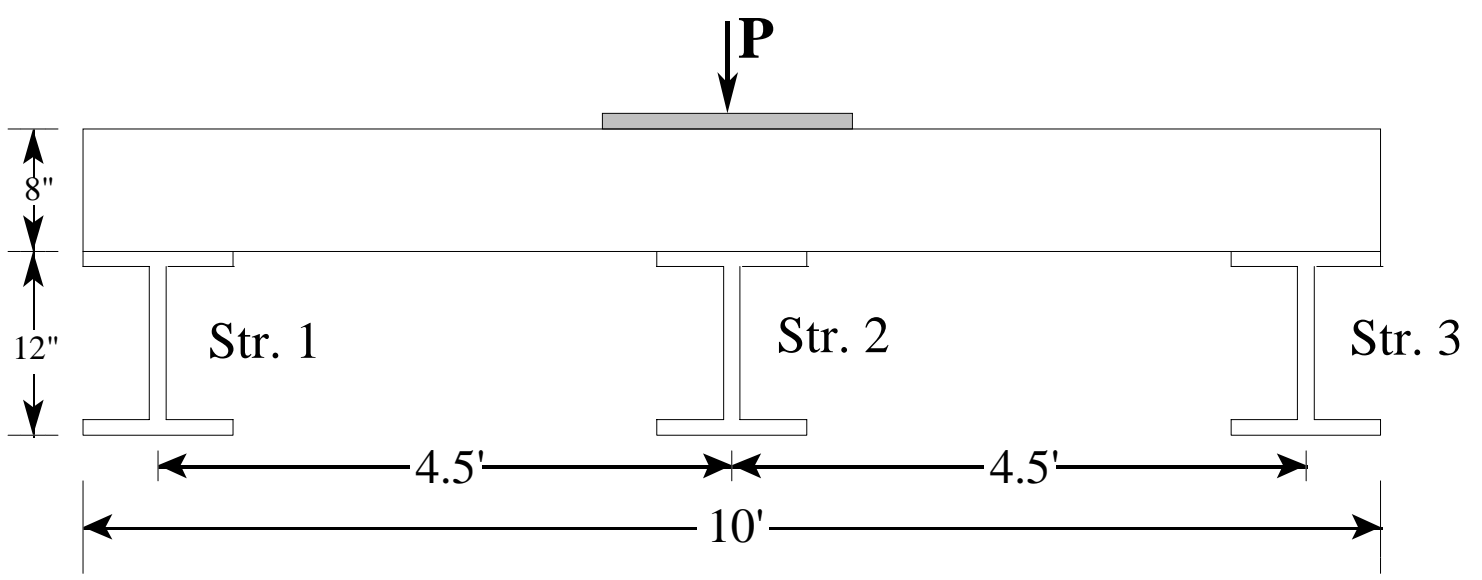

(A) Load Case 1

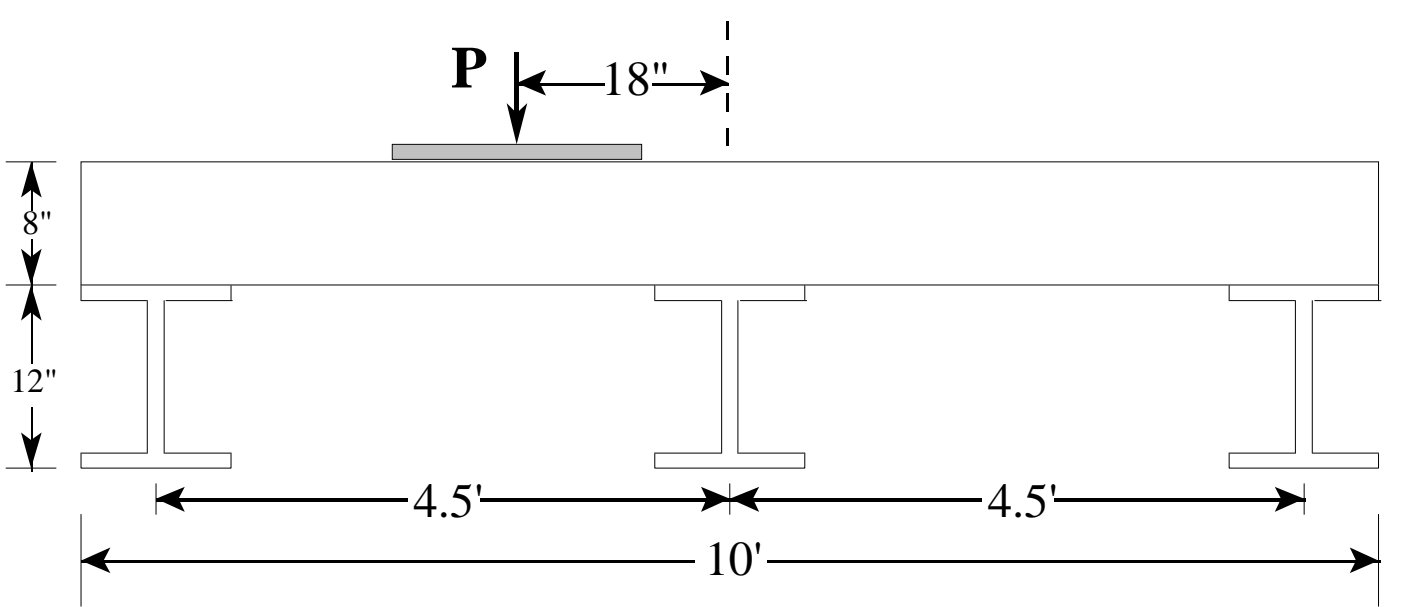

(B) Load Case 2

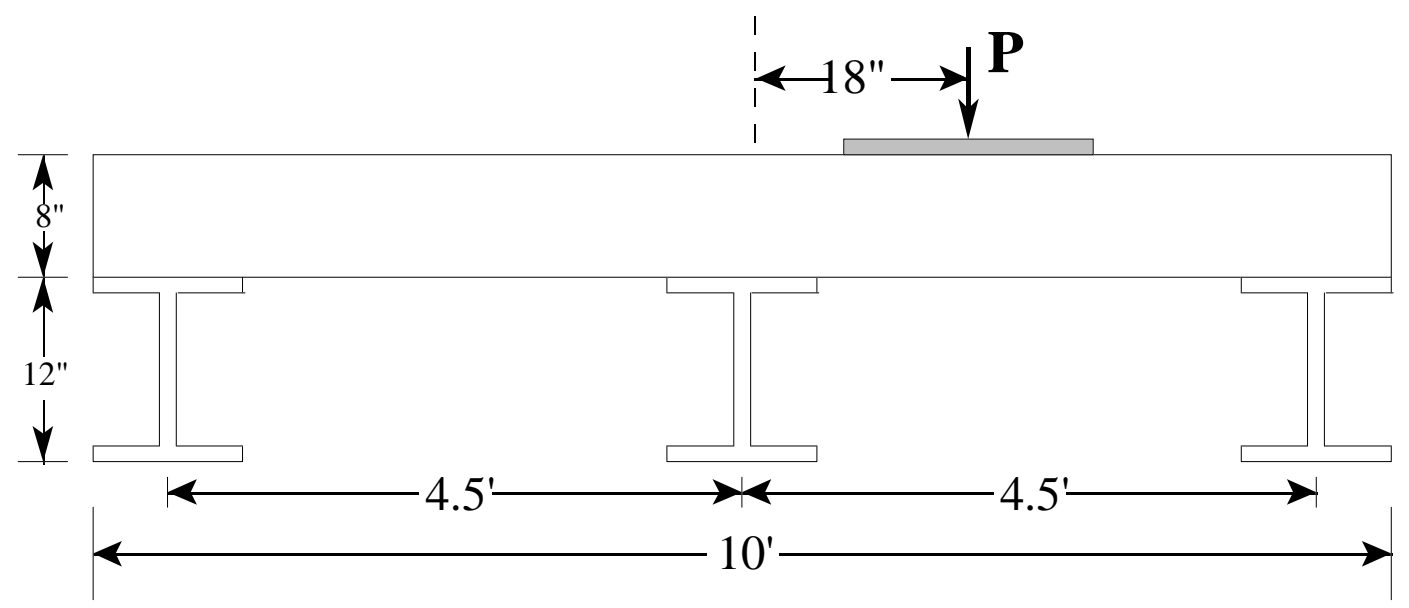

(C) Load Case 3

Figure 5.7 Three load cases for Bridge System 1 


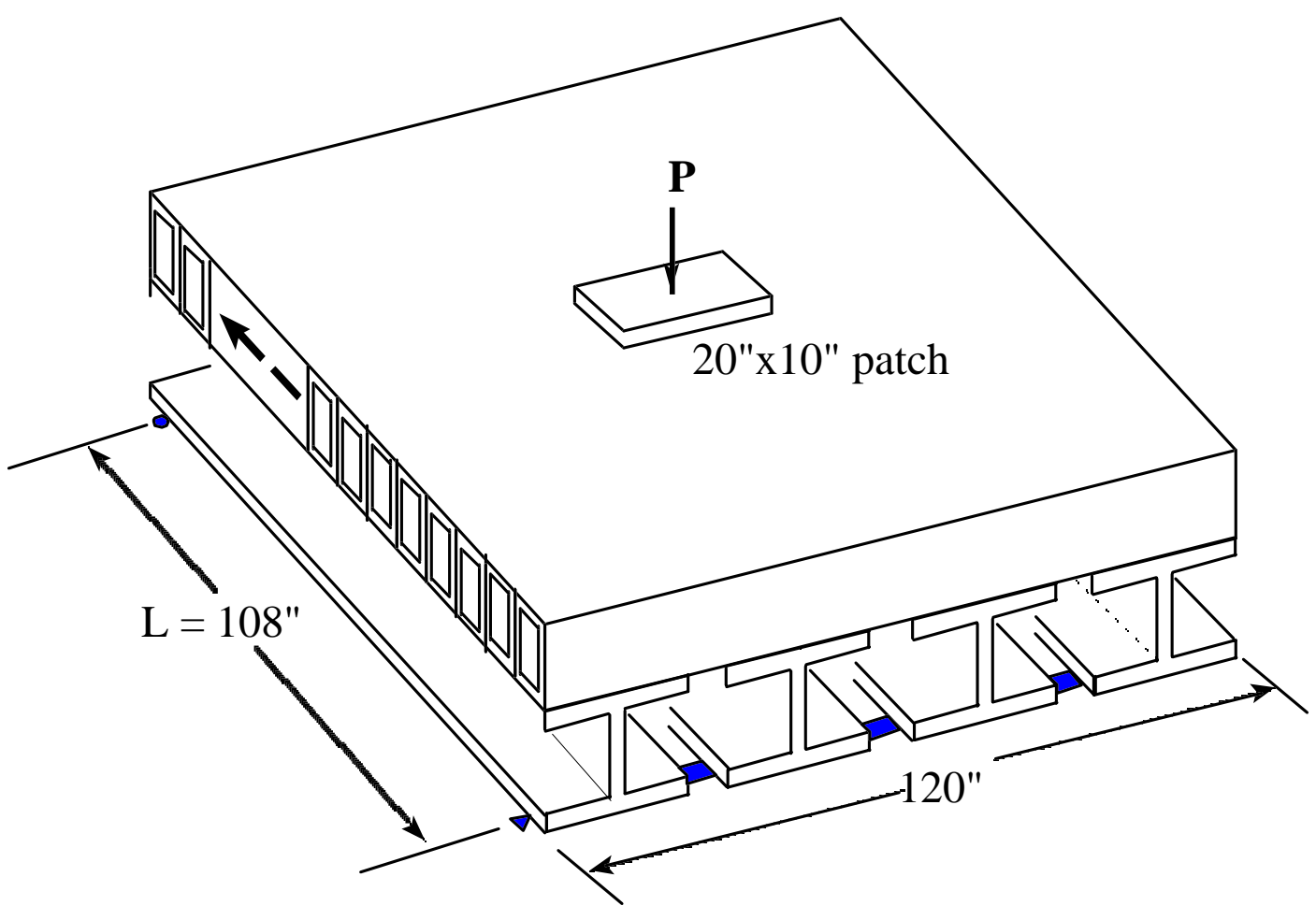

(a) Placement of Load and set-up of deck-and-stringer bridge

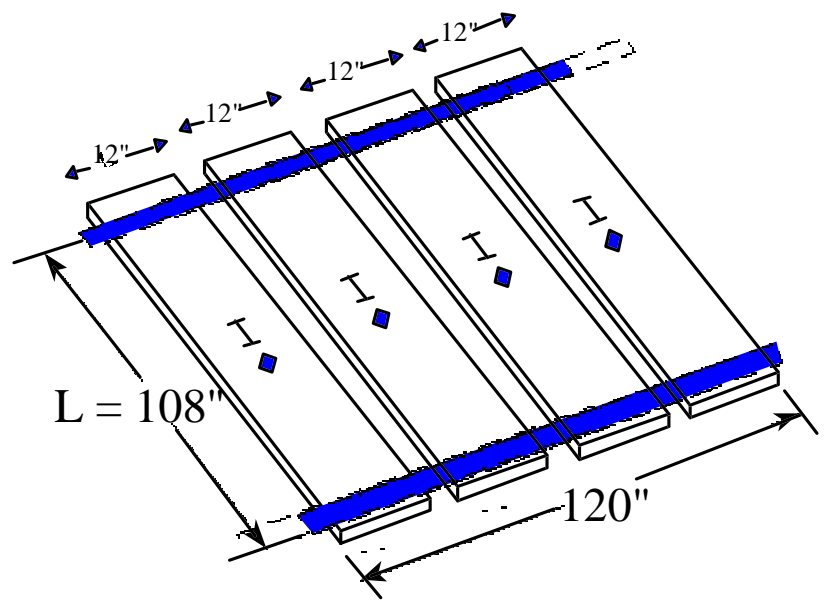

(b) Placement of LVDT's and Strain Gages

Figure. 5.8 Bridge System 2 with four stringers 


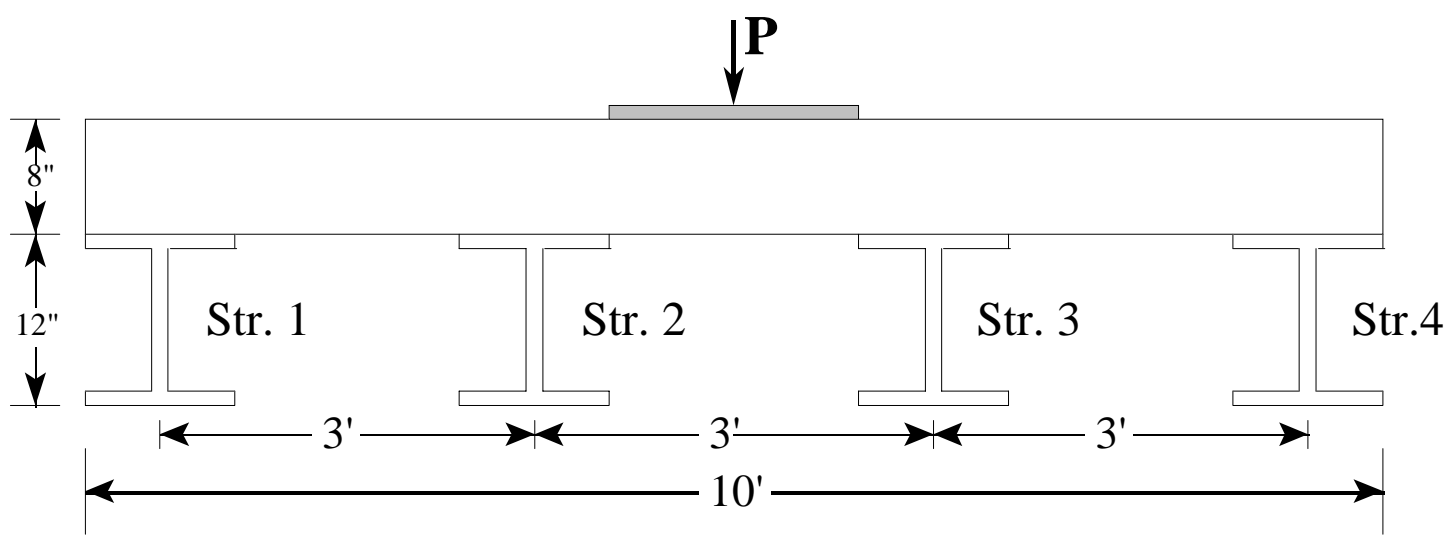

(A) Load Case 1

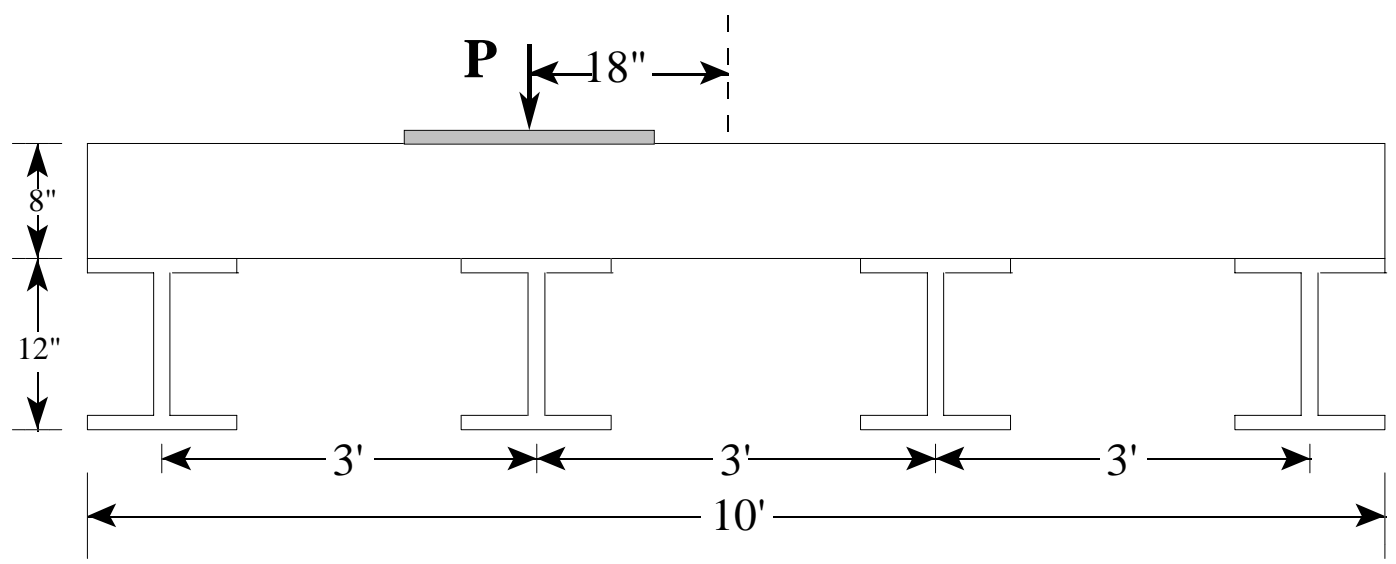

(B) Load Case 2

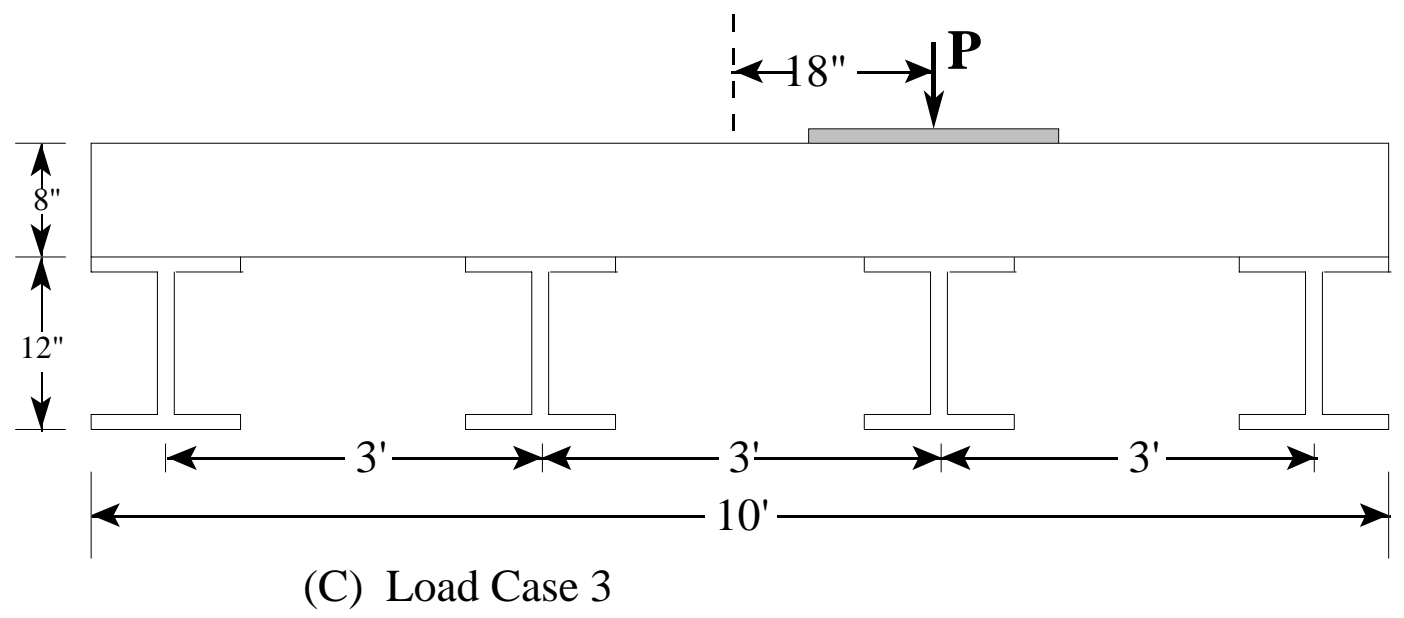

Figure 5.9 Three load cases for Bridge System 2 
For both bridge systems, the outside edges of the deck were clamped to the top flanges of the two outer stringers. Thus the separation of deck and stringers, as well as any upward lifting of deck, were prevented. In most cases, the system was tested up to 10 kips.

In addition to the load cases already listed, tests of both systems with wooden stiffeners added to the end of the stringers at the supports were also conducted for Load Case 3. The purpose of the stiffeners was to determine the influence of localized effects on the overall system response.

\subsubsection{Testing Results}

As with Deck 1, recorded values of displacement and longitudinal strain (taken at the center of the stringers) were analyzed using a linear regression program. The bridge systems were tested many times for each load case, and the average values used as the results. Tables 5.9 to 5.12 present these results for both bridge systems.

Table 5.9 Displacements [ $\delta / P$ (in/kip)] of stringers for Bridge System 1

\begin{tabular}{|c|c|c|c|}
\hline Displacement & Load Case 1 & Load Case 2 & Load Case 3 \\
\hline$\delta 1$ & 0.00415 & 0.00710 & 0.00279 \\
\hline$\delta 2$ & 0.01115 & 0.00899 & 0.01111 \\
\hline$\delta 3$ & 0.00413 & 0.00235 & 0.00729 \\
\hline
\end{tabular}


Table 5.10 Longitudinal strains of stringers $[\varepsilon / P(\mu \varepsilon / \mathrm{kip})$ for Bridge System 1

\begin{tabular}{|c|c|c|c|}
\hline Strain & Load Case 1 & Load Case 2 & Load Case 3 \\
\hline$\varepsilon 1$ & 19.352 & 33.272 & 11.200 \\
\hline$\varepsilon 2$ & 39.428 & 32.458 & 31.688 \\
\hline$\varepsilon 3$ & 20.012 & 11.174 & 36.988 \\
\hline
\end{tabular}

Table 5.11 Displacements [ $\delta / P(\mathrm{in} / \mathrm{kip})]$ of stringers for Bridge System 2

\begin{tabular}{|c|c|c|c|}
\hline Displacement & Load Case 1 & Load Case 2 & Load Case 3 \\
\hline$\delta 1$ & 0.00302 & 0.00557 & 0.00171 \\
\hline$\delta 2$ & 0.00714 & 0.00774 & 0.00493 \\
\hline$\delta 3$ & 0.00757 & 0.00498 & 0.00886 \\
\hline$\delta 4$ & 0.00290 & 0.00164 & 0.00522 \\
\hline
\end{tabular}

Table 5.12 Longitudinal strains of stringers $[\varepsilon / P(\mu \varepsilon /$ kip $)]$ for Bridge System 2

\begin{tabular}{|c|c|c|c|}
\hline Strain & Load Case 1 & Load Case 2 & Load Case 3 \\
\hline$\varepsilon 1$ & 13.992 & 25.558 & 10.666 \\
\hline$\varepsilon 2$ & 24.395 & 30.453 & 13.163 \\
\hline$\varepsilon 3$ & 29.926 & 19.682 & 35.796 \\
\hline$\varepsilon 4$ & 15.119 & 8.673 & 26.362 \\
\hline
\end{tabular}


The effect of the wooden stiffeners is presented in Tables 5.13 and 5.14. The "with by without" columns give a ratio of the deformation for a system with stiffeners to the same system without stiffeners. As evident from these ratios, the effect of the stiffeners was negligible and thus localized effects were not as severe as in the case of Deck 1.

Table 5.13 Effect of end stiffeners on stringer displacements $(\delta / P)$

\begin{tabular}{|c|c|c|c|c|c|c|}
\hline & \multicolumn{3}{|c|}{ Bridge System 1 (Load Case 3) } & \multicolumn{3}{|c|}{ Bridge System 2 (Load Case 3) } \\
\hline $\begin{array}{c}\text { Displacement } \\
\text { (in/kip) }\end{array}$ & $\begin{array}{l}\text { without } \\
\text { stiffener }\end{array}$ & $\begin{array}{c}\text { with } \\
\text { stiffener }\end{array}$ & $\begin{array}{l}\text { with by } \\
\text { without }\end{array}$ & $\begin{array}{l}\text { without } \\
\text { stiffener }\end{array}$ & $\begin{array}{c}\text { with } \\
\text { stiffener }\end{array}$ & $\begin{array}{l}\text { with by } \\
\text { without }\end{array}$ \\
\hline$\delta 1$ & 0.00729 & 0.00734 & 1.007 & 0.00171 & 0.00171 & 1.002 \\
\hline$\delta 2$ & 0.01111 & 0.01118 & 1.006 & 0.00493 & 0.00485 & 0.984 \\
\hline$\delta 3$ & 0.00279 & 0.00277 & 0.994 & 0.00886 & 0.00881 & 0.993 \\
\hline$\delta 4$ & ---- & ---- & ----- & 0.00522 & 0.00531 & 1.019 \\
\hline
\end{tabular}

Table 5.14 Effect of end stiffeners on stringer longitudinal strains $(\varepsilon / P)$

\begin{tabular}{|c|c|c|c|c|c|c|}
\hline & \multicolumn{3}{|c|}{ Bridge System 1 (Load Case 3) } & \multicolumn{2}{c|}{ Bridge System 2 (Load Case 3) } \\
\hline $\begin{array}{c}\text { Strain } \\
(\mu \varepsilon / \text { kip) }\end{array}$ & $\begin{array}{c}\text { without } \\
\text { stiffener }\end{array}$ & $\begin{array}{c}\text { with } \\
\text { stiffener }\end{array}$ & $\begin{array}{c}\text { with/ } \\
\text { without }\end{array}$ & $\begin{array}{c}\text { without } \\
\text { stiffener }\end{array}$ & $\begin{array}{c}\text { with } \\
\text { stiffener }\end{array}$ & $\begin{array}{c}\text { with/ } \\
\text { without }\end{array}$ \\
\hline$\varepsilon 1$ & 36.988 & 38.394 & 1.038 & 10.666 & 10.199 & 0.956 \\
\hline$\varepsilon 2$ & 31.688 & 31.095 & 0.981 & 13.163 & 12.975 & 0.986 \\
\hline$\varepsilon 3$ & 11.200 & 12.002 & 1.072 & 35.796 & 35.341 & 0.987 \\
\hline$\varepsilon 4$ & ---- & ---- & ----- & 26.362 & 26.344 & 1.001 \\
\hline
\end{tabular}


Again, $R^{2}$ values are used to determine the reliability of the data obtained from the bridge system tests. As seen from Tables 5.15 and 5.16, nearly all values are highly reliable, with only a few values from the off-center tests of Bridge System 2 being less than 0.8 .

Table 5.15 $R^{2}$ values for tests of Bridge System 1 (three-stringer)

\begin{tabular}{|c|c|c|c|c|}
\hline Variable & Load Case 1 & Load Case 2 & Load Case 3 & $\begin{array}{c}\text { Load Case 3 } \\
\text { with stiffener }\end{array}$ \\
\hline$\delta 1$ & $\mathbf{0 . 9 9 1}$ & $\mathbf{0 . 9 9 8}$ & $\mathbf{0 . 9 7 2}$ & $\mathbf{0 . 9 7 7}$ \\
\hline$\delta 2$ & $\mathbf{0 . 9 9 7}$ & $\mathbf{0 . 9 9 6}$ & $\mathbf{0 . 9 9 6}$ & $\mathbf{0 . 9 9 7}$ \\
\hline$\delta 3$ & $\mathbf{0 . 9 6 3}$ & $\mathbf{0 . 9 1 6}$ & $\mathbf{0 . 9 8 6}$ & $\mathbf{0 . 9 9 0}$ \\
\hline$\varepsilon 1$ & $\mathbf{0 . 9 5 8}$ & $\mathbf{0 . 9 9 0}$ & $\mathbf{0 . 8 9 0}$ & $\mathbf{0 . 8 6 5}$ \\
\hline$\varepsilon 2$ & $\mathbf{0 . 9 9 0}$ & $\mathbf{0 . 9 8 6}$ & $\mathbf{0 . 9 8 1}$ & $\mathbf{0 . 9 7 8}$ \\
\hline$\varepsilon 3$ & $\mathbf{0 . 9 7 3}$ & $\mathbf{0 . 8 9 1}$ & $\mathbf{0 . 9 8 2}$ & $\mathbf{0 . 9 4 2}$ \\
\hline
\end{tabular}

Table 5.16 $R^{2}$ values for tests of Bridge System 2 (four-stringer)

\begin{tabular}{|c|c|c|c|c|}
\hline Variable & Load Case 1 & Load Case 2 & Load Case 3 & $\begin{array}{c}\text { Load Case 3 } \\
\text { with stiffener }\end{array}$ \\
\hline$\delta 1$ & $\mathbf{0 . 9 9 0}$ & $\mathbf{0 . 9 9 7}$ & $\mathbf{0 . 9 6 7}$ & $\mathbf{0 . 9 6 5}$ \\
\hline$\delta 2$ & $\mathbf{0 . 9 9 2}$ & $\mathbf{0 . 9 9 3}$ & $\mathbf{0 . 9 7 5}$ & $\mathbf{0 . 9 7 6}$ \\
\hline$\delta 3$ & $\mathbf{0 . 9 9 3}$ & $\mathbf{0 . 9 8 4}$ & $\mathbf{0 . 9 9 6}$ & $\mathbf{0 . 9 9 5}$ \\
\hline$\delta 4$ & $\mathbf{0 . 9 4 1}$ & 0.733 & $\mathbf{0 . 9 8 3}$ & $\mathbf{0 . 9 8 1}$ \\
\hline$\varepsilon 1$ & $\mathbf{0 . 9 0 8}$ & $\mathbf{0 . 9 8 0}$ & 0.623 & 0.659 \\
\hline$\varepsilon 2$ & $\mathbf{0 . 9 7 6}$ & $\mathbf{0 . 9 8 9}$ & $\mathbf{0 . 9 0 7}$ & $\mathbf{0 . 9 1 4}$ \\
\hline$\varepsilon 3$ & $\mathbf{0 . 9 4 9}$ & $\mathbf{0 . 9 3 1}$ & $\mathbf{0 . 9 6 7}$ & $\mathbf{0 . 9 7 0}$ \\
\hline$\varepsilon 4$ & $\mathbf{0 . 8 4 7}$ & 0.605 & $\mathbf{0 . 9 6 5}$ & $\mathbf{0 . 9 6 2}$ \\
\hline
\end{tabular}


Finally, system symmetry is determined by comparing corresponding deformations of Load Cases 2 and 3. Tables 5.17 and 5.18 present these comparisons and show that both bridge systems behaved similarly, with the most reliable test results being near the point of the applied load.

Table 5.17 Deformation ratios for system symmetry (Bridge System 1)

\begin{tabular}{|c|c|c|}
\hline Load Case 2 & $\begin{array}{c}\text { Load Case 3 } \\
\text { by Load Case 2 }\end{array}$ & Load Case 3 \\
\hline$\delta 1$ & 1.027 & $\delta 3$ \\
\hline$\delta 2$ & 1.248 & $\delta 2$ \\
\hline$\delta 3$ & 1.187 & $\delta 1$ \\
\hline$\varepsilon 1$ & 1.112 & $\varepsilon 3$ \\
\hline$\varepsilon 2$ & 0.976 & $\varepsilon 2$ \\
\hline$\varepsilon 3$ & 1.002 & $\varepsilon 1$ \\
\hline
\end{tabular}

Table 5.18 Deformation ratios for system symmetry (Bridge System 2)

\begin{tabular}{|c|c|c|}
\hline Load Case 2 & $\begin{array}{c}\text { Load Case 3 } \\
\text { by Load Case 2 }\end{array}$ & Load Case 3 \\
\hline$\delta 1$ & 0.937 & $\delta 4$ \\
\hline$\delta 2$ & 1.145 & $\delta 3$ \\
\hline$\delta 3$ & 0.990 & $\delta 2$ \\
\hline$\delta 4$ & 1.043 & $\delta 1$ \\
\hline$\varepsilon 1$ & 1.031 & $\varepsilon 4$ \\
\hline$\varepsilon 2$ & 1.175 & $\varepsilon 2$ \\
\hline$\varepsilon 3$ & 0.669 & $\varepsilon 1$ \\
\hline$\varepsilon 4$ & 1.230 & \\
\hline
\end{tabular}




\subsubsection{Comparison with Finite Element Modeling and Theoretical Predictions}

Again, the finite element program NISA (described in Ch. 4) is used to model the actual FRP bridge systems, and the FE predictions are compared with the experimental and thoretical results. Tables 5.19 to 5.22 indicate that the measured displacements and strains compare well with both the FE modeling and predicted values for the symmetric loading case (Case 1) of Deck 1. As noted earlier, values for the asymmetric load cases (Cases 2 and 3) are most accurate close to the applied load. Figure 5.10 presents graphic results of Load Case 1 for both the 3-stringer and 4-stringer systems. Graphic results from NISA are given in Figs. 5.11 to 5.18. 
Table 5.19 Comparison of experimental, FE, and theoretical values for Load Case 1 (3-stringer symmetric)

\begin{tabular}{|c|c|c|c|}
\hline Parameter & Experiment & FE (Actual Deck) & Theoretical \\
\hline$\delta 1$ (in/kips) & 0.00415 & 0.00396 & 0.00470 \\
\hline$\delta 2$ (in/kips) & 0.01115 & 0.00893 & 0.00941 \\
\hline$\delta 3$ (in/kips) & 0.00413 & 0.00396 & 0.00470 \\
\hline$\varepsilon 1(\mu \varepsilon /$ kips) & 19.352 & 14.640 & NA* \\
\hline$\varepsilon 2(\mu \varepsilon /$ kips $)$ & 39.428 & 37.762 & NA \\
\hline$\varepsilon 3(\mu \varepsilon /$ kips $)$ & 20.012 & 14.640 & NA \\
\hline
\end{tabular}

* NA - Not applicable

Table 5.20 Comparison of experimental, FE, and theoretical values for Load Case 1 (4-stringer symmetric)

\begin{tabular}{|c|c|c|c|}
\hline Parameter & Experiment & FE (Actual Deck) & Theoretical \\
\hline$\delta 1$ (in/kips) & 0.00302 & 0.00261 & 0.00369 \\
\hline$\delta 2$ (in/kips) & 0.00714 & 0.00611 & 0.00689 \\
\hline$\delta 3$ (in/kips) & 0.00757 & 0.00611 & 0.00689 \\
\hline$\delta 4$ (in/kips) & 0.00290 & 0.00261 & 0.00369 \\
\hline$\varepsilon 1$ ( $\mu \varepsilon /$ kips) & 13.992 & 9.318 & NA \\
\hline$\varepsilon 2(\mu \varepsilon /$ kips $)$ & 24.395 & 25.397 & NA \\
\hline$\varepsilon 3$ ( $\mu \varepsilon /$ kips $)$ & 29.926 & 25.397 & NA \\
\hline$\varepsilon 4$ ( $\mu \varepsilon /$ kips $)$ & 15.119 & 9.318 & NA \\
\hline
\end{tabular}


Table 5.21 Comparison of experimental, FE, and theoretical values for Load Cases 2 and 3 (3-stringer asymmetric)

\begin{tabular}{|c|c|c|c|c|c|}
\hline $\begin{array}{c}\text { Parameter } \\
\text { Load Cases } 2 \text { and } 3\end{array}$ & $\begin{array}{l}\text { Experiment } \\
\text { Load Case } 2\end{array}$ & $\begin{array}{l}\text { Experiment } \\
\text { Load Case } 3\end{array}$ & $\begin{array}{c}\text { Average of } \\
\text { Load Cases } 2 \text { and } 3\end{array}$ & $\begin{array}{c}\text { FE } \\
\text { Actual Deck }\end{array}$ & Theoretical \\
\hline$\delta 1$ and $\delta 3$ (in/kips) & 0.00710 & 0.00729 & 0.00720 & 0.00705 & 0.00441 \\
\hline$\delta 2$ and $\delta 2$ (in/kips) & 0.00899 & 0.01111 & 0.01005 & 0.00811 & 0.00815 \\
\hline$\delta 3$ and $\delta 1$ (in/kips) & 0.00235 & 0.00279 & 0.00257 & 0.00174 & 0.00374 \\
\hline$\varepsilon 1$ and $\varepsilon 3(\mu \varepsilon /$ kips $)$ & 33.272 & 36.988 & 35.130 & 27.181 & $\mathrm{NA}$ \\
\hline$\varepsilon 2$ and $\varepsilon 2(\mu \varepsilon / \mathrm{kips})$ & 32.458 & 31.688 & 32.073 & 33.722 & NA \\
\hline$\varepsilon 3$ and $\varepsilon 1$ ( $\mu \varepsilon / \mathrm{kips})$ & 11.174 & 11.200 & 11.187 & 6.164 & NA \\
\hline
\end{tabular}


Table 5.22 Comparison of experimental, FE, and theoretical values for Load Cases 2 and 3 (4-stringer asymmetric)

\begin{tabular}{|c|c|c|c|c|c|}
\hline $\begin{array}{c}\text { Parameter } \\
\text { Load Cases } 2 \text { and } 3\end{array}$ & $\begin{array}{l}\text { Experiment } \\
\text { Load Case } 2\end{array}$ & $\begin{array}{l}\text { Experiment } \\
\text { Load Case } 3\end{array}$ & $\begin{array}{c}\text { Average of } \\
\text { Load Cases } 2 \text { and } 3\end{array}$ & $\begin{array}{c}\text { FE } \\
\text { Actual Deck }\end{array}$ & Theoretical \\
\hline$\delta 1$ and $\delta 4$ (in/kips) & 0.00557 & 0.00522 & 0.00540 & 0.00530 & 0.00352 \\
\hline$\delta 2$ and $\delta 3$ (in/kips) & 0.00774 & 0.00886 & 0.00830 & 0.00714 & 0.00778 \\
\hline$\delta 3$ and $\delta 2$ (in/kips) & 0.00498 & 0.00493 & 0.00496 & 0.00429 & 0.00415 \\
\hline$\delta 4$ and $\delta 1$ (in/kips) & 0.00164 & 0.00171 & 0.00168 & 0.00079 & 0.00287 \\
\hline$\varepsilon 1$ and $\varepsilon 4(\mu \varepsilon / \mathrm{kips})$ & 25.558 & 26.362 & 25.960 & 19.809 & NA \\
\hline$\varepsilon 2$ and $\varepsilon 3$ ( $\mu \varepsilon / \mathrm{kips})$ & 30.453 & 35.796 & 33.125 & 30.739 & NA \\
\hline$\varepsilon 3$ and $\varepsilon 2(\mu \varepsilon / \mathrm{kips})$ & 19.682 & 13.163 & 16.423 & 16.468 & NA \\
\hline$\varepsilon 4$ and $\varepsilon 1$ ( $\mu \varepsilon /$ kips $)$ & 8.673 & 10.666 & 9.670 & 2.750 & NA \\
\hline
\end{tabular}




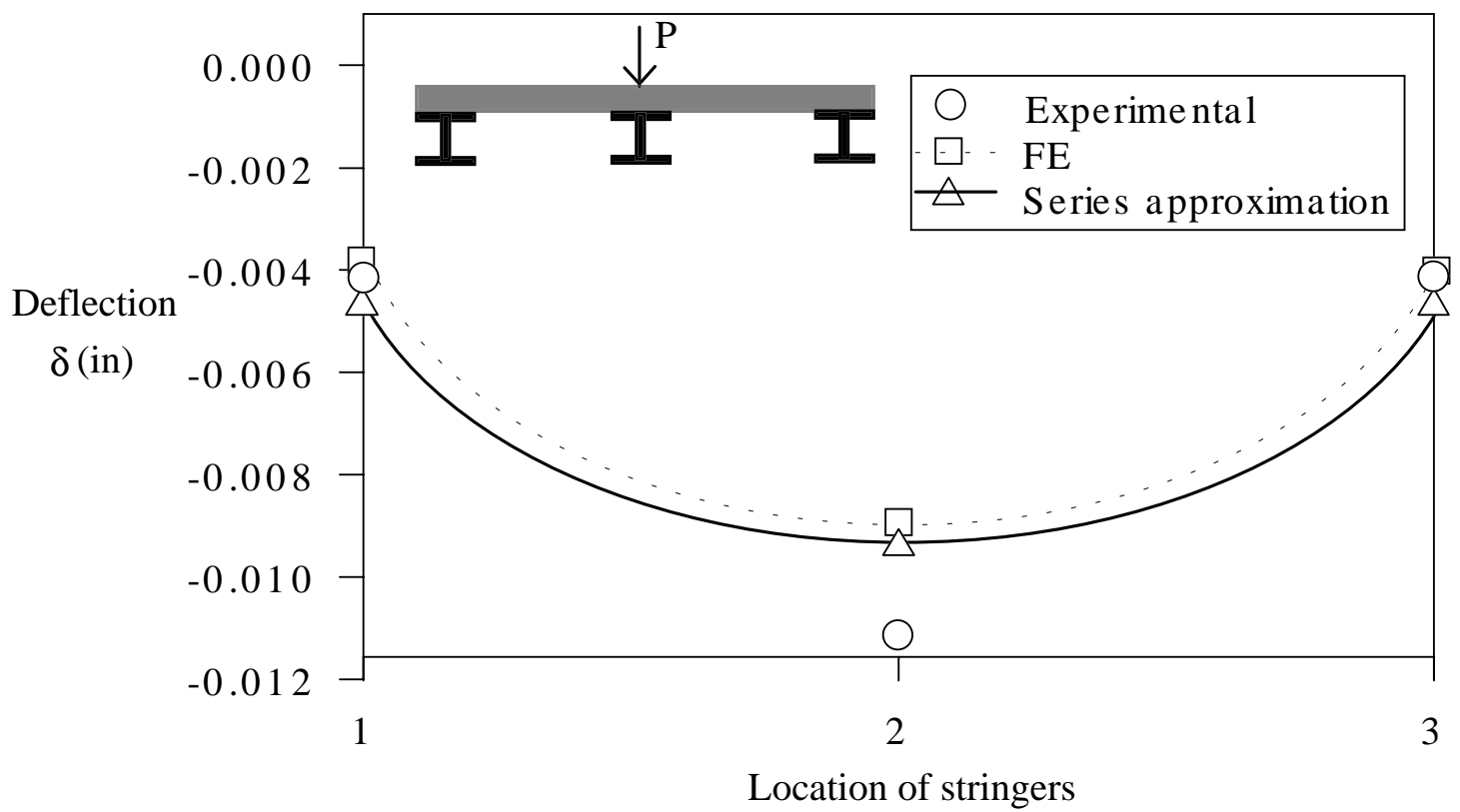

(a) Bridge system with three stringers

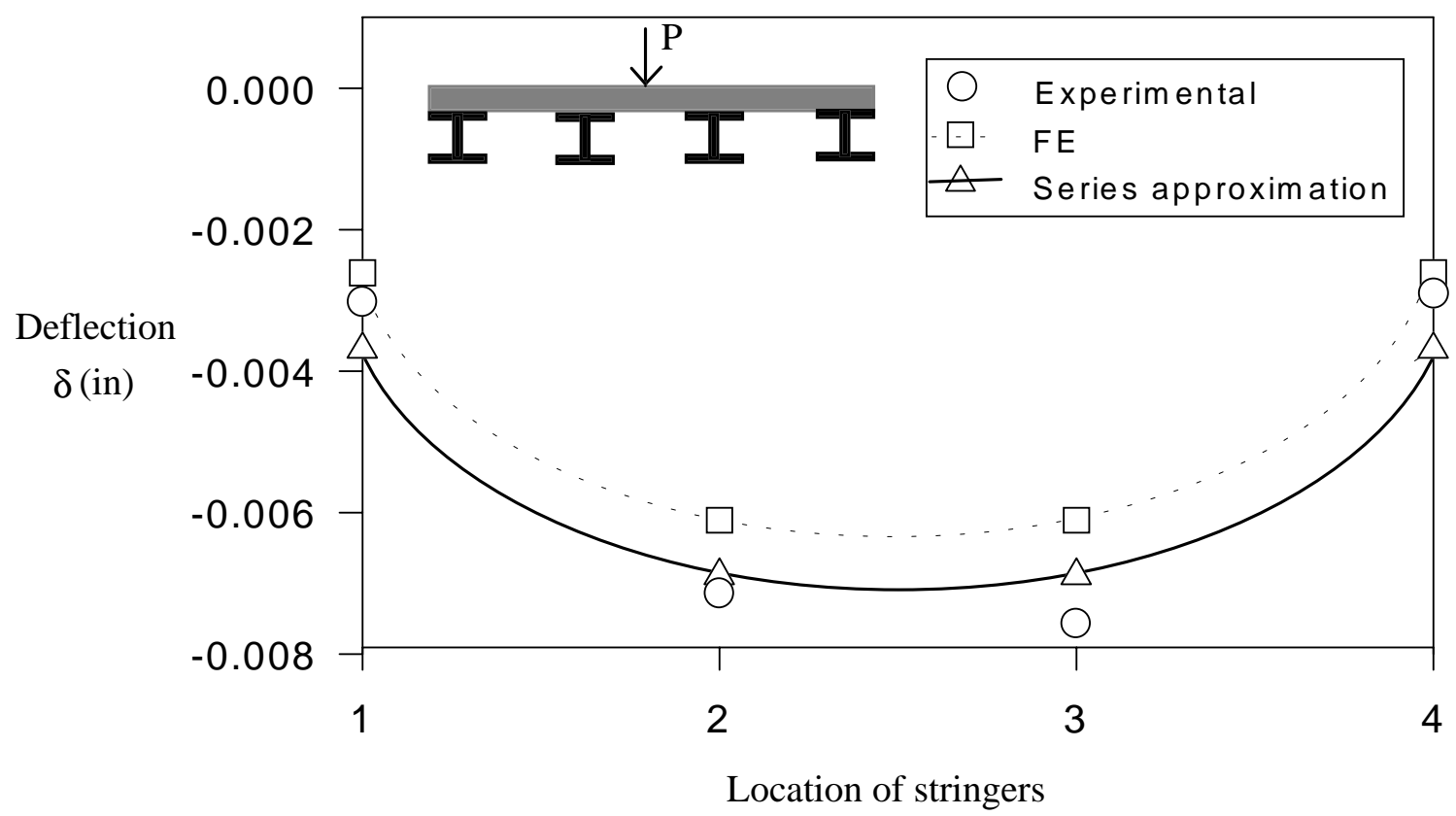

(b) Bridge system with four stringers

Figure 5.10 Comparison for deck/stringer bridge system 


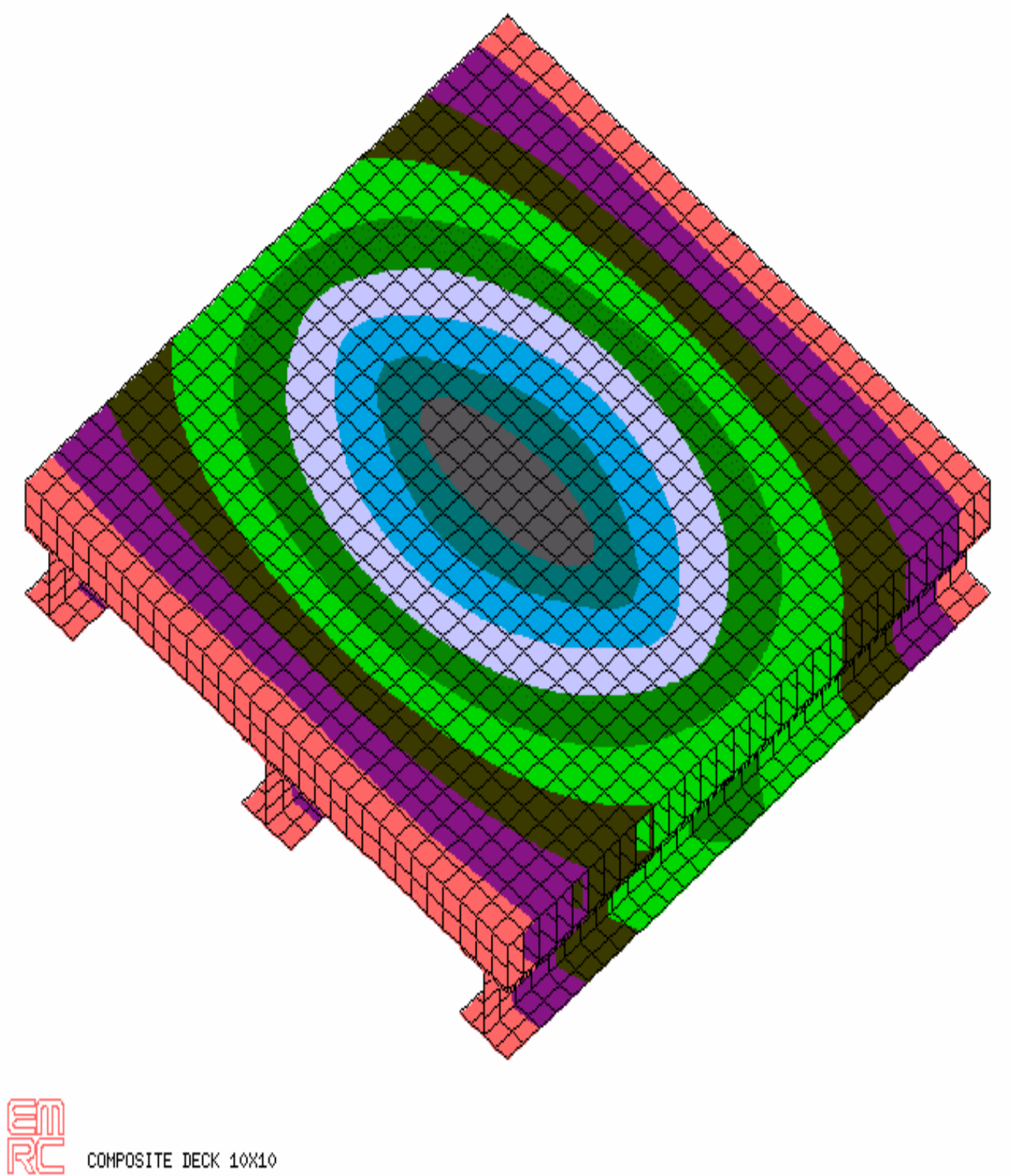

VIEW : - -009853

RANGE: 0,000999

(Band $* 1,0 E-4$ )

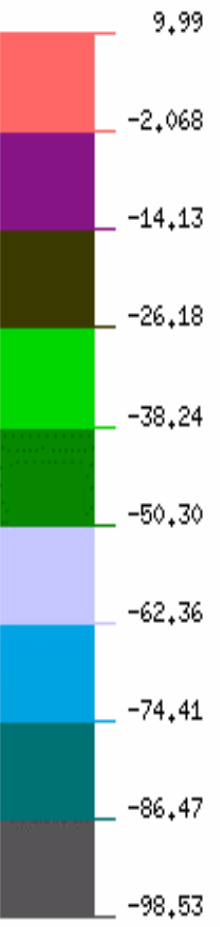

EMRC-NISA/DISPLAY JAN $/ 13 / 98 \quad 11 \div 43 \div 38$

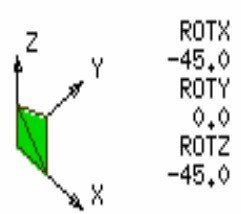

Fig. 5.11 Deflections of Deck System 1 under symmetric load 

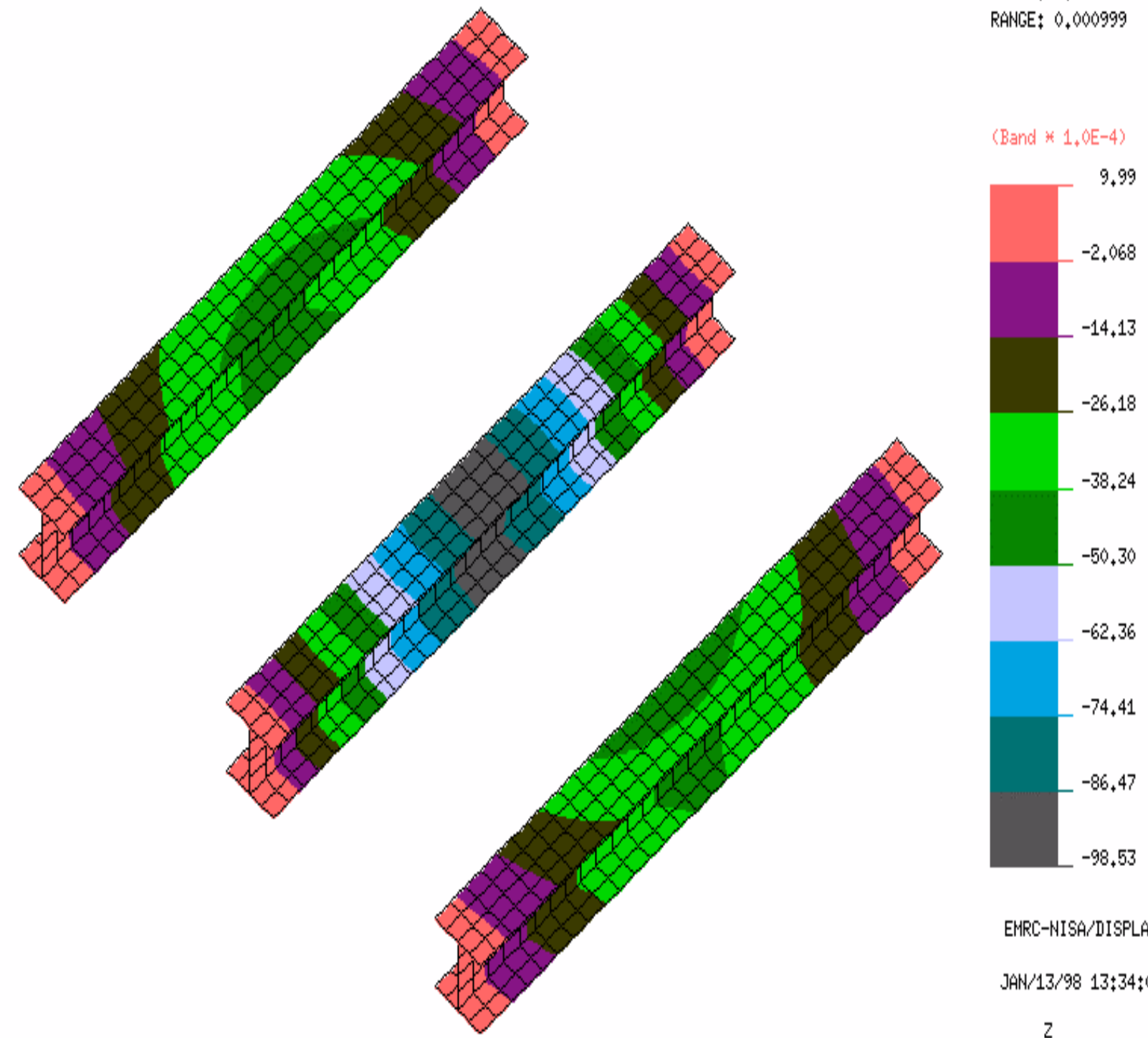

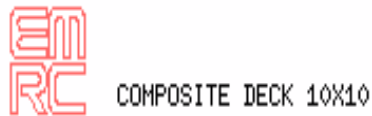

EMRC-NISA/DISPLAY JAN $/ 13 / 98 \quad 13 \div 34 \div 05$

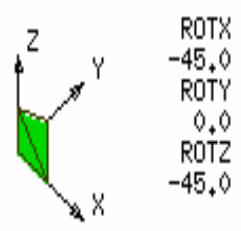

Fig. 5.12 Deflections of stringers in Deck System 1 under symmetric load 


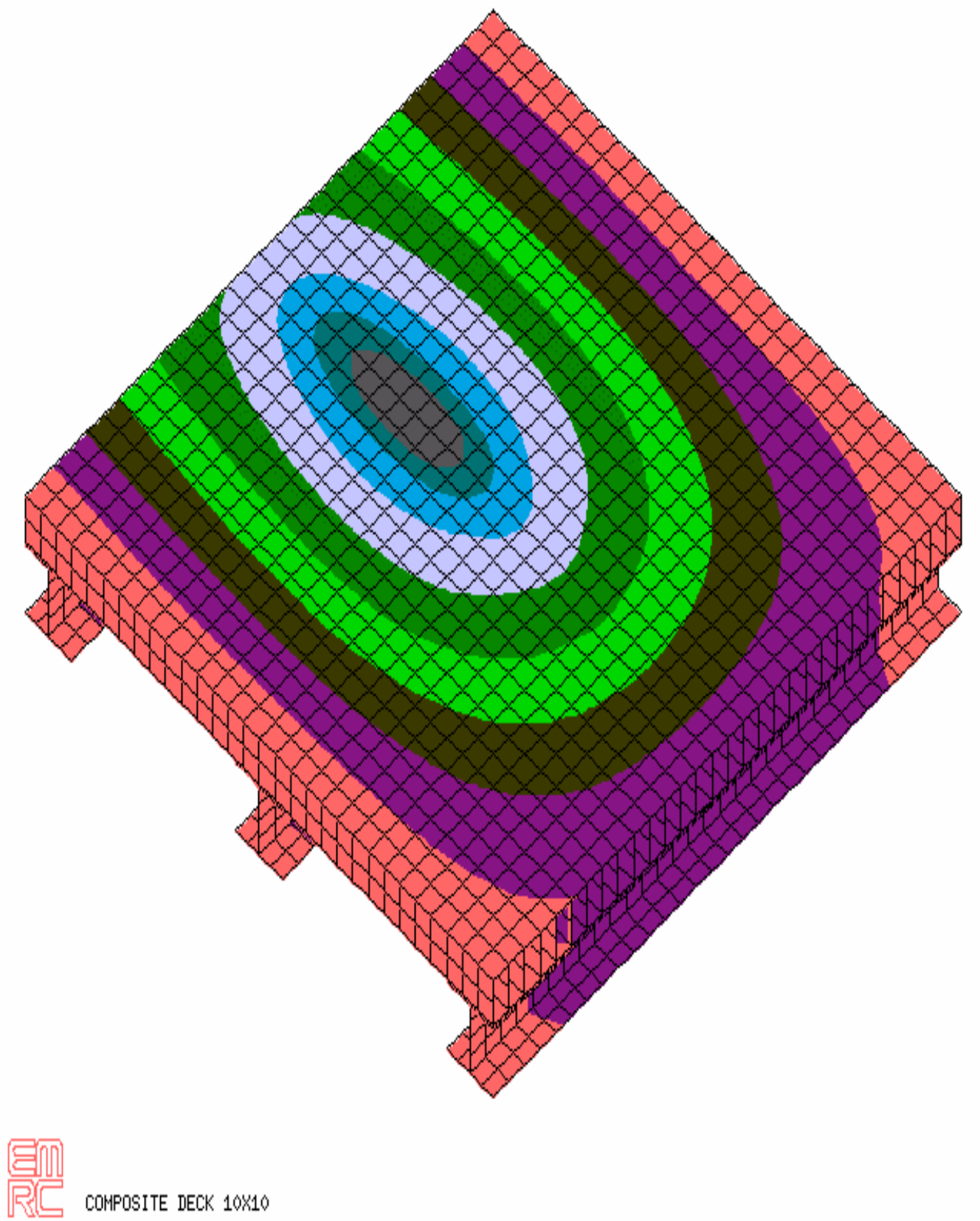

VIEW : -, 0119263

RANGE: 0,0009269

(Band $* 1,0 E-3$ )

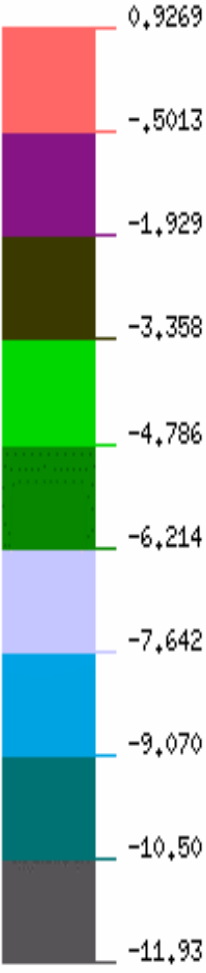

EMRC-NISA/DISPLAY JAN/13/98 $12 \div 44 \div 43$

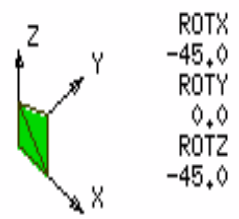

Fig. 5.13 Deflections of Deck System 1 under asymmetric load 


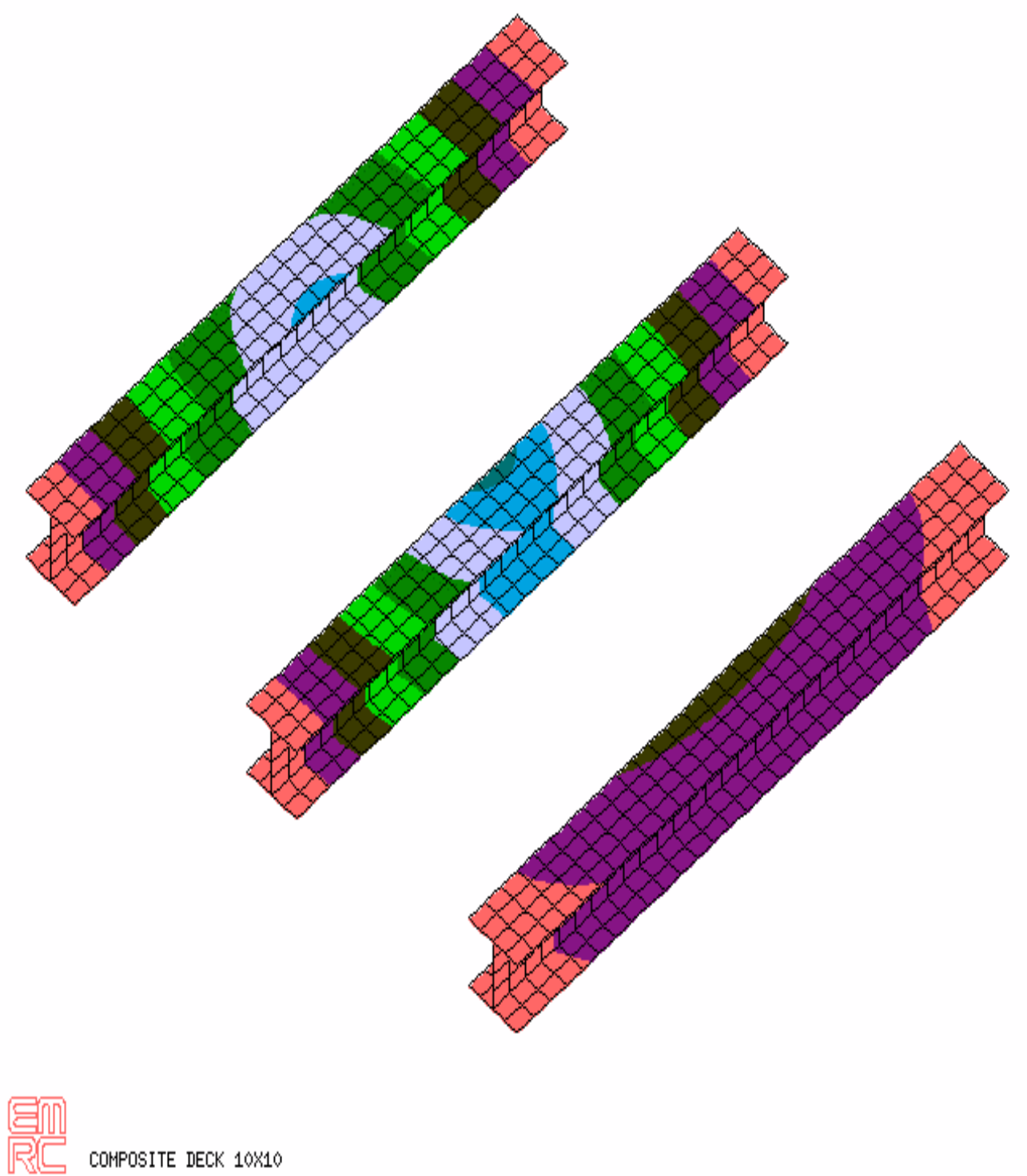

VIEW : - 0099894 RANGE: 0,0009269

(Band $* 1,0 E-3$ )

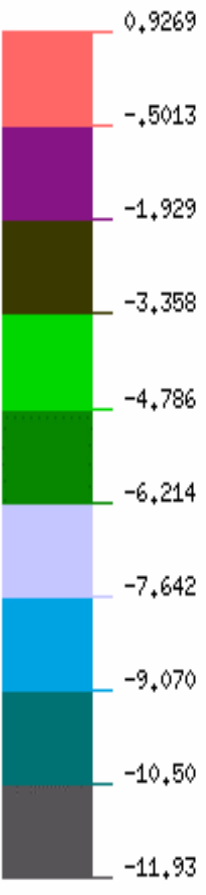

EMRC-NISA/DISPLAY JAN/13/98 12:58:48

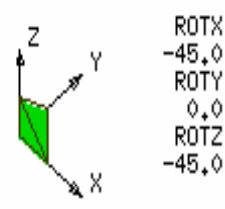

Fig. 5.14 Deflections of stringers in Deck System 1 under asymmetric load 


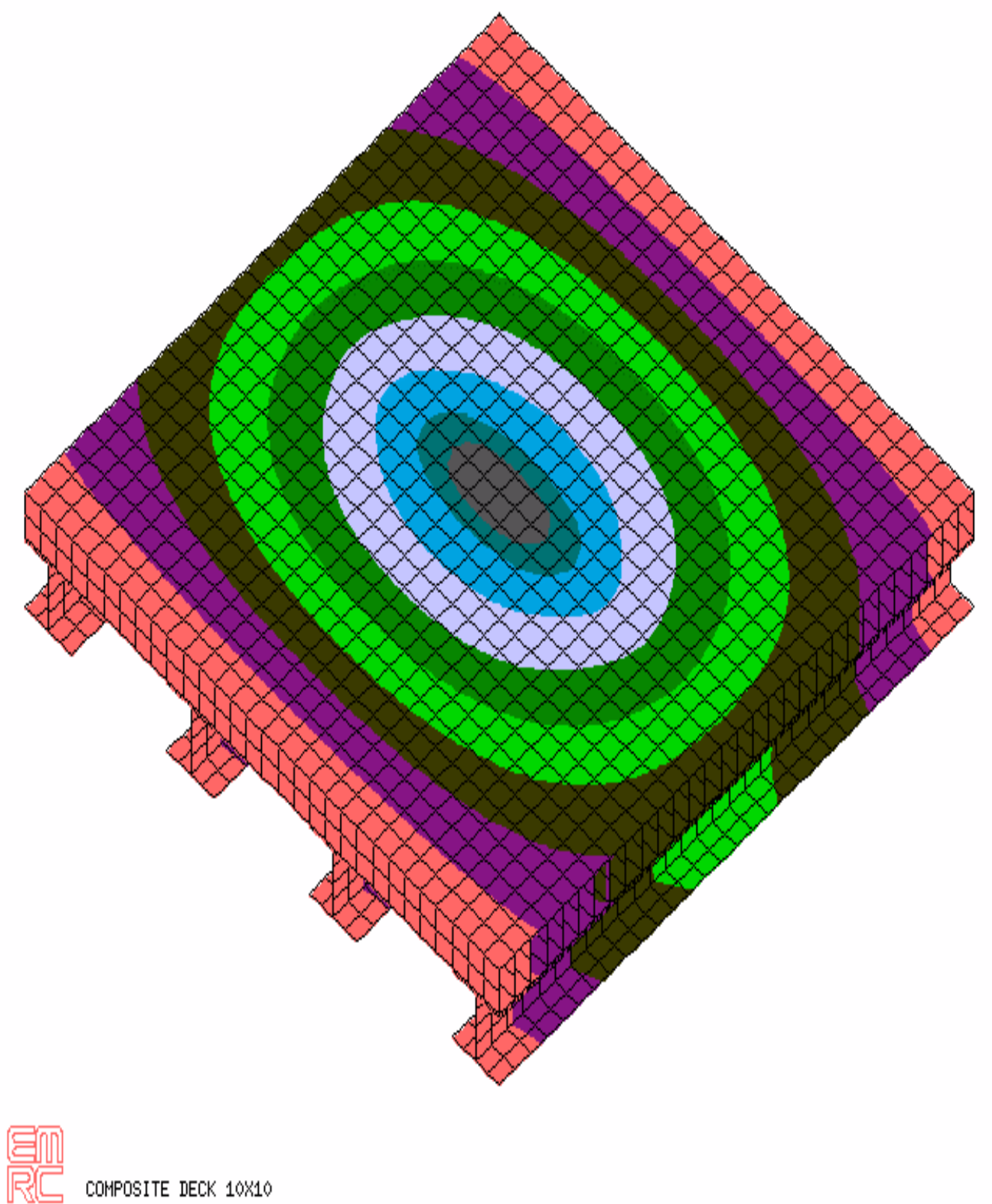

VIEW $:-, 008567$

RANGE: 0,0007077

(Band $* 1,0 E-4$ )

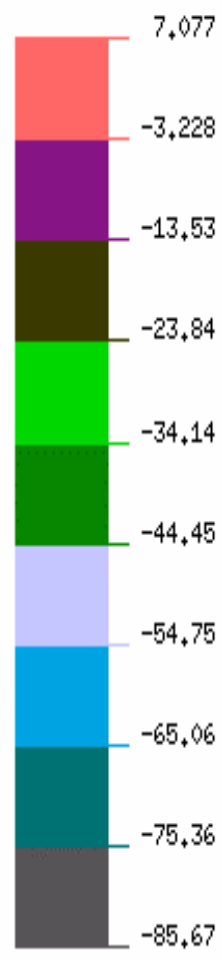

EMRC-NISA/DISPLAY JAN/13/98 $13 \div 15 \div 04$

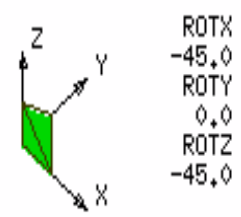

Fig. 5.15 Deflections of Deck System 2 under symmetric load 
WIEW : - -0074718

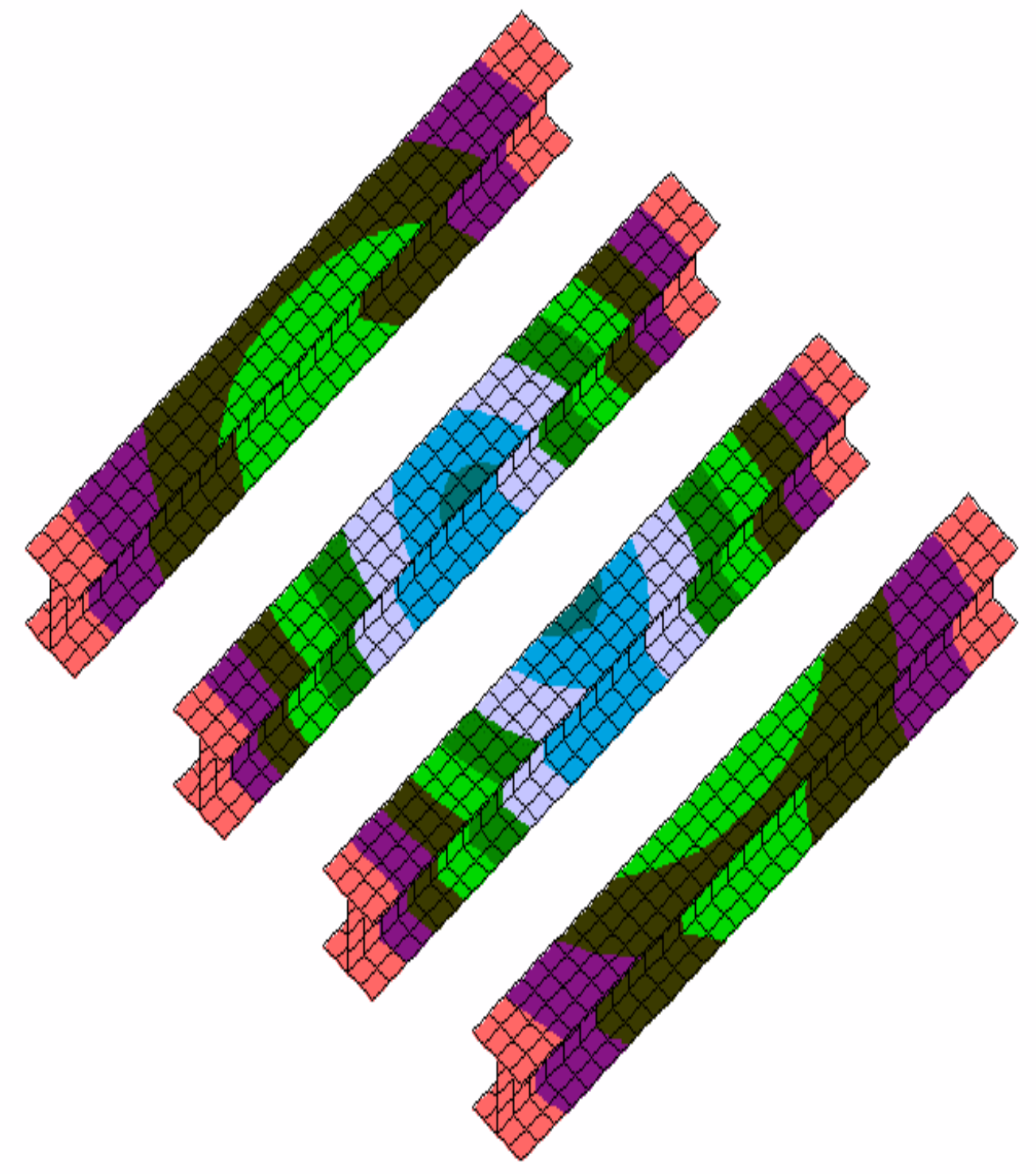

RANGE: 0,0007077

(Band $* 1,0 \mathrm{E}-4$ )

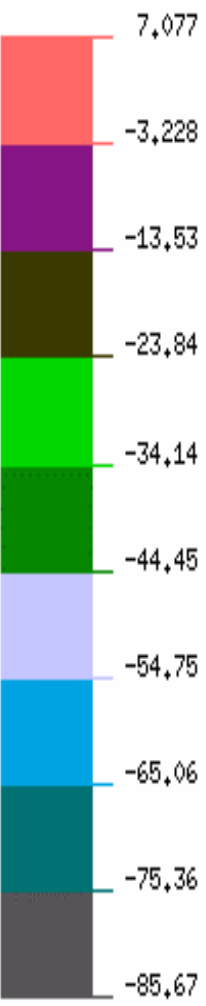

EMRC-NISA/DISPLAY JAN/13/98 $13 \div 20 \div 07$
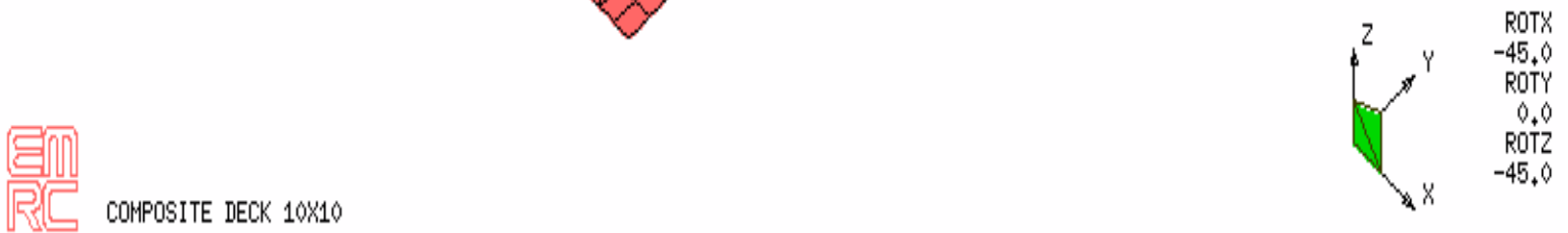

Fig. 5.16 Deflections of stringers in Deck System 2 under symmetric load 


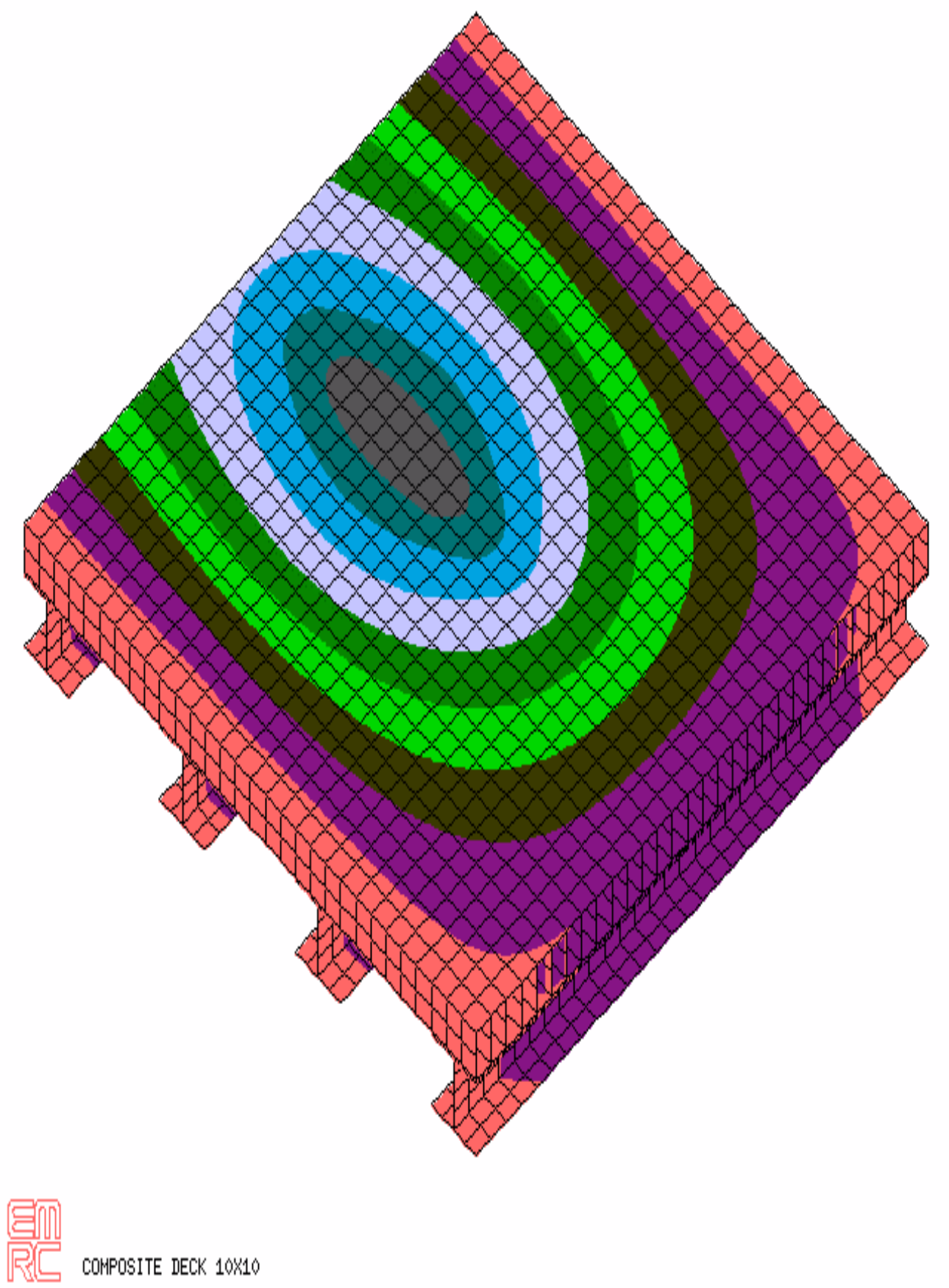

VIEW :,- 0079696

RANGE: 0,0007984

(Band $* 1,0 E-4$ )

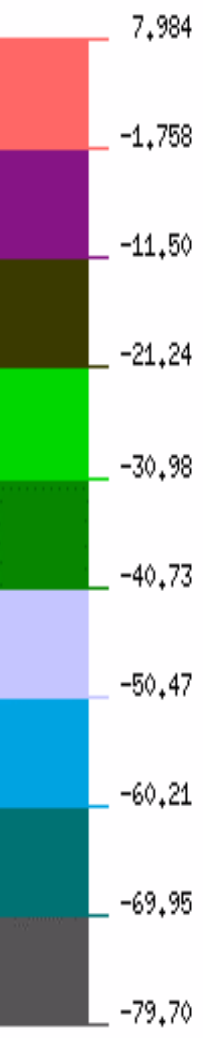

EMRC-NISA/DISPLAY JAN/13/98 13*23\$26

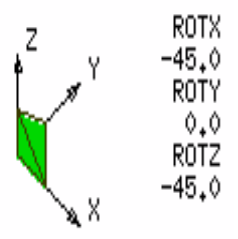

Fig. 5.17 Deflections of Deck System 2 under asymmetric load 


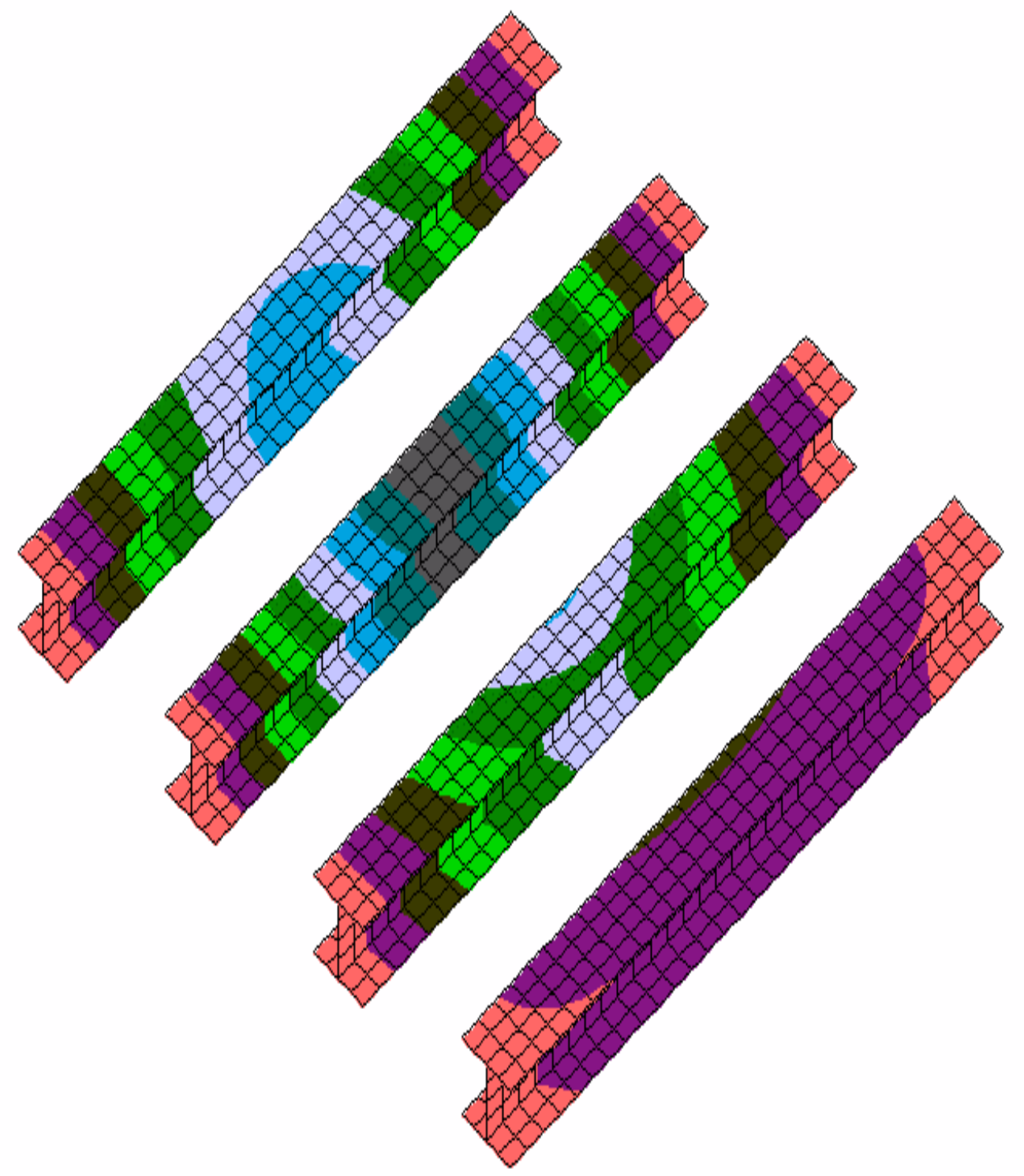

RANGE: 0,0007984

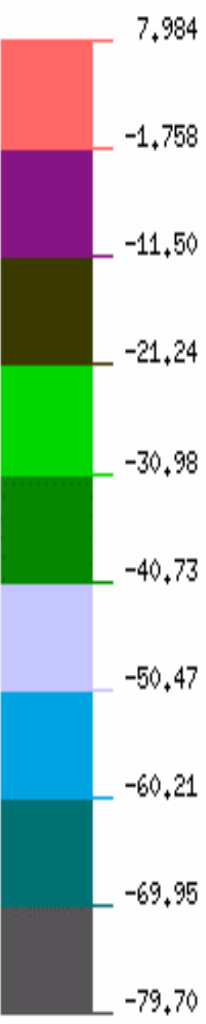

EMRC-NISA/DISPLAY JAN/13/98 13\$27\$11
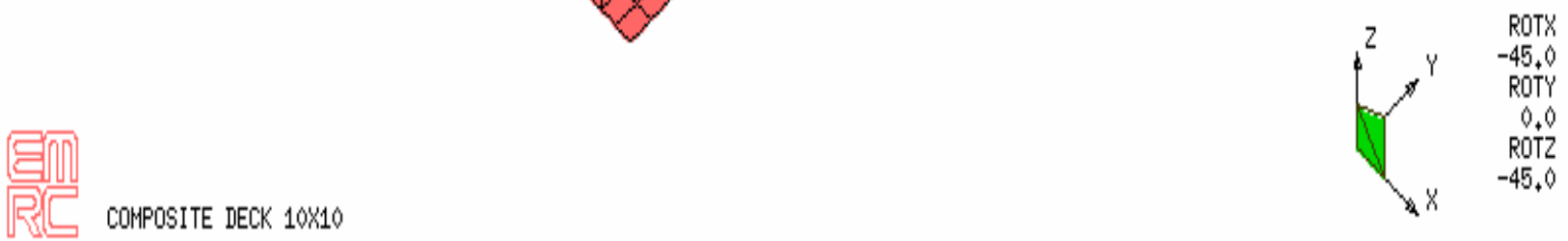

Fig. 5.18 Deflections of stringers in Deck System 2 under asymmetric load 


\subsection{Conclusions}

This chapter presents several experimental load cases for deck and deck-and-stringer bridge systems. The load was applied using a 20"x10" steel plate to simulate an AASHTO wheel load, and both symmetric and asymmetric loads were applied. Values of deflection and strain were measured at specific locations, and finite element modeling with the NISA program was used to verify all of the testing results. Also, $R^{2}$ values were used to determine the reliability of the data obtained from the testing.

For all symmetric load cases, the experimental results compared well with the FE predictions. With the asymmetric load cases, it was observed that the more reliable results occurred near the applied load. 


\section{Chapter 6}

\section{CONCLUSIONS AND RECOMMENDATIONS}

In this study, a systematic approach for the design of FRP deck-and-stringer bridges is presented. Given the component material properties and lay-up of the FRP shapes from the manufacturer, micro/macromechanics and mechanics of laminated beams models are employed to determine the laminate and beam stiffness properties. The design then proceeds to simplify a multi-cell deck as an equivalent orthotropic plate using elastic equivalence analysis. The behavior of the plate and stringer system is then analyzed using First Order Shear Deformation theory and Fourier polynomial series approximation. These formulations are applied to determine the response of the bridge system under symmetric, antisymmetric, and asymmetric loading cases. Each of the steps of this design procedure is verified with finite element modeling and/or experimental data. Finally, wheel-load distribution factors are derived from the deflection coefficients and deck/stringer interaction forces, and these factors are used in the design of the bridge system. 


\subsection{Conclusions}

Both the finite element modeling and experimental testing indicate that the simplified design approach presented in this study can be effectively used in the systematic analysis and design of FRP deck-and-stringer bridge systems. Once ply stiffnesses are evaluated from micromechanics, the laminated panel properties are obtained from macromechanics. Simplified equations for beam stiffnesses, formulated based on the Mechanics of Laminated Beams theory, are used in the Timosenko's beam equations to predict beam deflections as well as strains.

Applying these stiffness equations to the component FRP box beams of a multicellular bridge deck allows for the deck to be modeled as an equivalent orthotropic plate with stiffness properties that account for the size, shape, and material constituents of the deck.

A one-term approximation to a series solution that includes transverse shear deformations is formulated to approximate the analysis of single-span, simply-supported, stiffened and un-stiffened FRP composite plates. The formulation is applied to FRP deckand-stringer system under symmetric, anti-symmetric and asymmetric load cases, and is later used to define the wheel load distribution factors. Design guidelines of deck-andstringer bridge systems based on these derived wheel load distribution factors are then used to determine the spacing of the stringers, which in turn yields the number of stringers required for the system. These design guidelines can also be used to predict the behavior of any othotropic deck-and-stringer system if the deck stiffness properties and beam stiffness properties are known. 


\subsection{Recommendations}

Further research is needed to determine the influence of local deck bending (between two adjacent stringers) and punching shear effects (near supports) on the performance of deckand-stringer bridge systems. Also, additional formulations are needed that consider other multicellular bridge deck configurations beside box-beam decks.

The present series approximation should be extended beyond the one term approximation, especially for the antisymmetric load case. Finite element modeling of more complex bridge systems should also be conducted and correlated with the proposed design guidelines. 


\section{References}

1. Henry, J. A., Deck Girders System for Highway Bridges Using Fiber Reinforced Plastics. M.S. Thesis, North Carolina State University, 1985.

2. Ahmad, S. H. and Plecnik, J. M., Transfer of Composite Technology to Design and Construction of Bridges. U.S. DOT Report, September, 1989.

3. Plecnik, J. M. and Azar, W. A., Structural components, Highway Bridge Deck Applications. International Encyclopedia of Composites, edited by I. Lee and M. Stuart, 1991, 6, pp.430-445.

4. Bakeri, B. and Sunder, S. S. Concepts for hybrid FRP bridge deck system. Proceedings of $1^{\text {st }}$ Materials Engineering Congress, ASCE, Denver, CO. 1990, Vol. 2, pp.1006-1014.

5. McGhee, K. K., Barton, F. W. \& Mckeel, W. T. (1991). Optimum Design of Composite Bridge Deck Panels. Advances Composites Materials in Civil Engineering Structures, Proceedings of the Specialty Conference, A.S.C.E., Las Vegas, Nevada, Jan. 31-Feb. 1, 1991 , pp. 360-370

6. Standard Specifications for Highway Bridges, The American Association of State Highway and Transportation Officials (AASHTO), Washington, D. C., 1989.

7. Mongi, A. N. K. Theoretical and Experimental Behavior of FRP Floor System. M.S. Thesis, West Virginia University, Morgantown, WV. 1991.

8. GangaRao, H. V. S. and Sotiropoulos, S. N. Development of FRP Bridge Superstructural Systems. U.S. DOT Report, June, 1991.

9. Sotiropoulus, S. Performance of FRP Components and Connections for Bridge Deck Systems. Dissertation, Dept. of Civil and Environmental Engineering, WVU, 1995

10. Burnside, P., Barbero, E. J., Davalos, J. F., and GangaRao, H. V. S., Design optimization of an all-FRP bridge. Proceedings of $38^{\text {th }}$ Int. SAMPE Symposium, 1993.

11. Lopez-Anido, R., Troutman, D. L. and Busel, J. P., Fabrication and installation of modular FRP composite bridge deck. Proceedings of Int. Composites Expo'98, Composites Institute, 1998. pp.4-A (1-6).

12. Lopez-Anido, R., Howdyshell, P. A., Stephenson, L. D. and GangaRao, H. V. S., Fatigue and failure evalution of modular FRP composite bridge deck. Proceedings of Int. Composites Expo'98, Composites Institute, 1998. pp.4-B (1-6). 
13. Richards, D., Dumlao, C., Henderson, M. and Foster, D., Method of installation and the structural analysis of two short span composite highway bridges. Proceedings of Int. Composites Expo'98, Composites Institute, 1998. pp.4-E (1-6).

14. Zureick, A. Fiber-reinforced polymeric bridge decks, Seminar Note, National Seminar on Advanced Composite Material Bridges, FHWY, Washington, D.C., 1997.

15. Salim, H.A., Davalos, J.F., GangaRao, H.V.S. and Raju, P. An approximate series solution for design of deck-and-stringer bridges, Int. J. of Engineering Analysis, 1995, 2: $15-31$.

16. Davalos, J. F., Salim, H. A., Qiao, P., Lopez-Anido, R. and Barbero, E. J., Analysis and design of pultruded FRP shapes under bending. Composites, Part B: Engineering J., 1996, 27(3-4): 295-305.

17. Barbero, E. J. Pultruded structural shapes - From the constituents to the structural behavior. SAMPE Journal, 27(1): 25-30. 1991

18. Jones, R. M. Mechanics of Composite Materials. Hemisphere Publishing Corporation, New York, NY. 1975

19. Tomblin, J. S. Compressive Strength Models For Pultruded Glass Fiber Reinforced Composites. Ph.D. Dissertation, West Virginia University, Morgantown, WV. 1994

20. Budiansky, B. Micromechanics. Computers and Structures, 16(1-4): 3-12. 1983

21. Mura, T. Micromechanics of Defects in Solids. Martinus Nijhoff Publishers, Boston. 1987

22. Christensen, R. M. A critical evaluation for a class of micromechanics models. Journal of Mechanics of Physics and Solids, 38 (3): 379-404. 1990

23. Aboudi, J. Mechanics of Composite Materials - A unified Micromechanical Approach Elsevier, New York. 1991

24. Nemat-Nasser, S. and Hori, M. Micromechanics: Overall Properties of Heterogeneous Solids. Elsevier Science Publishers, Amsterdam. 1993

25. Luciano, R. and Barbero, E. J., Formulas for the stiffness of composites with periodic microstructure. Int. J. of Solids and Structures, 1994, 31(21): 2933-2944.

26. Nemat-Nasser, S. and Taya, M. On effective moduli of an elastic body containing periodically distributed voids. Quarterly of Applied Mathematics, 39: 43-59. 1981

27. Iwakuma, T. and Nemat-Nasser, S. Composites with periodic microstructure. Computers and Structures, 16(1-4): 13-19. 1983 
28. Nemat-Nasser, S., Iwakuma, T., and Hejazi, M. On composites with periodic structure. Mechanics of Materials, 1: 239-267. 1982

29. Harris, J. S., Environmental Effects on the Creep Response of Polymer Matrix Composites and Metal Matrix Composites. Master of Science Thesis, West Virginia University, Morgantown, WV. 1996

30. Salim, H.A., Modeling and Application of Thin-walled Composite Beams in Bending and Torsion, Ph.D. Dissertation, West Virginia University, Morgantown, WV, 1997.

31. Barbero, E. J., Lopez-Anido, R. and Davalos, J. F., On the mechanics of thin-walled laminated composite beams. J. Composite Materials, 1993, 27(8): 806-829.

32. Davalos, J. F., Qiao, P., Barbero, E. J., Troutman, D., and Galagedera, L., Design of FRP beams in engineering practice. Proceedings of Int. Composites Expo'98, Composites Institute, 1998. pp.12-E (1-6).

33. Salim, H.A., Davalos, J.F., Qiao, P. and Barbero, E.J., Experimental and analytical evaluation of laminated composite box beams, Proc. Of $40^{\text {th }}$ Int. SAMPE symposium, 1995, 40(1): 532-539.

34. Davalos, J. F., Qiao, P. and Barbero, E. J., Multiobjective material architecture optimization of pultruded FRP I-beams. Composite Structures, 1996, 35: 271-281.

35. Qiao, P., Davalos, J.F. and Barbero, E.J. Design optimization of fiber-reinforced plastic composite shapes, J. of Composite Materials, 1998, 32(2), 177-196.

36. Troitsky, M. S., Orthotropic Bridges, Theory and Design. The James F. Lincoln ARC Welding Foundation, Cleveland, Ohio, 1987.

37. Cusen, A.R. and Pama, R.P. Bridge Deck Analysis, John Wiley \& Sons, 1975.

38. Numerically Integrated Elements for System Analysis (NISA), Users Manual, Version 94.0, Engineering Mechanics Research Corp., Troy, MI, 1994.

39. Reddy, J.N. Energy and Variational Methods in Applied Mechanics. John Wiley, New York, 1984.

40. Salim, H.A., Davalos, J.F., Qiao, P., and Kiger, S. A. Analysis and design of FRP composite deck-and-stringer bridges, Composite Structures, 1997, 38: 295-307.

41. Davalos, J.F. and Salim, H. A., Effective flange-width of stress-laminated T-system timber bridges. J. Structural Engineering, ASCE, 1993, 119(3), 938-953.

42. Davalos, J. F. and Salim, H. A., Local deck effects in stress-lamianted T-system timber bridges. Int. J. of Structural Engineering Review, 1995, 5(1): 1143-1153. 